\title{
Instituto de Química
}

Variabilidade Intratipica de HPV-16 em Relação à

Origem Étnica e HLA de uma População de Alto Risco

para o Câncer do Colo do Útero

Katiana de Sales Junes

Tese de Doutorado

Orientadora: Luisa Lina Villa

São Paulo

$20 / 04 / 2005$ 


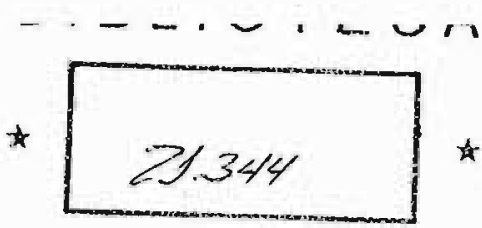

INSTITUTO DE OUIHICA UNNERSIDADE DE SAO PAULO

\section{DEDALUS - Acervo - CQ

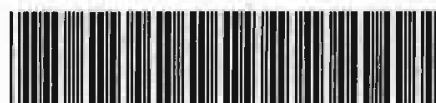 \\ 30100011166}

Ficha Catalográfica

Elaborada pcla Divisảo de Biblioteca e

1)ocumemaçào do ('onjunto das Quimicas da USP.

\section{Junes, Katiana de Sales}

J95v Variabilidade intratipica de HPV-16 $\mathrm{cm}$ relaçào à origem Etnica e HLA de uma populaça de alto risco para o cancer do colo do utero: Katiana de Sales Junes. - Sào Paulo. 2005 .

$135 p$

Iese (doutorado) - Instituto de Quimica da Liviversidade de Sào Paulo. Departamento de Bioquimica.

Orientador: Villa, Luisa Lina

1. Biologia molecular 2. Colo uterino : Câncer 3. Cảncer Inunologia I. T. Il. Villa, Luisa Lina, orientador 


\section{"Variabilidade intratípica de HPV-16 em relação à origem étnica e HLA de uma população de alto risco para o câncer do colo do útero"}

\section{KATIANA DE SALES JUNES}

Tese de Doutorado submetida ao Instituto de Química da Universidade de São Paulo como parte dos requisitos necessários à obtenção do grau de Doutor em Ciências - Área: Bioquímica.

Aprovado(a) por:

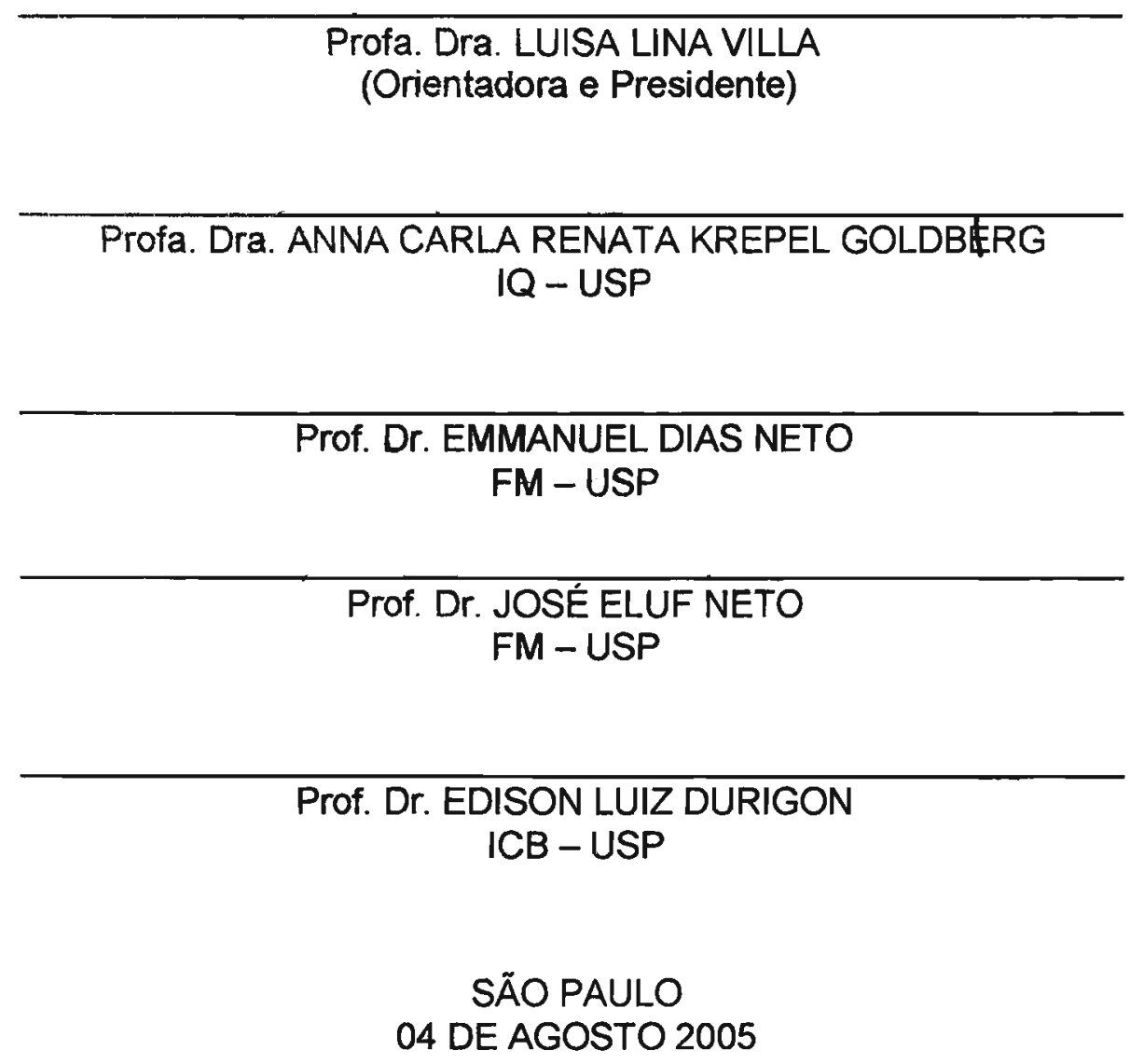

Profa. Dra. LUISA LINA VILLA

(Orientadora e Presidente)

04 DE AGOSTO 2005 
Quem é este que faz o mar se acalmar E a tempestade obedece a sua voz?

Quem é este que anda sobre as águas E por onde passa tudo pode transformar?

Quem é este que todas as coisas pode ver

E o coração do homem pode sondar?

Quem é este que cura as doenças E o corpo e a alma pode restaurar? 
À minha família querida...Que agora é maior Minha doce mãe Maria e os meus irmãos Dal e Lú My loving husband Tristan 


\section{AGRADECIMENTOS}

A Deus, por todas as coisas...a Tua presença é o meu sustento, a Tua palavra o meu alimento pra superar todas as adversidades.

À minha mãe, Maria, mesmo estando distante uma da outra estamos sempre tão juntas e isso é de um prazer incomparável. Te amo mãe e te agradeço muito por tanto amor e dedicação. Aos meus maninhos, Dal e Lú e ao tio Pão-Pi. Pelo apoio, conselhos e o amor que há entre nós.

For my Tristan, there would be no such words to describe the many ways you have changed my life. You helped me to make it through being so understanding and most importantly being just as much in love with me as I am with you. Thank you for show me what love is all about.

À minha orientadora, Luisa Villa, pelo carinho e por ter me dado esta grande oportunidade que mudou a minha vida em todos os sentidos.

Ao grupo da virologia, pelos 7 anos de intenso e divertido convívio. Vou levar um poquinho de cada um de vocês no meu coração.

A Paty e o Fabio P., pelos 6 anos de casamento (bodas de ferro!!), pela amizade e apoio que vocês têm me dado. Vou guardá-los no meu coração as lembranças jamais mudarão.

Ao papai Paulo Maciag, pelos conselhos e amizade. Pela grande colaboração no desenvolvimento deste trabalho.

À Neide, pela amizade, conselhos e franqueza ...mulher virtuosa quem a achará? Pois o seu valor muito excede ao de jóias preciosas...Prov. 31:10.

À Stella, pela amizade, carinho e extrema eficiência.

A todos os amigos do Ludwig que contribuíram com valiosas sugestões.

Ao Instituto Ludwig na pessoa do Prof. Dr. Ricardo Brentani.

Aos Dr. Sidney Santos, Diogo Meyer e Bernardo Bertoni, pelas dicas e colaboração na análise dos microssatélites.

À Anna Christina e ao Fabrício Carvalho pela ajuda durante a tipagem das STR.

À FAPESP pelo apoio financeiro e a pós da quimica pela grande ajuda. 


\section{Sumário}

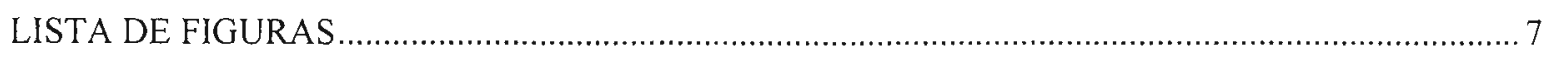

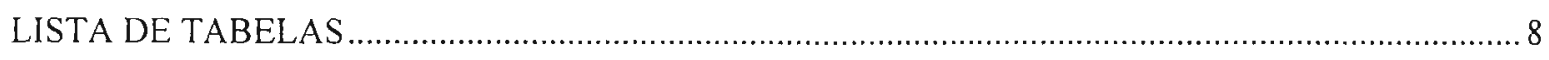

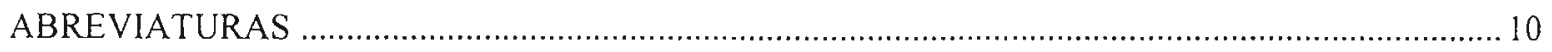

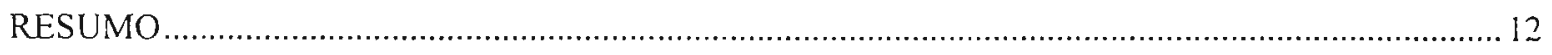

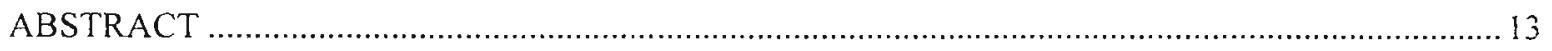

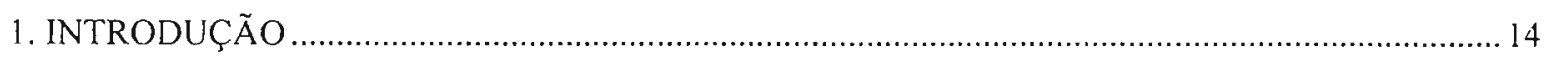

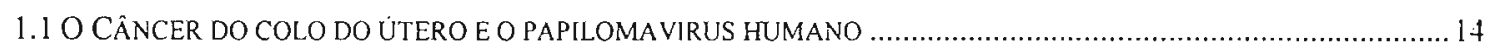

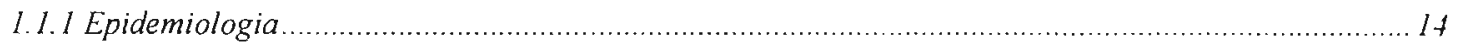

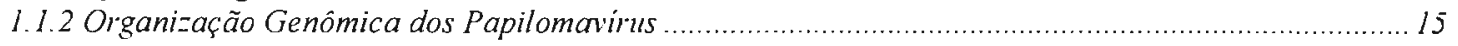

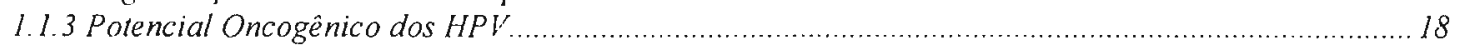

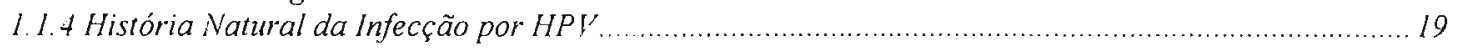

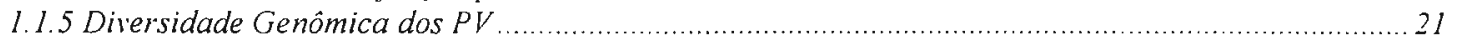

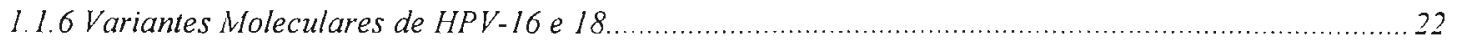

1.1.7 V'ariabilidade Intratipica do HPY-16 Associada ao Risco de Veoplasia Cervical.............................225

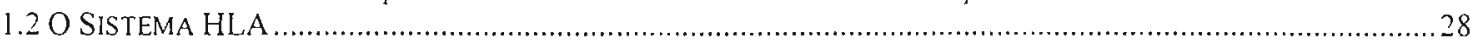

1.2.I Associação entre Genótipos de HLA e a lnfeç̧ão por HPV ......................................................... 3!

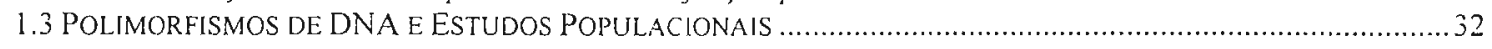

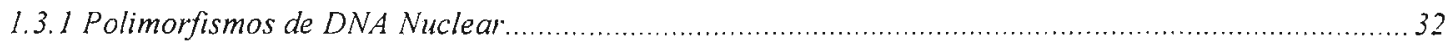

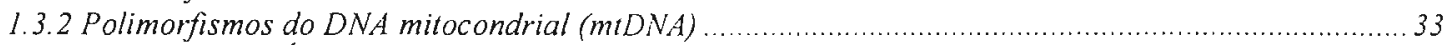

1.3.3 Diferenciação Étnica de Populações ................................................................................... 3 t

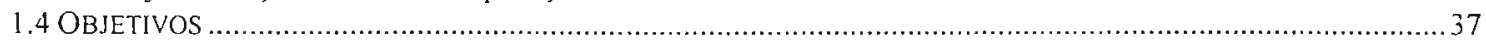

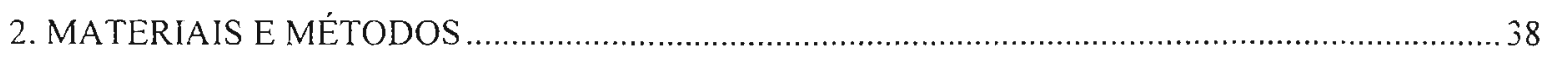

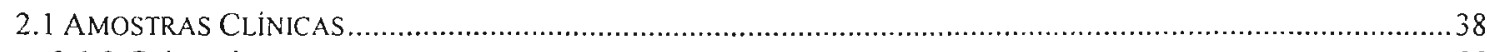

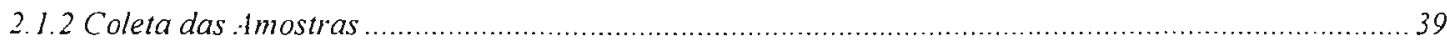

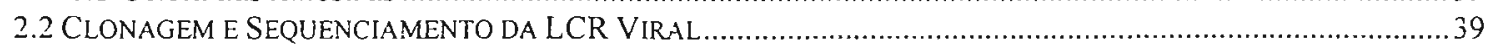

2.3 ANÁLISE DE VARIANTES DO GENE E6 DE HPV-16 POR HIBRIDIZAÇÃO EM PONTOS..................................40

2.4 Polimor fismos de dNA Utilizados na determinaÇÃo da Origem ÉtNica da População de BelÉM

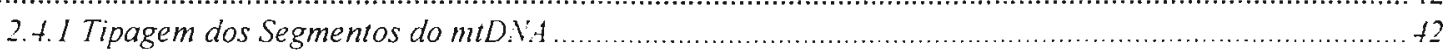

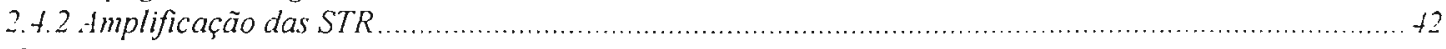

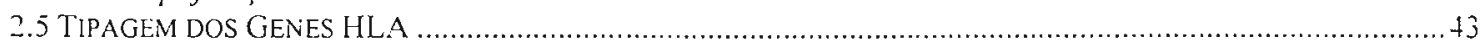

2.5.1 Amplificação do Gene HLA-DQB1 .................................................................................... 43

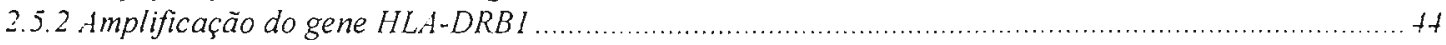

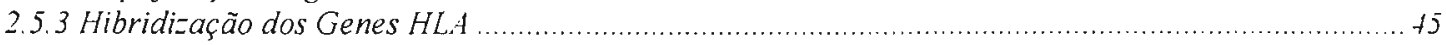

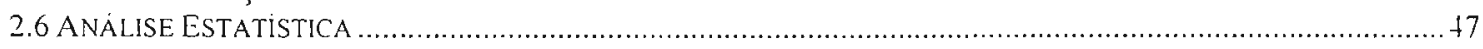

2.6.1 No Estudo de Associação dos Genes HL.t com o CCU ............................................................. 47

2.6.2 Nas Estimativas de Contribuiçăo Étnica .............................................................................. +8

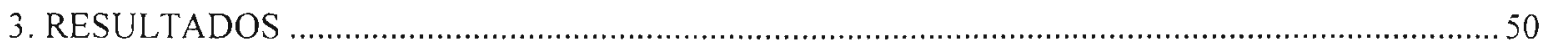

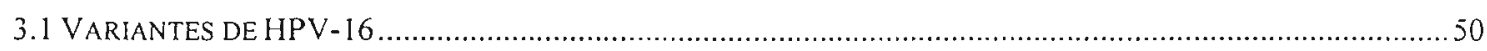

3. 1. I Distribuição das Variantes da LCR de HPV-16 ...................................................................... 50

3.1.2. Análise do Polimorfismo na Posição 350 do Gene E6 de HPI -16 ............................................... 53

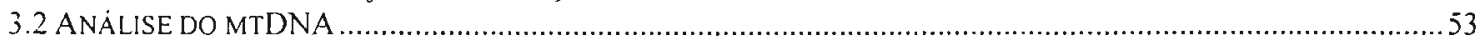

3.2. I Estimativa de Mistura Interétnica Baseada no mtDNA .............................................................55

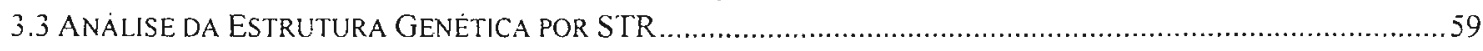

3.3. I Empregando Freqüências Genotipicas da População Hibrida .................................................... 65

3.3.2 Empregando Frequências alélicas das Populą̧ões Híbrida e Parentais.......................................66

3.4 ANȦLISE DOS GENES HLA-DQB I E HLA-DRB I E O DESEN VOLVIMENTO DE CCU ................................67

3.4.1 Análise dos Genes HLA-DQBI e HLA-DRBI e as Variantes Moleculares de HPV-16 ....................96 


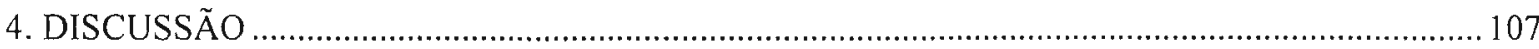

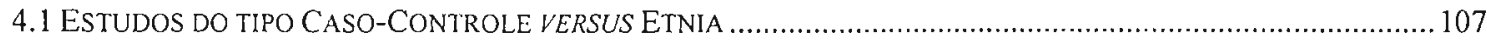

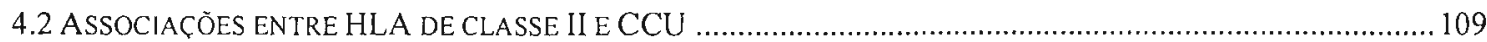

4.3 VARIANTES DE HPV-16 E HLA DE CLASSE II NO DESENVOLVIMENTO DE CCU .......................................115

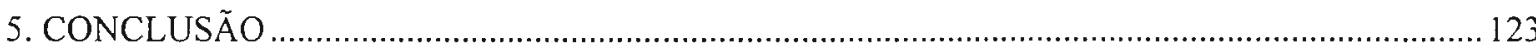

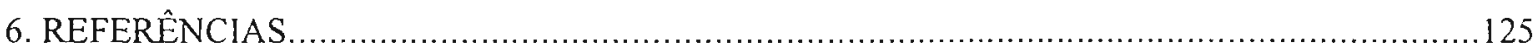




\section{LISTA DE FIGURAS}

FIGURA 1. MAPA FÍSICO DO GENOMA DO HPV-16 17

FIGURA 2. ÁRVORE FILOGENETICA DOS HPV-16 E HPV-18 ….................................................23

FIGURA 3. REPRESENTAÇÃO ESQUEMÁTICA DAS MOLÉCULAS HLA DE CLASSE I E II. .....30 FIGURA 4. FREQÜENNCIA DOS HAPLOGRUPOS DO MTDNA OBSERVADOS NAS AMOSTRAS DE BELÉM. .56

FIGURA 5. CONTRIBUIÇÃO ÉTNICA DE ACORDO COM O MTDNA ENTRE CASOS E CONTROLES

FIGURA 6. COMPARAÇÃO DA DISTRIBUIÇÃO DAS FREQÜENECIAS ALÉLICAS DAS STR D3S1358, VWA, FGA E D8S1179 ENTRE AMOSTRAS NORMAIS E DE CCU E NIC III..........62

FIGURA 7. COMPARAÇÃO DA DISTRIBUIÇÃO DAS FREQÜÊNCIAS ALÉLICAS DAS STR D21S11, D18S51, D5S818, D13S317 E D7S820 ENTRE AMOSTRAS NORMAIS E DE CCU E NIC III. 


\section{LISTA DE TABELAS}

TABELA 1. PADRÃO DE SUBSTITUIÇÃO NUCLEOTÍDICA DAS VARIANTES DA LCR DE HPV16 ENCONTRADAS EM BELÉM (PA).

TABELA 2. FREQÜÊNCIA DAS VARIANTES DA LCR DE HPV-16 NAS AMOSTRAS DE NIC III E CCU 52

TABELA 3. HAPLÓTIPOS E HAPLOGRUPOS MITOCONDRIAIS OBSERVADOS NAS AMOSTRAS DE BELÉM. 54

TABELA 4. HAPLÓTIPOS MITOCONDRIAIS DE AMOSTRAS AGRUPADAS COMO NÃO A-D. 55

TABELA 5. DISTRIBUIÇÃO DAS FREQÜÊNCIAS ALÉLICAS DE 9 STR NOS CASOS DE CCU E NIC III.

TABELA 6. DISTRIBUIÇÃO DAS FREQÜÊNCIAS ALÉLICAS DE 9 STR NOS CONTROLES......61

TABELA 7. ANÁLISE POR LOCUS DO EQUILÍBRIO DE HARDY-WEINBERG ENTRE CASOS E CONTROLES.

TABELA 8. DIFERENCIAÇÃO GENÉTICA NA POPULAÇÃO DE BELÉM .65

TABELA 9. PROPORÇÕES DE ANCESTRALIDADE DO DNA NUCLEAR E MTDNA .67

TABELA 10. DISTRIBUIÇÃO SÓCIO-DEMOGRÁFICA NO ESTUDO CASO-CONTROLE. .69

TABELA 11. RAZÕES DE CHANCES (OR) E INTERVALO DE CONFIANÇA DE 95\% (IC) PARA CCU DE ACORDO COM HLA-DRB1. .70

TABELA 12. RAZÕES DE CHANCES (OR) E INTERVALO DE CONFIANÇA DE 95\% (IC) PARA CCU DE ACORDO COM HLA-DQB1. .72

TABELA 13. RAZÕES DE CHANCES (OR) E INTERVALO DE CONFIANÇA DE 95\% (IC) PARA CCU HPV-16 POSITIVOS DE ACORDO COM HLA-DRBl. .75

TABELA 14. RAZÕES DE CHANCES (OR) E INTERVALO DE CONFIANÇA DE 95\% (IC) PARA CCU HPV-16 POSITIVOS DE ACORDO COM HLA-DQB1 .77

TABELA 15. RAZÕES DE CHANCES (OR) E INTERVALO DE CONFIANÇA DE 95\% (IC) PARA CCU DE ACORDO COM OS HAPLÓTIPOS HLA-DRB1-DQB1.

TABELA 16. RAZÕES DE CHANCES (OR) E INTERVALO DE CONFIANÇA DE 95\% (IC) P.ARA CCU DE ACORDO COM OS HAPLÓTIPOS HLA-DRB1-DQB1. 82

TABELA 17. RAZÕES DE CHANCES (OR) E INTERVALO DE CONFIANÇA DE 95\% (IC) PARA POSITIVIDADE DE HPV DE ACORDO COM HLA-DQB1.

TABELA 18. RAZÕES DE CHANCES (OR) E INTERVALO DE CONFIANÇA DE 95\% (IC) PARA POSITIVIDADE DE HPV DE ACORDO COM HLA-DRB 1 
TABELA 19. RAZÕES DE CHANCES (OR) E INTERVALO DE CONFIANÇA DE 95\% (IC) PARA POSITIVIDADE DE HPV DE ACORDO OS HAPLÓTIPOS HLA-DRB1-DQB1. 90

TABELA 20. RAZÕES DE CHANCES (OR) E INTERVALO DE CONFIANÇA DE 95\% (IC) PARA CCU DE ACORDO COM HLA-DQB1 E DRB1. 92

TABELA 21. RAZÕES DE CHANCES (OR) E INTERVALO DE CONFIANÇA DE 95\% (IC) PARA CCU DE ACORDO COM HLA-DQB 1 E DRB1. 94

TABELA 22. RAZÕES DE CHANCES (OR) E INTERVALO DE CONFIANÇA DE 95\% (IC) PARA CCU POSITIVOS PARA VARIANTES AA DE ACORDO COM HLA-DRBI E DQBI. .97

TABELA 23. RAZÕES DE CHANCES (OR) E INTERVALO DE CONFIANÇA DE 95\% (IC) PARA CCU POSITIVOS PARA VARIANTES B-2 (RAMO AA) DE ACORDO COM HLA-DRB1 E DQB 1 . 98

TABELA 24. RAZÕES DE CHANCES (OR) E INTERVALO DE CONFIANÇA DE 95\% (IC) PARA CCU POSITIVOS PARA VARIANTES DO RAMO E DE ACORDO COM HLA-DRB1 E DQB1.99

TABELA 25. RAZÕES DE CHANCES (OR) E INTERVALO DE CONFIANÇA DE 95\% (IC) PARA CCU POSITIVOS PARA VARIANTES PROTÓTIPO (RAMO E) DE ACORDO COM HLA-DRBI E DQB 1 100

TABELA 26. RAZÕES DE CHANCES (OR) E INTERVALO DE CONFIANÇA DE 95\% (IC) PARA CCU POSITIVOS PARA VARIANTES B-12 (RAMO E) DE ACORDO COM HLA-DRB1 E DQB1. 101

TABELA 27. RAZÕES DE CHANCES (OR) E INTERVALO DE CONFIANÇA DE 95\% (IC) PARA CCU E6350G E E6350T POSITIVOS DE ACORDO COM HLA-DRB1.... 104

TABELA 28. RAZÕES DE CHANCES (OR) E INTERVALO DE CONFIANÇA DE 95\% (IC) PARA CCU E6350G POSITIVOS E E6350T POSITIVOS DE ACORDO COM HLA-DQB1. 105 


\section{ABREVIATURAS}

\begin{tabular}{|c|c|}
\hline AA: & asiático-americano \\
\hline Af: & africano \\
\hline APL: & peptídeos ligantes alterados \\
\hline As + AI: & asiático-ameríndio \\
\hline As: & asiático \\
\hline CCU: & carcinoma do colo uterino \\
\hline DNA: & ácido desoxirribonucleico \\
\hline E: & europeu \\
\hline EDTA: & ácido etilenodiaminotetracético \\
\hline GRE: & glucocorticoid responsive-element \\
\hline HLA: & antígenos leucocitários humano \\
\hline HPV: & papilomavírus humano \\
\hline HSIL: & lesão intraepitelial escamosa de alto grau \\
\hline IC: & intervalo de confiança \\
\hline IEC: & Instituto Evandro Chagas \\
\hline ILPC-SP: & Instituto Ludwig de Pesquisa sobre o Câncer, filial de São Paulo. \\
\hline INCA: & Instituto Nacional do Câncer \\
\hline IOL: & Instituto Ofir Loiola \\
\hline LCR: & longa região controladora \\
\hline LSIL: & lesão intraepitelial escamosa de baixo grau \\
\hline MHC: & complexo principal de histocompatibilidade \\
\hline $\mathrm{mM}:$ & milimolar \\
\hline NIC & neoplasia intraepitelial cervical \\
\hline $\mathrm{nm}:$ & nanômetro \\
\hline OR: & Odds ratio; razões de chance \\
\hline pb: & pares de bases \\
\hline PCR: & reação em cadeia da polimerase \\
\hline PV: & papilomavírus \\
\hline RFLP: & polimorfismo de tamanho de fragmento \\
\hline rpm: & rotação por minuto \\
\hline
\end{tabular}


SDS: dodecilsulfato de sódio

SIL: lesão intraepitelial escamosa

SSC: $\quad$ solução salina citrato

SSPE: $\quad$ solução salina fosfato-EDTA

TBE: $\quad$ Tris-borato-EDTA

TE: $\quad$ Tris EDTA

TEMED: $\quad \mathrm{N}, \mathrm{N}, \mathrm{N}^{\prime}, \mathrm{N}^{\prime}-$ Tetramethylethylenediamine 


\section{RESUMO}

A infecção por papilomavirus é a principal causa de desenvolvimento de neoplasias intraepiteliais cervicais (NIC) e câncer do colo do útero (CCU). Estudos epidemiológicos têm demonstrado que a persistência do genoma viral encontra-se associado a variantes moleculares específicas de papilomavirus humano (HPV) de alto risco. As moléculas HLA de classe II têm um importante papel na resposta imune. Associações entre HLA e CCU ou infecção por HPV tem sido demonstrado em diferentes populações. O nosso objetivo foi verificar se a variabilidade de HLA-DRB1 e DQB1 estavam associada ao CCU e NIC III em mulheres de Belém, uma população formada pelos 3 principais grupos étnicos humanos e uma área de alto risco para o CCU no Norte do Brasil. Foi investigada a existência de diferenças na distribuição de alelos HLA entre mulheres com CCU e NIC III portadoras de diferentes variantes de HPV-16 e mulheres citologicamente normais. Os genes HLA DQB1 e DRB1 foram tipados pelo método de PCR-SSO em 95 casos e 287 controles de mulheres com citologia normal atendidas em um centro de prevenção do colo do útero na mesma cidade. As variantes de HPV-16 foram tipadas por sequenciamento de um fragmento da região controladora do genoma viral (LCR). O polimorfismo na posição 350 do gene E6 foi tipado baseado em um protocolo de hibridização em pontos, para identificar a alteração na posição $350 \mathrm{~T} \rightarrow \mathrm{G}$. A magnitude das associações foi estimada por odds ratio (OR) e os respectivos intervalos de confiança (IC), ajustados para potenciais fatores de confusão. Uma associação positiva foi observada entre CCU e os haplótipos DRB1*1501-DQB1*0602, DRB 1*04-DQB 1*0301 e DRB1*1602-DQB1*0301. Ao contrário, DRB1*01-DQB1*0501 mostrou um efeito protetor. Os alelos DRB $1 * 0804, \mathrm{DQB} 1 * 0402$ apresentaram efeito protetor contra positividade por HPV. O alelo DQB1*0502 e o grupo DRB1*15 foram positivamente associados. Os nossos resultados mostram que as associações positivas de DRB $1 * 1501$ e DRB $1 * 1602$ podem ser atribuídas a variantes asiático-americanas quando comparado a variantes européias. $\mathrm{O}$ risco conferido a $\mathrm{DRB} 1 * 1501$ foi encontrado associado tanto a variantes $\mathrm{E} 6350 \mathrm{G}$ quanto a variantes $\mathrm{E} 6350 \mathrm{~T}$, entretanto, o maior efeito foi devido às variantes E6250T. A associação positiva de DRB1*1602 foi significativa somente no grupo de mulheres positivas para E6350G. Estes resultados estão de acordo com a composição étnica da população estudada bem como um maior potencial oncogênico de certas variantes. Nossos dados sugerem que a contribuição dos alelos HLA na susceptibilidade genética ao CCU difere de acordo com a distribuição das variantes de HPV em uma dada região geográfica ou grupo étnico. 


\begin{abstract}
Papillomavirus infection is the major cause for the development of cervical intraepithelial neoplasia (CIN) and invasive cervical cancer (ICC) in human. Epidemiological studies have demonstrated that persistence of the viral genome and development of cervical cancer are associated with specific molecular variants of high-risk human Papillomavirus (HPV). Human leukocyte antigen (HLA) molecules play a role in immune response and associations between HLA and ICC or HPV infections have been reported in several populations. We aimed to verify if HLA-DRBI and DQB 1 variability is related to ICC and CIN III in women from Belem, a population formed by the three main human ethnic groups and a high-risk area for this disease in Northern Brazil. We also investigated if there are differences in the HLA class II alleles distribution between women with ICC and CIN III that harbor different HPV-16 variants and women without cancer. HLA DRB1 and DQB1 were typed by PCR-SSO based methods in 95 ICC cases and 287 controls consisting of normal cytology from women attending cervical cancer screening programs in the same city. HPV-16 variants were typed by sequencing a PCR-amplified fragment of long control region (LCR) of the viral genome. The E6350 polymorphism was typed on the basis of a dot blot protocol targeting a specific nucleotide alteration in the position $350 \mathrm{~T} \rightarrow \mathrm{G}$ of the E6 gene. The magnitude of associations was estimated by odds ratio (OR) and the respective $95 \%$ confidence interval (CI), adjusted for potential confounder factors. A positive association was found between ICC cases and DRB1*1501-DQB1*0602, DRB1*04-DQB1*0301 and DRB1*1602-DQB 1*0301 haplotypes. Conversely, DRB1*01-DQB $1 * 05$ showed a protective effect. DRB $1 * 0804$, DQB $1 * 0402$ showed negative association against HPV infection. DQB $1 * 0502$ and DRB $1 * 15$ were positively associated with HPV infection. Our study showed that positive association of DRB1*1501 and DRB1*1602 alleles may be attributed to AsianAmerican then European variants. Furthermore, the DRB1*1501 was found associated with both women carrying E6350G or E350T, however, a higher effect was observed for E6350T variants carriers. The positive association of DRB $1 * 1602$ was significant for women harboring E6350G then E6350T variants. These data are in agreement with ethnical component of the studied population as well as a higher oncogenic potential of certain HPV variants. Our results also suggest that the contribution of HLA class II alleles to the genetic susceptibility to ICC differs depending on the HPV-16 variants distribution in a given geographic and ethnic group.
\end{abstract}




\section{INTRODUÇÃO}

\subsection{O Câncer do colo do útero e o papilomavirus humano}

\subsubsection{Epidemiologia}

Atualmente, o câncer do colo do útero (CCU) apresenta incidência mundial de 470.000 casos diagnosticados a cada ano (Ferlay et al., 2004). Sendo observado no Brasil uma das maiores taxas de incidências desta doença (Fraumeni et al., 1993).

Estima-se que o câncer do colo do útero seja o terceiro mais comum na população feminina, sendo superado apenas pelos cânceres de pele não melanoma e de mama. As estimativas do INCA apontam que 20.690 casos novos serão observados no Brasil no ano de 2005, com um risco estimado de 22 casos a cada 100 mil mulheres. A distribuição dos casos de CCU varia conforme a região analisada, o Norte do Brasil (sem considerar os tumores de pele não melanoma) apresenta as taxas de incidência mais elevadas desta doença. com $23 \%$ dos casos. Nas regiões Sul, Centro-Oeste, Sudeste e Nordeste representa o segundo tumor mais incidente (INCA, 2005).

Os papilomavirus humano (HPV) são freqüentemente encontrados na população em geral. Estudos caso-controle em vários países indicam a presença do DNA viral em mais de 90\% dos cânceres do colo uterino (Bosch et al., 1995). O HPV-16 ocorre em maior freqüência (50\%), seguido pelo HPV-18 (12\%), HPV $45(8 \%)$ e HPV $31(5 \%)$ (revisado em IARC Working Group, 1995; Muñoz, 1997). Têm sido verificadas pequenas oscilações na prevalência dos tipos de HPV nos diversos graus de lesões das diferentes populações estudadas. Esta variação reflete diferentes metodologias utilizadas nos estudos, prováveis erros de classificação na citologia oncótica ou diferenças no comportamento sexual (Bosch et al., 1994; Castellsagué et al., 1997). 
A transmissão do HPV ocorre, principalmente, através de contato sexual seja ele vaginal, vulvar, peniano, cervical ou anal (revisado em IARC Working Group, 1995). Estudos transversais demonstram que variáveis como idade e comportamento sexual são os mais importantes determinantes da infecção cervical por HPV, o que confere um perfil de doença sexualmente transmissivel (Franco, et al., 1997). Bauer e col. (1991), observaram uma prevalência de $46 \%$ do DNA viral em 467 universitárias americanas sexualmente ativas. No entanto, a menor incidência de lesões neoplásicas do colo uterino sugere que grande parte das mulheres infectadas não desenvolve lesão. A maioria das infecções genitais é transiente, contudo, uma pequena proporção de mulheres com o DNA viral apresentam persistência da infecção por um mesmo tipo ou uma mesma variante molecular de um tipo de HPV. Este tipo de infecção está associado a maior risco de desenvolvimento de malignidade (Remmink et al., 1995; Londesborough et al., 1996; Villa et al., 1997).

\subsubsection{Organização Genômica dos Papilomavírus}

Os Papilomavirus (PV) são pequenas partículas de aproximadamente 55nm, formadas por um capsídeo icosaédrico não envelopado composto por 72 capsômeros. Estes vírus são pertencentes à família Papillomaviridae, cujo genoma consiste de uma única molécula de DNA circular dupla fita, de aproximadamente $8.000 \mathrm{pb}$ complexado a proteínas semelhantes a histonas (Favre et al., 1975; revisado por de Villiers et al., 2004). O genoma dos PV encontrase dividido funcionalmente em três segmentos: i) uma região não codificante denominada região controladora ou Long Control Region (LCR) que compõe aproximadamente $10 \%$ do genoma viral, nesta região são encontrados vários sítios de ligação para fatores de transcrição virais e celulares que participam na regulação da replicação e transcrição do genoma viral (revisado por Bernard, 2002); ii) a região precoce (Early) que contém de 6 a 8 genes que participam na replicação do DNA viral (E1, E2, E8) e no estímulo da proliferação celular (E5, 
E6 e E7); iii) e a região tardia (Late) com 2 ORF que codificam as proteínas estruturais do capsídeo L1 e L2 (revisado por zur Hausen, 2000) (Figura 1). 


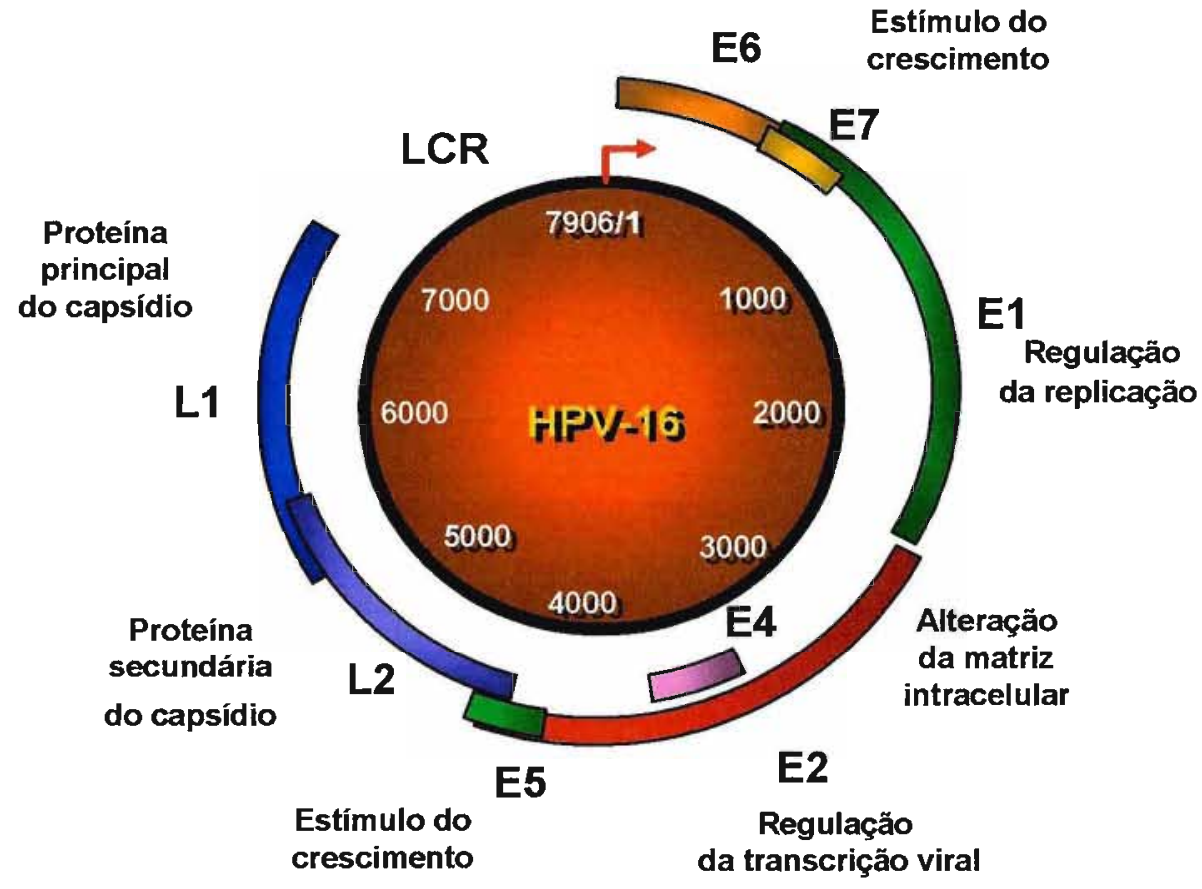

Figura 1. Mapa físico do genoma do HPV-16. REGIÃO PRECOCE (EARLY), REGIÃO TARDIA (LATE), A LCR (LONG CONTROL REGION) CORRESPONDE A REGIÂOO REGULATÓRIA (REVISADO POR VILLA, 1997). 


\subsubsection{Potencial Oncogênico dos HPV}

Os HPV têm sido encontrados em vários tipos de lesões, desde displasias leves até o carcinoma invasivo do colo uterino (CCU), e carcinoma de pênis (revisado por zur Hausen, 1996). Tem sido evidenciada a distribuição preferencial de certos tipos de HPV em condilomas e neoplasias malignas (Lörincz, et al., 1992). Os tipos mais associados ao câncer no colo do útero invasivo são classificados como de alto risco (HPV-16, 18, 31, 33, 35, 39, 45, $51,52,56,58,66$ e 68$)$. Os tipos menos freqüentes em lesões malignas formam o grupo dos HPV de baixo risco (HPV 6, 11, 26, 40, 42, 53, 55, 57, 59).

Diferenças no potencial oncogênico entre HPV de baixo e alto risco têm sido verificadas por ensaios de transformação in vitro (Barbosa et al., 1991). Foi observado que as proteínas E6 e E7 de HPV-16 e 18 transformam cultura de células primárias na presença de um oncogene ativado (Barbosa \& Schlegel, 1989; Storey \& Banks, 1993). Estas proteínas de tipos de HPV de alto risco também apresentam a habilidade de imortalizar queratinócitos primários de prepúcio ou o epitélio cervical humano (Sedman et al., 1991). Os ensaios de transformação in vitro com culturas de queratinócitos também demonstram que a atividade transformante do HPV-18 é dez vezes maior que a apresentada pelo HPV-16 (Villa \& Schlegel, 1991).

A proteína E7 de HPV-16 é composta por 98 aminoácidos e forma complexo com o produto do gene do retinoblastoma (pRB) (Dyson et al., 1989), dessa forma, interferindo com a ligação de pRB a família de fatores de transcrição E2F. Em conseqüência, ocorre ativação da transcrição de genes celulares específicos da entrada na fase de síntese do ciclo celular tais como: DNA polimerase $\alpha$, quinase dependente de ciclina-2 e timidina quinase. Estas são normalmente expressas em queratinócitos diferenciados. A proteína E7 também pode se 
associar com os inibidores de quinase dependentes de ciclinas $\mathrm{p} 21^{c p l l}$ e $\mathrm{p} 27^{k i p l}$, o que contribui para a estimulação da progressão do ciclo celular (revisado por Doorbar, 1998).

Simultaneamente, E6 de HPV de alto risco ligam-se e promovem a degradação do produto do gene supressor de tumor p53, através de sua associação com E6-AP, uma proteína com função de ubiquitina ligase (Werness et al., 1990; Scheffner et al., 1993). Assim, a associação entre E6 e E6-AP, promove a degradação de p53 pela via de proteólise dependente de ubiquitina (Scheffner et al., 1990). Dessa forma, ocorre a perda do controle do ciclo celular antes exercido por p53. Este é um dos primeiros passos para a instabilidade cromossômica em células infectadas por HPV de alto risco (16 e 18) (revisado por Zur Hausen, 2002).

\subsubsection{História Natural da Infecção por HPV}

Os HPV possuem tropismo pelo tecido epitelial com especificidade para diferentes sítios anatômicos devido à ativação da replicação viral por fatores de transcrição epitélioespecíficos (revisado por zur Hausen, 2002). A infecção das células por HPV pode ser dividida em estágios inicial e tardio, de acordo com o grau de diferenciação do epitélio celular. As lesões induzidas por PV são originadas pela infecção de queratinócitos na camada basal do epitélio em um estágio inicial da expressão dos genes precoces. Especula-se que o receptor para a entrada do vírus na célula seja a integrina $\alpha 6 \beta 4$, a qual encontra-se confinada na camada basal (Evander et al., 1997), entretanto, são necessários mais estudos para o esclarecimento desta questão. A infeç̧ão produtiva ocorre nos estágios tardios do ciclo de vida viral em queratinócitos diferenciados. Nessa fase é observada a produção e a montagem das partículas infecciosas pela expressão das proteínas codificadas pelos genes tardios L1 e L2 (revisado por zur Hausen, 2002).

O CCU parece ser proveniente de uma evolução contínua de lesões precursoras caracterizadas por atipias celulares, que ocorrem principalmente na área da junção escamo- 
colunar (J.E.C.) da cérvice uterina. Estas lesões precursoras podem ser: displasia leve, moderada, severa e carcinoma in situ (CIS). Diversas classificações histopatológicas são utilizadas para os diferentes estágios destas alterações. Uma das nomenclaturas mais comuns é neoplasia intraepitelial cervical (NIC) (Richart, 1990), que leva em consideração achados histológicos. De acordo com o grau de estadiamento, estas lesões podem ser divididas em três categorias: i) NIC grau I - as alterações acometem um terço do epitélio basal (displasia leve); ii) NIC grau II - apresenta comprometimento dos terços inferior e médio do epitélio (displasia moderada); iii) NIC grau III - todas as camadas epiteliais encontram-se alteradas, sendo equivalente ao CIS (displasia severa). Já a classificação de Bethesda (Luff, 1992), refere-se a diagnósticos citológicos e divide as lesões intraepiteliais escamosas (SIL) em: i) Baixo grau (LSIL) - condiloma plano e NIC I; ii) alto grau (HSIL) - inclui NIC II, NIC III e CIS; iii) carcinoma invasivo.

Nas LSIL e NIC I, o DNA viral encontra-se no estado epissomal (não-integrado ao DNA celular), o que permite a síntese de proteínas tardias e a formação de partículas virais. Já nas HSIL e NIC II ou III, o DNA apresenta-se freqüentemente integrado ao genoma da célula hospedeira, não havendo formação de partícula viral. O processo de integração ocorre mediante a quebra da molécula circular do DNA viral, na maioria das vezes, dentro da região onde se encontra o gene E2, responsável pelo controle da replicação e transcrição viral (Jeon \& Lambert. 1995: Vernon et al., 1997). Desta forma, ocorre a expressão aumentada dos transcritos gênicos de E6 e E7 e conseqüente estímulo da proliferação celular. 


\subsubsection{Diversidade Genômica dos PV}

Os PV compõem um grupo de vírus heterogêneos e são encontrados em diversos taxa. Atualmente, tem sido identificado mais de 30 tipos de PV animal. Em humanos, são encontrados cerca de 120 tipos infectando vários sítios anatômicos, dos quais mais de 40 tipos estão associados a lesões anogenitais (revisado por de Villiers et al., 2004).

A classificação taxonômica dos PV é baseada na identidade das sequiências nucleotídicas do gene L1. Para ser caracterizado um novo tipo de PV é necessário que haja diferenças nas seqüências nucleotídicas maiores que $10 \%$ quando comparado a tipos previamente descritos. Um subtipo é caracterizado quando as diferenças nas seqüências variam de 2 a $10 \%$, e uma nova variante molecular de um tipo é definida quando as diferenças nestas seqüências nucleotídicas são menores que $2 \%$ (revisado por Bernard, 2005).

Os PV apresentam organização, tamanho genômico, ORF e função das proteínas similares. De todas as ORF, E1 e L1 são as mais conservadas entre os genes precoces e tardios, respectivamente (Bernard et al., 1994). A diferença intratípica nessas regiões varia de 0 a $2,3 \%$, e a diferença intertípica mais próxima varia entre 9,8 a 17,4\%. Esta alta conservação do genoma dos HPV sugere uma origem monofilética para estes vírus (Chan et al.,1992a; 1992b).

A análise das seqüências dos genes tais como E5, E6, E7, L1, L2 e da LCR em HPV16 e 18 indicam que o polimorfismo intratípico é muito limitado. A variação intratípica observada nesses tipos de PV é menor que 2,5\% dentro das ORF e até $5 \%$ na LCR (Chan et al, 1992a; Ong et al, 1993; Ho et al., 1993). 


\subsubsection{Variantes Moleculares de HPV-16 e 18}

Ho e col. (1991) iníciaram os estudos de variabilidade do HPV-16 analisando um segmento de $364 \mathrm{pb}$ da LCR viral. Foi observado que as seqüências nucleotídicas dos isolados de HPV-16 poderiam ser distinguidas devido a presença de 33 eventos de mutações representados por transições, transversões, inserções e deleções observadas nesta região do genoma. Em seguida, Chan e col. (1992a) examinaram o mesmo segmento do genoma viral em 118 espécimes provenientes do Brasil, Alemanha, Cingapura e Tanzânia. Nesse estudo, foram caracterizadas 38 variantes moleculares de HPV-16. Posteriormente, Ho e col. (1993) ampliaram esta amostra analisando 305 isolados oriundos de 25 regiões geográficas e/ou alguns grupos étnicos isolados na África, Eurásia, e nas Américas. Neste estudo foi identificado um total de 48 variantes moleculares de HPV-16 incluindo as variantes que haviam sido caracterizadas por Chan e col. (1992a).

Através da construção de uma árvore filogenética utilizando métodos de distância genética, verificou-se que o HPV-16 evoluiu ao longo de 5 ramos principais: dois predominantes na África (Af-1 e Af-2), um ramo asiático-americano (AA), um europeu (E) e um ramo asiático (As). A maior variabilidade foi encontrada nas amostras oriundas da África (Figura 2). Além disso, algumas variantes apresentavam combinações de mutações características de determinadas localizações geográficas (Ho et al., 1993). 


\section{A: HPV-16}
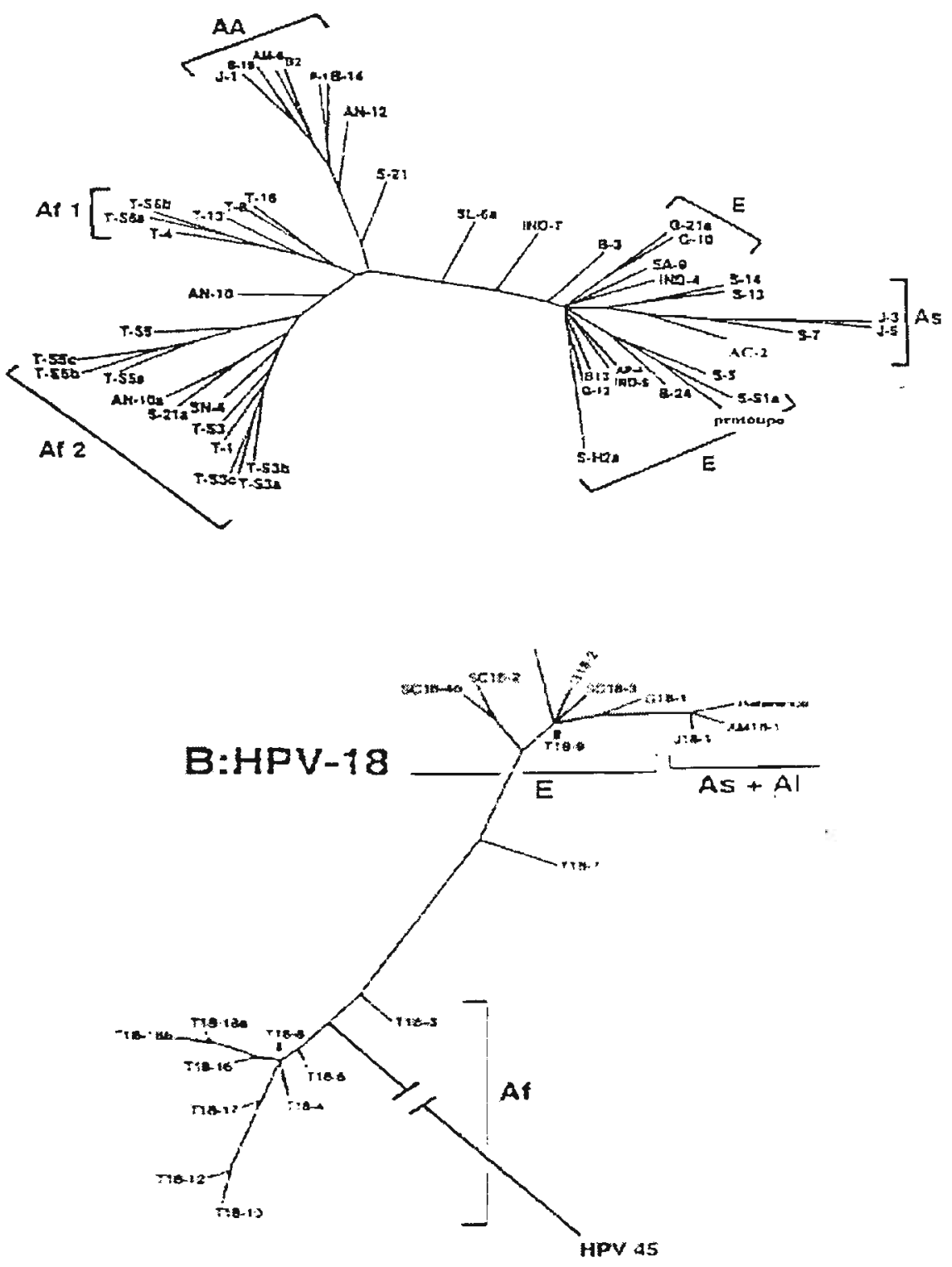

Figura 2. Árvore filogenetica dos HPV-16 e HPV-18. Estas árvores foram construídas a partir da variabilidade nucleotídica de um fragmento da LCR de isolados de HPV-16 e 18 oriundos dos 5 continentes (extraído de Ho et al., 1993 e Ong et al.. 1993). 
Ong e col. (1993) estudaram a variabilidade de HPV-1 8 analisando um fragmento de $321 \mathrm{pb}$ da LCR. Neste trabalho foram identificadas 37 variantes moleculares que se agrupavam em 3 ramos na árvore filogenética: um ramo africano (Af), um europeu (E) e um ramo denominado asiático-ameríndio (As + AI) (ver Figura 2). Semelhante a HPV-16, a maior variabilidade foi encontrada nas amostras africanas. As variantes identificadas nas amostras brasileiras apresentaram mutações características dos ramos europeu e asiático-ameríndio. Em um dos espécimes de uma tribo indígena da Amazônia, foi identificada uma variante que diferia por uma mutação de ponto quando comparada a uma variante asiática encontrada no Japão (Ong et al., 1993). Este fato sugere que a taxa de mutação do HPV seja muito baixa. A partir desse achado e considerando também outras evidências sobre a natureza e biologia destes vírus, foi utilizado um conceito de 'relógio molecular' no qual estimou-se que uma mutação nestes genomas levaria um período de 12.000 a 14.000 anos para se fixar em uma variante (Ong et al., 1993). De modo interessante, esse é o tempo estimado para o povoamento do Novo Mundo por populações humanas ancestrais.

A diversidade das seqüências nucleotídicas em HPV-16 e 18 sugere origem monofilética e especiação na África num período estimado em 200.000 anos antes do presente, com subseqüente diversificação a partir de duas grandes linhagens, uma africana e uma eurasiana. Estas originaram os 5 ramos principais da árvore de HPV-16, com posterior difusão destes vírus através de migrações das populações humanas ancestrais (Ho et al., 1991; 1993: Ong et al., 1993).

As Américas, ao contrário dos outros continentes, foram povoadas mais recentemente (entre 10.000 a 40.000 anos atrás) por populações humanas provenientes da Ásia através de rotas migratórias ocorridas na Beríngea antes da última glaciação (Bonatto \& Salzano, 1997). As análises das amostras americanas sugerem que variantes dos ramos $\mathrm{E}$ e $\mathrm{AA}$ tenham sido transferidas para o Novo Mundo em um período de aproximadamente 12.000 anos (que 
coincide com o estimado para o povoamento das Américas). Mais recentemente, essas duas linhagens teriam sido trazidas para a América do Sul junto com a migração de grupos da América do Norte.

Nestes estudos de variabilidade na LCR, grande parte das amostras foi proveniente de carcinoma e lesões de vários graus $(80 \%)$ e, somente, $20 \%$ pertencem a amostras com citologia normal. Os genótipos de HPV-16 mais freqüentes em diferentes populações mundiais foram o protótipo $(\mathrm{E}), \mathrm{B}-2(\mathrm{AA})$ e a variante $\mathrm{B}-12(\mathrm{E})$, sendo que esta foi a variante mais freqüente nos espécimes, independente do tipo de lesão. Diferenças na prevalência destes isolados foram observadas nas regiões geográficas: em Cingapura, o protótipo foi o genótipo mais freqüente tanto em amostras normais quanto em amostras de carcinoma; no Brasil, o protótipo e a variante B-2 foram encontradas em igual proporção; e na Alemanha, a variante B-12 foi a mais prevalente em carcinoma (Ho et al., 1993). Tais divergências na distribuição geográfica das variantes podem ser, em parte, o reflexo de diferentes contribuições dos grupos étnicos nas regiões, ou provável diferença no potencial oncogênico das variantes.

Outros estudos a respeito da variabilidade de HPV têm sido realizados utilizando regiões codificadoras do genoma tais como E5, E6, E7, L1 (Icenogle et al., 1991; Eschle et al., 1992; Pushko et al., 1994). Em 1995, Yamada e col. analisaram variações nos genes L1 e L2 e E6 e constataram que estas regiões são filogeneticamente compatíveis com os achados da LCR.

\subsubsection{Variabilidade Intratípica do HPV-16 Associada ao Risco de Neoplasia Cervical}

No início dos anos 90, foi levantada a hipótese das variantes apresentarem potencial oncogênico diferente. A variabilidade intratípica na LCR estaria associada a diferenças na capacidade de ligação de fatores celulares e virais que atuam na regulação da replicação e 
transcrição viral, resultando em maior ou menor atividade transcricional. Já a variabilidade nos genes que codificam proteínas, como E6 e E7, estaria associada a um maior potencial de imortalização e transformação celular.

Ho e col. (1991) através de ensaios de transcrição in vitro, utilizando o gene repórter clorafenicol acetiltransferase (CAT), não observaram diferenças significativas entre a LCR das variantes na capacidade de ativar a transcrição, concluindo não haver associação entre variação genômica e variação no potencial carcinogênico. Entretanto, diferentes propriedades biológicas e bioquímicas foram encontradas nas variantes moleculares de HPV (Stöppler et al., 1996; Sherman et al., 1997). Foi verificado que variantes do ramo AA apresentam maior capacidade de degradar p53 e aiterar a diferenciação de queratinócitos (Stöppler et al., 1996). Ainda mais, variantes do gene E6 (ramo Af-2), que diferem entre si por substituições de aminoácidos na extremidade amino-terminal da proteína, apresentam maior capacidade de transativação ou inibição de p53, quando comparadas com o protótipo (Sherman et al., 1997). Veress e col. (1999) através de ensaios de transcrição in vitro, usando o gene repórter da luciferase de vagalume, verificaram que as variantes do ramo europeu possuíam atividade de transcrição semelhante ao controle (protótipo). No entanto, a variante asiático-americana B-2 apresentou atividade transcricional 1,7 vezes maior em relação ao protótipo. Nesse mesmo trabalho, foi realizado o mapeamento da região responsável pela maior atividade de transcrição desta variante, onde foi constatado que as alterações entre os nucleotídeos 7660 7890 eram responsáveis pelo aumento da transcrição (Veress et al., 1999). Outro estudo também identificou maior atividade transcricional da variante asiático-americana B-2 (Kozuka et al., 2000). Mais recentemente, Sichero e col. (2005) observaram uma significativa variação na atividade transcricional das variantes de HPV-18, com diferenças de 2,64 a 5,91 (variantes do ramo E) e de 5,16 a 8,18 (variantes do ramo $\mathrm{AS}-\mathrm{AI}$ ) vezes mais atividade quando comparadas à variante usada com referência (B-18-2 do ramo E). 
Os dados epidemiológicos têm sido importantes para o entendimento da história natural da infecção dos HPV e o papel das variantes moleculares nas neoplasias cervicais (Villa et al, 1997). Estudos longitudinais demonstram que algumas variantes de HPV-16 e 18 tendem a persistir, o que poderia significar uma vantagem funcional importante na progressão da doença (Xi et al., 1995; Londesborough et al., 1996; Lizano et al., 1997a; Villa et al., 2000). Análises genotípicas de isolados de HPV-16 têm verificado associação entre uma variante do gene E6 e a infecção persistente, o que levaria ao desenvolvimento de HSIL (Londesborough et al., 1996). Esta variante apresenta uma substituição no nucleotídeo $350 \mathrm{~T} \rightarrow \mathrm{G}$ que resulta na mudança do aminoácido 83 de leucina para valina. Tem sido sugerido que este polimorfismo encontra-se associado a malignidade, podendo variar de acordo com a população estudada. Zehbe e col. (1998a) verificaram alta prevalência da substituição 350G em mulheres suecas com CCU. Entretanto, Nindl e col. (1999b) encontraram distribuição uniforme desta substituição em lesões pré-invasoras e invasoras de mulheres da Alemanha. Ainda mais, este polimorfismo foi considerado um fator de baixo risco em mulheres italianas e holandesas (Bontkes et al., 1998; Zehbe et al., 1998b). Deste modo, sugere-se que diferenças genéticas entre as populações sejam um fator adjuvante do potencial oncogênico das variantes.

Os estudos de prevalência que analisaram amostras provenientes de diversos graus de lesões verificaram que a variante européia de HPV-16 denominada B-12 é a mais freqüente no mundo (Ho et al., 1993). Também foi observado que em povos indígenas da América do Sul (Mundurucu, Tiriyó e Waiãpi na Amazônia e ameríndios do Chaco na Argentina), as variantes européias encontram-se em $83 \%$ das amostras (Ho et al., 1993). Os isolados deste ramo filogenético também prevaleceram em lesões de alto grau e carcinoma oriundas de índias quechuas da província argentina de Jujuy (93\%) (Picconi et al., 1999). Yamada e col. (1997) verificaram que as variantes africanas constituiam $92 \%$ dos espécimes provenientes da África e somente $9 \%$ destas foram detectadas em outras regiões geográficas. As variantes do ramo $\mathrm{E}$ 
foram encontradas na maioria dos espécimes de todas as regiões (com exceção das amostras africanas), variando de $60 \%$ no sudeste da Ásia a 93\% na América do Norte. As variantes asiáticas constituíram $26 \%$ dos espécimes do sudeste asiático. estas foram raras ou ausentes nos outros continentes. As variantes do ramo AA foram encontradas nas Américas Central e do Sul (20\% dos espécimes) e na Europa (14\% dos espécimes) (Yamada et al., 1997). Na cidade de São Paulo, tem sido verificado o predomínio de variantes européias $(66,7 \%)$ em espécimes cervicais oriundos de LSIL, entretanto, deve-se considerar também a presença da variante asiático-americana B-2 em 29\% dos casos (Villa et al., 2000). Em amostras de CCU, provenientes da população de Belém (PA), as variantes européias foram encontradas em $42 \%$ das amostras. Foi observado também um predomínio da variante do ramo AA em relação aos isolados do ramo E (Junes, 2000). Resultados similares foram obtidos na cidade de João Pessoa (PB) (Souza, 2001), e no Distrito Federal (Cruz et al., 2004). As diferenças na prevalência das variantes em diversos estudos podem ser devido à origem das populações estudadas ou ao tipo de lesão analisada.

\subsection{O Sistema HLA}

As moléculas HLA são importantes no desenvolvimento e controle da resposta imune. uma vez que estas estão envolvidas na apresentação de peptídeos antigênicos às células $T$. Os genes HLA apresentam um alto grau de polimorfismo e estão localizados na região denominada Complexo Principal de Histocompatibilidade (MHC) na posição 6p21.3 do genoma humano (revisado por Moss \& Khana, 1999).

O MHC humano foi dividido em três regiões denominadas de classe I, II e III. Na região de classe I estão os genes que codificam moléculas expressas na superfície da maioria das células nucleadas (HLA-A, B, C, E, H, G e F). Sua função mais conhecida é a 
apresentação de peptídeos antigênicos aos linfócitos $\mathrm{T} \mathrm{CD} 8^{+}$(citotóxicos) e regular a ação de células NK (natural killer) (Dembic et al., 1986). Na região de classe II estão os genes HLADR, DQ e DP que codificam moléculas expressas em células apresentadoras de antígenos, como linfócitos B, células dendríticas (células de Langerhans) e macrófagos. Estas moléculas apresentam peptídeos antigênicos aos linfócitos $\mathrm{T} \mathrm{CD}^{+}$(auxiliares). Na região de classe III estão os genes que codificam as proteínas do sistema complemento e o fator de necrose tumoral (TNF) (revisado por Moss \& Khana, 1999).

As moléculas de classe I e II são estruturalmente semelhantes, sendo constituídas por uma cadeia polipeptídica $\alpha$ e uma $\beta$. Com a diferença de que nas moléculas de classe $\mathrm{I}$, a cadeia $\alpha$ é codificada pelos genes de classe I (HLA-A, -B, ou -C) e a cadeia $\beta$ pelo gene da $\beta_{2}$ microglobulina (localizado no cromossomo 15 , não pertencente ao $\mathrm{MHC}$ ). Já as cadeias $\alpha$ e $\beta$ das moléculas de classe II são codificadas exclusivamente por genes HLA de classe II (Figura 3). Como exemplo, a molécula HLA-DR é codificada pelos o genes HLA-DRAl (cadeia $\alpha$ ) e HLA-DRB1 (cadeia $\beta$ ).

As moléculas de classe I e II estruturalmente formam uma fenda na porção superior das moléculas, originando o sítio de ligação do peptídeo antigênico a ser apresentado aos linfócitos T (Bjorkman et al., 1987, Brown et al., 1993). É nesta região da fenda que está localizado o sítio polimórfico das moléculas HLA. Estes sítios também são denominados pockets e sua composição varia conforme o alelo que codifica a molécula, o que gera uma grande diversidade de seleção e apresentação de antígenos entre indivíduos. 


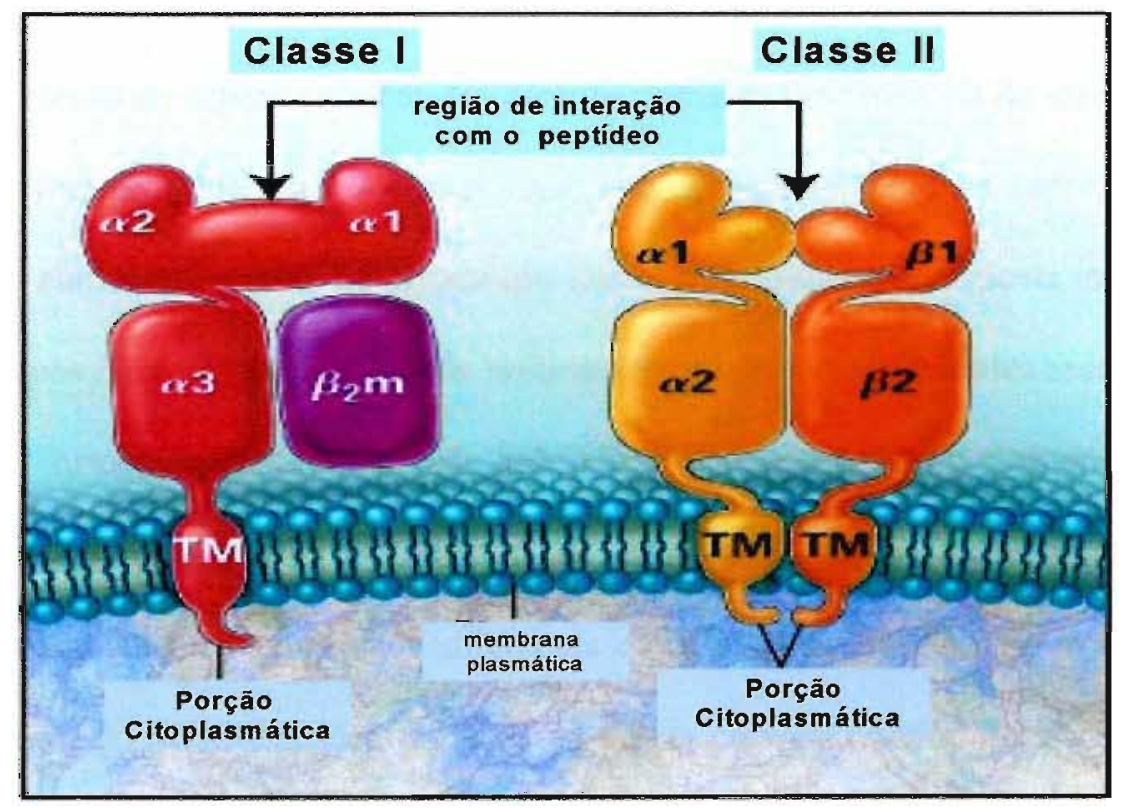

Figura 3. Representação esquemática das moléculas HLA de classe I e II. Na molécula HLA classe I, a fenda de ligação do peptídeo é formada pelos domínios $\alpha 1$ e $\alpha 2$; e a região semelhante à imunoglobulina é constituída pelo domínio $\alpha 3$ da cadeia de HLA classe I e pela B2-microglobulina. O sítio de ligação da molécula CD8 está localizado no domínio a3. Na molécula de classe II, a fenda de ligação do peptídeo é formada pelos domínios $\alpha 1$ e $\beta 1$, e a região semelhante à imunoglobulina é formada pelos domínios $\alpha 2$ e $\beta 2$, sendo neste último o sítio de ligação da molécula CD4. 


\subsubsection{Associação entre Genótipos de HLA e a Infecção por HPV}

Evidências epidemiológicas apontam o HPV como o principal agente responsável pelo desenvolvimento do câncer cervical. No entanto, somente uma minoria de infecção persistente por estes vírus progride para o câncer, indicando o envolvimento de outros fatores ou cofatores que aumentam o risco de progressão para a malignidade. A resposta imune juntamente com genótipos HLA do indivíduo pode influenciar na ocorrência de lesões associadas ao HPV. Uma maior susceptibilidade à infecção pelo HPV tem sido atribuída a alguns polimorfismos de genes HLA (Apple et al., 1994; revisado por Maciag \& Villa, 1999). Estudos realizados em diversas populações têm verificado diferentes e controversos resultados de associação entre polimorfismos do MHC e susceptibilidade ao câncer cervical (Apple et al., 1995; Hildesheim et al., 1998; Cuzick et al., 2000). Dados relativos à população brasileira demonstram associação do haplótipo DRB 1*15-DQB1*0602 e entre as pacientes com CCU HPV positivas (Maciag et al., 2000). Estes genótipos poderiam aumentar as chances de estabelecimento de infecção persistente de HPV, elevando o risco de desenvolvimento de lesões cervicais malignas. Com o objetivo de esclarecer esta questão. polimorfismos de genes HLA classe II vêm sendo investigados em um estudo prospectivo realizado na cidade de São Paulo (Franco et al., 1999; Maciag et al., 2002).

Estudos sugerem que a resposta imune celular é a mais importante no controle da infecção por HPV. Assim, interações apropriadas entre moléculas $\mathrm{MHC}$ e peptídeos antigênicos possuem um papel crucial na ativação de células T. Estas moléculas são codificadas por diferentes genes e alelos e apresentam distintas propriedades de ligação ao antígeno. Logo, a variabilidade observada no MHC do hospedeiro torna-se importante na definição de uma resposta imune eficiente contra um patógeno ou células tumorais. Da mesma forma. epitopos virais também podem afetar as propriedades de reconhecimento antigênico do 
sistema imune. Foi observado em uma grande proporção de pacientes HLA-B7 positivas uma variante de HPV-16 que apresenta uma mutação de ponto na proteína E6 (G131). Esta substituição. que altera a ligação do epítopo à molécula HLA-B7, poderia influenciar no reconhecimento apropriado por linfócitos específicos, uma vez que a ativação de células $T$ depende da apresentação de peptídeos antigênicos em moleculas HLA presentes nas células apresentadoras de antígenos (Ellis et al., 1995). Assim, a diversidade das variantes em regiões codificadoras do genoma viral, juntamente com alelos HLA, poderiam influenciar a formação da resposta imune. Diferentes epítopos do HPV podem ser imunogênicos em alguns indivíduos mas em outros não. Parte deste resultado pode ser atribuído ao HLA do indivíduo, entretanto, deve-se considerar também a variabilidade do HPV (Maciag \& Villa, 1999). O conhecimento destas interações é importante para o esclarecimento do papel das moléculas HLA na resposta imune contra infecções por HPV e o câncer cervical.

\subsection{Polimorfismos de DNA e Estudos Populacionais}

\subsubsection{Polimorfismos de DNA Nuclear}

Os polimorfismos de DNA são caracterizados pela presença de múltiplos alelos em um locus, onde mais de um alelo apresenta freqüência relativa igual ou superior a $1 \%$ (Bodmer \& Cavalli-Sforza, 1976). Os principais tipos de marcadores observados no DNA genômico são: Polimorfismo de um Único Nucleotídeo (SNP), Polimorfismos de Comprimento de Fragmentos de Restrição (RFLP), Número Variável de Repetição em Tandem (VNTR).

Os SNP são polimorfismos caracterizados pela substituição, perda ou adição de um único nucleotídeo. Esses polimorfismos são a classe de variantes mais comuns do genoma humano. Os RFLP foram a primeira geração de marcadores de DNA, os quais são caracterizados pela presença de apenas dois alelos (sítio presente ou ausente) o que limita as 
informações desta técnica para o uso em genética de populações e estudo de mapeamento, pois poucos indivíduos são informativos e a heterozigosidade para o locus em questão é no máximo de $50 \%$ (Parsons \& Holland, 1998). Os VNTR são unidades de repetição in tandem cujas seqüências cernes são encontradas repetidas em diferentes números de vezes. De acordo com o tamanho das unidades de repetições, os VNTR são classificados em 3 grupos: microssatélites (1-2 pb), Short Tandem Repeats (STR, 3-6pb) e minissatélites (>10pb) (Shriver et al., 1995). Em populações humanas as análises de polimorfismo genético são empregadas para inferir acerca da contribuição genética e do caminho percorrido pelas populações ancestrais até a formação das populações atuais. Para tanto, as STR têm sido extensivamente utilizadas pois apresentam elevado número de alelos, alta heterozigose e encontram-se em regiões não codificantes de DNA; as quais são menos afetadas pela seleção natural. Estas características tornam estes polimorfismos altamente informativos para os estudos de estrutura genética de populações (Harding, 1992; Armour et al., 1996; Cerdas-Flores et al., 2002).

\subsubsection{Polimorfismos do DNA mitocondrial (mtDNA)}

O mtDNA é uma pequena molécula circular, dupla fita de $16.569 \mathrm{pb}$, localizado na mitocôndria. Este apresenta aproximadamente $90 \%$ de sequências codificadoras, as quais consistem de 2 genes de rRNA, 22 genes de tRNA para a síntese das proteínas mitocondriais e 13 genes estruturais de proteínas essenciais à respiração mitocondrial (Anderson et al., 1981). A molécula do mtDNA apresenta uma região não codificante entre os genes tRNA ${ }^{\text {Phc }} e$ tRNA $^{\text {Pro }}$ denominada de alça-D, onde inicia-se a replicação do mtDNA.

O genoma mitocondrial apresenta algumas características ímpares que o torna excelente ferramenta para o estudo de genética de populações e evolução humana: i) o mtDNA tem herança exclusivamente materna (Giles et al., 1980); ii) é haplóide e não sofre recombinação em humanos (Ingman et al., 2000), logo as diferenças acumuladas entre duas 
moléculas qualquer refletem variações que ocorreram desde que elas compartilharam um ancestral comum; iii) o mtDNA possui taxa de mutação 10 vezes maior do que se observa no DNA nuclear (Horai et al., 1995). A taxa de mutação na alça-D também é dez vezes maior do que a observada no resto do genoma mitocondrial, tornando essa região o alvo preferencial dos estudos por sequenciamento que visam quantificar a variabilidade genética intra e interpopulação humana (Horai \& Hayasaka, 1990; Horay et al., 1993).

A análise da variação do mtDNA por RFLP na população global permitiu identificar um número de clados monofiléticos nos quais todos os mtDNA puderam ser classificados. Esses clados ou haplogrupos foram distinguidos por mutações ancestrais que ocorreram há milhares de anos. Isto permitiu identificar variações continente-específicas para africanos, europeus caucasianos (Torroni et al., 1994) e asiáticos (Schurr et al., 1990).

Quase todos os mtDNA de origem africana podem ser classificados em um dos 3 principais haplogrupos (L1, L2, L3). O haplogrupo L1 é considerado ancestral, uma vez que foi encontrado na raiz da árvore filogenética humana do mtDNA. Acredita-se que os super haplogrupos eurasianos M e N deixaram África a aproximadamente 50.000-60.000 anos para dar origem aos haplogrupos da Ásia (A,B,C,D,F) e Europa (H, I, J, K, T, U, V, W, X).

\subsubsection{Diferenciação Étnica de Populações}

Para estimar a contribuição étnica em uma população um marcador genético é considerado ideal quando este apresenta elevada freqüência alélica diferencial $(\delta)$ entre as populações. Estes alelos são chamados "alelos população-específicos" (PSA) os quais apresentam elevados valores de $\delta(>50 \%)$ (Dean et al., 1994; Shriver et al., 1997). Chakraborty e col. (1991) sugerem que a precisão das estimativas de mistura interétnica é diretamente dependente do nível de diferenças nas freqüências alélicas $(\delta)$ entre as populações 
parentais. Assim, em estudos de mistura interétnica a representatividade das populações parentais e de suas freqüências alélicas são fundamentais para a obtenção de estimativas mais precisas dos coeficientes de mistura.

Vários grupos populacionais têm sido investigados em relação a diversos loci de STR. Os resultados destes trabalhos revelaram que o número de alelos dos diferentes loci é muito semelhante entre as populações. Contudo, algumas populações apresentam diferenças significativas em suas freqüências alélicas, sugerindo que estes sistemas podem ser utilizados para identificar diferentes grupos étnicos (Chakraborty et al., 1992; Deka et al., 1992).

Com objetivo de melhor explorar a informação molecular provenientes dos VNTR, alguns modelos estatísticos, que se baseiam no processo mutacional destes marcadores, têm sido propostos. A estatística $\mathrm{F}_{\mathrm{ST}}$ está relacionada ao modelo de mutação dos alelos infinitos (Infinite Alelle Model, IAM), onde cada mutação produz um novo alelo de qualquer tamanho, resultando em um número infinito de alelos (Kimura \& Ohta, 1964). A estatística $\mathrm{R}_{\mathrm{ST}}$ (Slatkin,

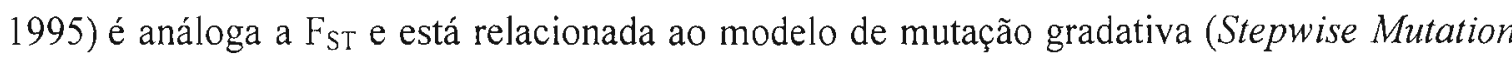
Model, SMM), o qual assume que cada alelo pode mutar em uma unidade de repetição tanto para mais quanto para menos, podendo levar a formação de um alelo já existente (Kimura \& Ohta, 1978). Foi observado por Shriver e col. (1993) que as três classes de VNTR estão sujeitas a diferentes forças de mutação, com os loci de STR seguindo o modelo SMM e os loci de microssatélites e minissatélites desviando-se para o modelo IAM.

Os registros históricos também mostram evidências do processo de mistura e os modelos sugeridos de formação da população podem ser investigados pela análise genética e, então, confrontados com o que se conhece sobre a estrutura demográfica, social e histórica da população miscigenada.

A variabilidade em VNTR é freqüentemente utilizada em estudos de genética de populações, uma vez que estes marcadores têm indicado boa diferenciação entre as populações 
estudadas (Deka et al., 1992; Nolelli et al., 1992; Bortolini et al., 1995; Robinson et al., 1996; Zago et al., 1996; Hutz et al., 1997; Katsuyama et al., 1998; Vallinoto et al.. 1998; Rodrigues, 1999; Silva et al., 1999).

Zago e col. (1996) estudaram 6 VNTR (incluindo D1S80, D4S43, APO3'-B, VW) entre populações ameríndias e compararam com três outras populações brasileiras incluindo brancos, negros e japoneses. Os dados obtidos permitiram uma clara distinção entre as quatro populações analisadas, uma vez que foram observadas diferenças no padrão de distribuição alélica, além da presença ou ausência de alelos específicos de determinada população. Silva e col. (1999) aplicaram os mesmos marcadores para estimar diferenças genéticas entre populações afro-brasileiras, populações afro-venezuelanas e africanas, resultando em um elevado grau de diferenciação entre as cinco populações estudadas.

Adicionalmente, os estudos do genoma mitocondrial humano têm sido amplamente utilizados para traçar a origem e os padrões de migração do homem moderno. Estes trabalhos têm sido realizados principalmente pela análise de RFLP (Wallace et al., 1985; Torroni et al., 1993), deleção de 9 pb (Hertzberg et al., 1989) e substituições nucleotídicas que ocorrem na a)ça-D (Horai \& Hayasaka, 1990; Stoneking, 1993).

A análise do mtDNA é bastante útil uma vez que a abordagem utilizando polimorfismos de DNA nuclear não permite detectar diferenças no grau de contribuição masculina e feminina de cada etnia (fluxo gênico assimétrico) no processo de miscigenação. Quando uma população é formada pela mistura de genes de duas ou mais populações, homens e mulheres de cada uma das populações parentais podem não contribuir com a mesma proporção de genes para o conjunto gênico da população miscigenada (Batista-dos-Santos et al., 1999; Ribeiro-dos-Santos et al., 2002). Entretanto, deve-se considerar que a contribuição de uma determinada etnia pode ser dramaticamente reduzida quando se analisa o mtDNA e o DNA do cromossomo $\mathrm{Y}$, uma vez que esta é uma herança uniparental. 


\subsection{Objetivos}

Estudos longitudinais demonstram que algumas variantes moleculares do HPV-16 encontram-se mais associadas ao desenvolvimento de HSIL. As diferenças na prevalência das variantes de HPV-16 observadas em diversos estudos poderiam ser atribuídas a uma contribuição diferencial de grupos étnicos em diferentes regiões. O polimorfismo de genes HLA parece contribuir na suscetibilidade ao desenvolvimento de lesões malignas relacionadas ao HPV. Assim, este projeto visa identificar possíveis associações entre alelos e haplótipos dos genes HLA-DRB1 e DQB1 com o desenvolvimento de câncer no colo do útero na região Norte do Brasil.

Os objetivos específicos referentes a este projeto são:

1. Determinar a prevalência das variantes de HPV-16 na população de mulheres citologicamente normais da cidade de Belém (PA) em relação à prevalência de variantes em mulheres com câncer do colo do útero.

2. Definir a correlação entre grupo étnico e distribuição de variantes de HPV-16 nesta população.

3. Estudar a associação entre alelos e haplótipos dos genes HLA-DQB1 e HLA-DRB1 e a infecção por variantes de HPV-16. 


\section{MATERIAIS E MÉTODOS}

\subsection{Amostras Clínicas}

Foram utilizadas amostras provenientes de um estudo desenvolvido no Instituto Evandro Chagas (IEC, Belém-PA), em colaboração com o Instituto Ludwig de Pesquisa Sobre o Câncer de São Paulo (ILPC-SP). Os espécimes consistiram de biópsias oriundas da cérvice uterina de mulheres com idade entre 18 e 81 anos, com diagnóstico histopatológico de neoplasia intraepitelial cervical de grau III (NIC III) e carcinoma epidermóide invasor do colo do útero (CCU). A coleta das amostras foi realizada de forma seqüencial no período entre 1992 e 1996 no centro de referência para o câncer na região Norte, Instituto Ofir Loila (IOL) (Noronha et al., 1999).

Todas as amostras HPV-16 e 18 do estudo acima mencionado, foram previamente selecionadas para a análise de variantes moleculares (Junes, 2000), sendo 81 espécimes HPV16 positivos e 14 HPV-18 positivos. Desta forma, um total de 95 biópsias do colo do útero foram analisadas no presente estudo, sendo 21 com diagnóstico histológico de NIC III e 74 casos de CCU.

Este estudo também inclui amostra aleatória de mulheres oriundas de um projeto apoiado pelo programa de apoio ao desenvolvimento científico e tecnológico (PADCT) realizado em Belém-PA. A coleta foi iniciada em setembro de 2000 a janeiro de 2003, cerca de 1000 esfregaços cervicais foram coletados. Deste estudo, foram selecionadas 302 amostras para a realização das tipagens dos genes HLA de classe II DRB1 e DQB1. Estes espécimes compõem o grupo controle e estão divididos do seguinte modo: 
102 esfregaços cervicais de mulheres positivas para o DNA de HPV (incluindo esfregaços com diagnóstico de atipia de células escamosas de significado indeterminado, ASCUS), porém sem lesões neoplásicas.

200 esfregaços de mulheres com citologia normal do colo uterino, negativos para a presença do DNA de HPV.

\subsubsection{Coleta das Amostras}

Dos espécimes coletados do colo do útero através de biópsias, um fragmento foi fixado em formol tamponado e encaminhado ao Serviço de Patologia do Instituto Ofir Loiola para a realização do diagnóstico histopatológico. Um outro fragmento foi armazenado em nitrogênio líquido para o posterior isolamento do DNA utilizando o kit Glass Max DNA Isolation Spin Cartridge Sistem, GIBCO/BRL. MD, USA. Esta etapa foi realizada pelo laboratório do Dr. Wyller Mello (IEC).

Posteriormente, o DNA isolado foi encaminhado ao ILPC-SP onde foi realizado o teste de HPV utilizando a técnica de PCR segundo Manos e col. (1989). Em seguida foi realizada a tipagem de HPV pela técnica de hibridização em pontos (dot-blot) ou line blot ou RFLP (Ting \& Manos, 1990; Bauer et al., 1993).

\subsection{Clonagem e Sequenciamento da LCR Viral}

A análise da variabildade intratípica do HPV-16 em amostras de CCU da população de Belém foi realizada previamente (Junes, 2000). Para a caracterização das variantes moleculares, 81 espécimes positivos para HPV-16 foram selecionados para a amplificação de um fragmento da LCR conforme Ho e col. (1991). Esta é uma região hipervariável do genoma 
viral que permite a observação de maior diversidade entre as variantes de um tipo de HPV quando comparada com regiões codificadoras. A técnica consistiu na amplificação de um fragmento de $364 \mathrm{pb}$ da LCR próximo à origem de replicação viral, com posterior clonagem e seqüenciamento do produto de PCR para a caracterização ao nível de variantes moleculares. As sequiências de cinco clones de cada amostra foram analisadas através de comparação com seqüências depositadas no banco de dados Genebank e publicação em revista científica (Ho et al., 1993).

\subsection{Análise de Variantes do gene E6 de HPV-16 por Hibridização em Pontos}

As amostras HPV-16 positivas também foram submetidas a uma amplificação de um fragmento do gene E6, para posterior hibridização com sondas complementares a este gene (Wheeler et al., 1997). Das 81 amostras positivas para HPV-16 que tiveram um fragmento da LCR seqüenciado, 76 também foram tipadas por hibridização utilizando 2 sondas de oligonucleotídeos complementares à posição do nucleotídeo 350 do gene E6: $350 \mathrm{~T}$ (5'TTGTTATAGTITGTATGGAA3') e 350G (5'TTGTTATAGTG (Yamada et al., 1995), (Junes. 2000).

Inicialmente $60 \mu \mathrm{l}$ da reação de PCR foram desnaturados por 10 minutos com $1 \mathrm{ml}$ de solução de desnaturação (NaOH 0,4 M, EDTA 25 M). A membrana Hybond-N+ (Amersham, UK) foi ajustada a uma dot machine. Sempre com o vácuo ligado, foram pipetados sobre a membrana $50 \mu 1$ da solução de desnaturação acrescida do DNA amplificado. Após a aspiração completa da amostra desnaturada, cada poço foi lavado com 400ul de 20x SSPE ( $\mathrm{NaCl} 3,6 \mathrm{M}$, $\mathrm{NaH}_{2} \mathrm{PO}_{4}-\mathrm{H}_{2} \mathrm{O} 0,2 \mathrm{M}, \mathrm{NaOH} 0.11 \mathrm{M}$, EDTA $0,02 \mathrm{M}$ ajustado para $\mathrm{pH}=7,4$ ). Em seguida, a membrana foi exposta à luz ultravioleta, por 10 minutos, para a fixação dos DNA. As membranas contendo os amplicons correspondentes ao gene E6 foram submetidas à 
hibridização utilizando 2 sondas separadamente. Foi realizada uma pré-hibridização incubando as membranas, sob agitação, a $65^{\circ} \mathrm{C} \operatorname{com} 200 \mathrm{ml}$ de $0,1 \times$ SSPE contendo $0,5 \%$ de SSC, por 10 minutos. As hibridizações com as sondas biotiniladas $(2,0 \mathrm{pmol}$ de sonda para cada $50 \mathrm{mi}$ de solução de hibridização) foram conduzidas por 3 horas em 5x SSPE contendo SDS 0,1\%, em um forno de hibridização (Hybaid, UK), utilizando-se garrafas para hibridização de $200 \mathrm{ml}$. Em cada garrafa foi hibridizada apenas uma membrana. As hibridizações com as sondas complementares ao gene $\mathrm{E} 6$ foram conduzidas a $42,5^{\circ} \mathrm{C}$. Em seguida à hibridização, foram feitas as lavagens para retirada da sonda ligada inespecíficamente. Cada garrafa foi enxaguada com $125 \mathrm{ml}$ de solução de lavagem, 2x SSPE contendo SDS $0,1 \%$, à temperatura ambiente. Posteriormente, as membranas foram lavadas com 2x SSPE com agitação, durante 10 minutos por 2 vezes, com troca de solução entre as lavagens. As membranas hibridizadas com a sonda $350 \mathrm{G}$ foram lavadas a $44^{\circ} \mathrm{C}$, já as membranas hibridizadas com a sonda $350 \mathrm{~T}$ foram lavadas a $47^{\circ} \mathrm{C}$. Ao final foi realizada uma lavagem a temperatura ambiente, por 10 minutos, com a mesma solução. Cada 2 membranas foram incubadas em $100 \mathrm{ml}$ de 2 x SSPE, 0,1\% SDS, e $600 \mu \mathrm{l}$ do conjugado estreptavidina-HRP $(1 \mathrm{mg} / \mathrm{ml}$; Vector Laboratories, CA, USA) a uma concentração final de $30 \mathrm{ng} / \mathrm{ml}$ durante 20 minutos a temperatura ambiente, sob agitação. Após a incubação, as membranas foram enxaguadas em 500ml de $2 x$ SSPE, 0,1\% SDS, seguido de duas lavagens de 10 minutos, sob agitação vigorosa a temperatura ambiente em $500 \mathrm{ml}$ de $2 \mathrm{x}$ SSPE, 0,1\% SDS, com troca de solução entre as lavagens. Para a revelação foi utilizado um sistema de detecção direta de ácidos nucléicos (ECL ${ }^{\mathrm{TM}}$ Amersham Life Science, $\mathrm{UK})$. Logo após um filme de raio-X (X-OMAT $\left.{ }^{\mathrm{TM}} \mathrm{KODAK}\right)$ era exposto às membranas por 510 minutos, sendo depois expostas à outro filme por 1 hora. Após cada um desses períodos, os filmes foram mergulhados em revelador por 45 segundos, seguido de uma imersão rápida em água, e em solução fixadora por 2 minutos. Seguiu-se uma lavagem por 5 minutos em água, e posterior secagem dos fïlmes. 


\subsection{Polimorfismos de DNA Utilizados na Determinação da Origem Étnica da População de Belém}

\subsubsection{Tipagem dos Segmentos do mtDNA}

Todas as amostras (esfregaços cervicais citologicamente normais e de CCU e NIC III) foram submetidas à análise dos segmentos de mtDNA pela amplificação dos fragmentos de DNA através da técnica de PCR. O produto amplificado das regiões do mtDNA (663 HaeIII, 3.592 HpaI, 5.176 AluI, 13.259 HincII, 7.025 AluI, 12.308 HinfI, 13.366 BamHI, 13.704, BstNI e deleção de 9 pb) também foi submetido à análise de tamanho de fragmento (RFLP) utilizando as enzimas de restrição correspondentes (exceto a deleção de 9 pb). Desta forma foi realizada a análise das mutações que definem os haplogrupos mitocondriais previamente definidos por Torroni et al. (1993).

A visualização foi realizada por meio de eletroforese vertical, modelo V16-2 (BRL, Bethesda Research Laboratories, Gainthersburg, MD, USA), utilizado PAGE a 8\%, BTE 1x (Tris-borato $89 \mathrm{mM}$ e EDTA, $\mathrm{pH} 8,32 \mathrm{mM}$ ), $150 \mathrm{~V}$ constantes por cerca de 3 horas e coloração com nitrato de prata com algumas modificações do protocolo descrito por Sanguinetti et al., (1994). Os marcadores de peso molecular $\phi X 174 /$ HaelII e 100 pb (GIBCOBRL) foram aplicados em cada gel.

\subsubsection{Amplificação das STR}

Para a tipagem das STR foi utilizado o kit comercial AmpFLSTR Plus ${ }^{\text {TM }}$ PCR Amplification Kit (Applied Biosystems). Este Kit é recomendado pelo TWGDAM (Technical Working Group on DNA Analysis Methods), e é baseado na deteç̧ão do tamanho dos fragmentos por fluorescência, permitindo a amplificação de 9 loci de STR (D3S1358. D5S818, 
D7S820, D8S1179, D13S317, D18S51, D21S11, FGA e VWA), além do locus da amelogenina. Como controles interno foi utilizado o padrão de tamanho Gene-Scan-500 ROX. A eletroforese dos produtos de PCR ocorreu em um ABI Prism ${ }^{3} 3100$ DNA Sequencer (Foster City, CA). Os dados foram coletados pelo ABIPRISM ${ }^{\circledR} 3100$ Collection Software (Perkin, Elmer) e analisados através do GeneScan ${ }^{\circledR}$ Analysis 2.1. A genotipagem automática dos alelos foi realizada utilizando o Genotyper $(\mathbb{R})$ Software 3.1 .

\subsection{Tipagem dos Genes HLA}

A tipagem dos genes HLA-DQB1 e HLA-DRB1 foi realizada utilizando a técnica de PCR-SSO. Os iniciadores utilizados para a amplificação do segundo exon destes genes, assim como as sondas específicas utilizadas na hibridização são recomendadas pelo $12^{\circ}$ Workshop Internacional de Histocompatibilidade (12 ${ }^{\circ}$ IHWC) (Bignon \& Fernandez-Viña, 1994).

\subsubsection{Amplificação do Gene HLA-DQB1}

Para o preparo da reação de amplificação do segundo exon do gene HLA-DQB1 (volume final de $30 \mu \mathrm{l}$ ), foram utilizados os seguintes componentes e respectivas concentrações: $1 \times$ tampão Taq $\left(\mathrm{KCl} 50 \mathrm{mM}\right.$, Tris- $\left.\mathrm{HCl} 10 \mathrm{mM}, \mathrm{pH} 8,3, \mathrm{MgCl}_{2} 1,5 \mathrm{mM}\right), 0,2 \mathrm{mM}$

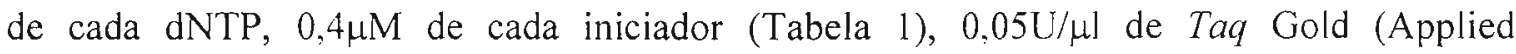
Biosystems) e 2,5 $\mu$ l de DNA. As ciclagens foram efetuadas da seguinte forma: 1 ciclo inicial de desnaturação do DNA a $94^{\circ} \mathrm{C}$ por 2 minutos, seguida de 35 ciclos de desnaturação a $94^{\circ} \mathrm{C}$ por 30 segundos, anelamento a $55^{\circ} \mathrm{C}$ por 30 segundos, extensão a $72^{\circ} \mathrm{C}$ por 30 segundos e 10 minutos de extensão final a $72^{\circ} \mathrm{C}$. Os iniciadores utilizados na amplificação do gene HLADQB1 foram: 2DQBAMP-A 5'CATGTGCTACTTCACCAACGG3' e 2DQBAMP-B 5'CTGGTAGTTGTGTCTGCACAC (Bignon \& Fernandez-Viña. 1994). 


\subsubsection{Amplificação do gene HLA-DRB1}

Devido à complexa organização genômica e ao elevado número de alelos no locus DRBl, a tipagem deste gene é realizada em duas etapas. Inicialmente, faz-se uma reação de PCR utilizando iniciadores genéricos que amplificam o segundo exon dos genes HLA-DRB (incluindo DRB1, DRB3, DRB4. DRB5 além de pseudogenes como DRB6). O produto genérico é submetido à hibridização com sondas específicas que permitem a classificação em 7 grupos alélicos:

- DR1 - inclui os alelos DRB1*01;

- $\quad$ DR2 - inclui os alelos DRB1*15 e DRB1*16;

- DR4 - inclui os alelos DRB1*04 e DRB1*1410;

- DR52 - inclui os alelos DRB1*03, e DRB1*11, DRB1*12, DRB1*13, DRB1*14 e DRB $1 * 08$ (DR8);

- $\quad$ DR7 - DRB 1*0701;

- $\quad$ DR9 - DRB1*09012;

- $\mathrm{DR} 10-\mathrm{DRB} 1 * 1001$.

Após a definição destes grupos, as amostras são amplificadas utilizando iniciadores específicos para cada grupo.

$\mathrm{Na}$ amplificação genérica de HLA-DRB foram utilizados simultaneamente dois iniciadores a 5' (2DRBAMP- $A_{1}$ e $\left.A_{2}\right)$ em virtude de diferenças existentes entre as seqüências alélicas nesta posição. Em um volume final de $100 \mu$ foram adicionados: 1x tampão Taq $(\mathrm{KCl}$ $50 \mathrm{mM}$, Tris- $\left.\mathrm{HCl} 10 \mathrm{mM}, \mathrm{pH} 8.3, \mathrm{MgCl}_{2} 1,5 \mathrm{mM}\right), 0,2 \mathrm{mM}$ de cada dNTP, 0,3 $3 \mathrm{M}$ dos iniciadores $\mathrm{A}_{1}$ e $\mathrm{A}_{2}$ e $0,6 \mu \mathrm{M}$ do iniciador $\mathrm{B}, 0,05 \mathrm{U} / \mu \mathrm{l}$ de Taq Gold (Applied Biosistems) e 2.5 $\mu$ l de DNA. As ciclagens foram efetuadas da seguinte forma: 1 ciclo inicial de desnaturação 
do DNA a $94^{\circ} \mathrm{C}$ por 2 minutos e 30 segundos, seguida de 35 ciclos de desnaturação a $94^{\circ} \mathrm{C}$ por 30 segundos, anelamento a $55^{\circ} \mathrm{C}$ por 30 segundos, extensão a $72^{\circ} \mathrm{C}$ por 30 segundos e 10 minutos de extensão final a $72^{\circ} \mathrm{C}$. As seqüências dos iniciadores usados são: forward (2DRBAMP-A 1 5 $5^{\circ}$ CCCCACAGCACGTTTCTTG3 $3^{\circ}$ e 2 2DRBAM-A $_{2}$ 5'CCCCACAGCACGTTTCCTG3'); 5'CCGCTGCACTGTGAAGCTCTC3') (Bignon \& Fernandez-Viña, 1994).

\subsubsection{Hibridização dos Genes HLA}

Com o auxílio de uma pipeta multicanal de repetição (Eppendorf), $1,2 \mu l$ do produto de PCR (HLA-DQB1 ou HLA-DRB1) foi aplicado em membranas Hybond-N+. Em cada membrana foram incluidos controles constituídos por amostras cujos alelos já haviam sido determinados. Em seguida as membranas foram desnaturadas em $\mathrm{NaOH} 0.4 \mathrm{M}$ por 3 minutos e hidratadas em SSPE 3x por 2 minutos. A fixação das amostras nas membranas foi realizada em um UV Crosslinker (Fisher Biotech).

O processo de hibridização foi realizado em garrafas de $200 \mathrm{ml}$ e forno de hibridização Hybaid. Inicialmente as membranas foram bloqueadas em $10 \mathrm{ml}$ de SSPE $0.1 \mathrm{x}$ - SDS $0,5 \%$. durante 20 minutos. à $42^{\circ} \mathrm{C}$. A solução então foi retirada e colocado $10 \mathrm{ml}$ da solução de hibridização (SSPE 5X - SDS 0,1\% e 2 pmoles da sonda biotinilada) por 3 a 12 h. A Tm de cada oligonucleotídeo foi calculada a partir da seguinte expressão (Sambrook et al., 1989):

$$
T m=81,5+16,6\left(\log _{10}\left[N a^{+}\right]\right)+0,41(\% G+C)-600 / N
$$

Após a hibridização, foram realizadas 3 lavagens de 10 minutos: A primeira sendo de baixo rigor à temperatura ambiente e as duas seguintes de alto rigor à temperatura de 44 ou 
$47^{\circ} \mathrm{C}$, de acordo com a sonda utilizada. Nestas lavagens são utilizados $10 \mathrm{ml}$ de SSPE $2 \mathrm{x}-$ SDS 0,1\%. Logo após, as membranas foram incubadas com uma solução contendo $4 \mu$ (solução estoque de $1 \mathrm{mg} / \mathrm{ml}$ ) do conjugado Horseradish peroxidase-Streptavidin (Dynal) para $90 \mathrm{ml}$ de SSPE $2 \mathrm{x}$ - SDS $0,1 \%$, durante 20 minutos à temperatura ambiente. Logo após, as membranas foram submetidas a 3 lavagens com $10 \mathrm{ml}$ de SSPE $2 \mathrm{x}$ - SDS $0,1 \%$ à temperatura ambiente, para retirada de excesso de conjugado. A primeira por 5 minutos e as seguintes por 10 minutos. Em seguida, as membranas foram retiradas das garrafas de hibridização e colocadas todas juntas, em SSPE $2 \mathrm{x}$ - SDS $0,1 \%$.

A revelação foi feita através de quimioluminescência, utilizando o Kit ECL - Direct Nucleic acid Labelling and Detection System (Amersham Life Science). Onde foi colocado $0,5 \mathrm{ml}$ de solução A e $0,5 \mathrm{ml}$ de solução B sobre a membrana. Em seguida, o filme de raio-X Kodak X-Omat K XK-1 é exposto às membranas por 10 minutos, uma segunda exposição é feita, variando de 30 a 60 minutos.

A remoção das sondas foi feita pelo aquecimento por 10 minutos das membranas a $70^{\circ} \mathrm{C}$ em água Mili-Q, após este procedimento as membranas podem ser reutilizadas. Algumas vezes, foi necessário realizar algumas variações no protocolo original. Estas variações foram baseadas no comportamento de cada sonda. Para algumas destas, foi utilizado TMACl (cloreto de amônia tetrametilado) na fase de hibridização com modificações na temperatura de hibridização e lavagem de acordo com a Tm da sonda.

$\mathrm{O} 12^{\circ}$ Workshop Internacional de Histocompatibilidade $\left(12^{\circ} \mathrm{IHWC}\right)$ recomenda o uso de 36 sondas para a caracterização dos alelos HLA-DQB1. Na tipagem do gene HLA-DRB1 são recomendadas 30 sondas para a tipagem genérica e 98 para a tipagem específica dos grupos de HLA-DRB1 (DR1, DR2, DR4 e DR52) (Bignon \& Fernandez-Viña, 1994). Resultados favoráveis foram obtidos com um total de 27 sondas para HLA-DQB1 e 111 
sondas para HLA-DRB1 (tipagem genérica e específica), o que permitiu uma boa definição dos alelos.

\subsection{Análise Estatística}

\subsubsection{No Estudo de Associação dos Genes HLA com o CCU}

Os dados foram analisados através de tabela de contingência, do tipo $2 \times 2$. A magnitude de associação entre os alelos HLA-DQBl e HLA-DRBl com o CCU foi estimada através da razão de chance ("odds ratio" - OR) e seu respectivo intervalo de confiança (IC95\%), usando o software SPSS 13.0 (SPSS, Chicago, II).

\begin{tabular}{l|c|c|c} 
& $\begin{array}{c}\text { Portadores do grupo } \\
\text { HLA analisado }\end{array}$ & $\begin{array}{c}\text { Não-portadores do grupo } \\
\text { HLA analisado }\end{array}$ & \\
\hline Casos & $\mathrm{a}$ & $\mathrm{b}$ & $\mathrm{a}+\mathrm{b}$ \\
\hline Controles & $\mathrm{c}$ & $\mathrm{d}$ & $\mathrm{c}+\mathrm{d}$ \\
\hline & $\mathrm{a}+\mathrm{c}$ & $\mathrm{b}+\mathrm{d}$ & $\mathrm{a}+\mathrm{b}+\mathrm{c}+\mathrm{d}$
\end{tabular}

Para cada comparação foi estimada uma razão de chance (OR), obtida através da fórmula de WOOLF (1955): $\mathrm{OR}=\mathrm{a} . \mathrm{d} / \mathrm{b} . \mathrm{c}$

Nos casos em que algum dos valores ( $a, b, c, d$ ) corresponde a zero, a OR resultante teria valores extremos (zero ou infinito), e esta estimativa é imprecisa e, portanto, nestes casos não é calculada.

Os valores da OR na análise realizada estimam a razão de probabilidade de uma paciente com CCU ser portadora de um determinado grupo HLA. O cálculo da OR, diferente do valor de $P$, indica se a tendência da associação é positiva ou negativa: se o valor for 1 , indica que a probabilidade desta paciente ser portadora de determinado alelo é a mesma de não 
ser portadora. Valores acima de 1, indicam uma maior probabilidade de ser portadora do alelo, e valores menores que 1 , uma chance menor.

Para testar a significância estatística do desvio da OR em relação à unidade, utilizou-se o teste exato de Fischer bilateral (ZAR, 1974). Os intervalos de confiança de 95\% (IC 95\%) para os valores de OR foram calculados conforme a expressão (WOOLF, 1955):

$$
I C(95 \%)=e^{\left[\ln (O R)-1,96 \cdot \sqrt{\frac{1}{a}+\frac{1}{b}+\frac{1}{c}+\frac{1}{d}}\right] a\left[\ln (O R)+1,96 \cdot \sqrt{\frac{1}{a}+\frac{1}{b}+\frac{1}{c}+\frac{1}{d}}\right]}
$$

A exclusão da unidade no intervalo de confiança de $95 \%$ corresponde a um valor de $P$ inferior a 0,05 . No entanto, o cálculo do IC permite estimar a precisão da medida, pois intervalos mais estreitos são mais precisos que intervalos mais largos.

As OR foram ajustadas para as variáveis idade e etnia (de acordo com o mtDNA) através de regressão logistica não condicional.

\subsubsection{Nas Estimativas de Contribuição Étnica}

As freqüências dos haplótipos e haplogrupos do mtDNA foram obtidas por simples contagem, assim como as freqüências alélica das STR.

A diferenciação genética entre casos e controles usando DNA nuclear (STR) foi estimada utilizando-se AMOVA - Análise de Variância Molecular (Excoffier et al., 1992). A distância genética aplicada foi $\mathrm{F}_{\mathrm{ST}}$ reformulada por Slatkin $(1995),\left(\mathrm{R}_{\mathrm{ST}}\right)$, que incorpora o modelo de mutação SMM, implementados no programa ARLEQUIN (Schneider et al., 2000). Valores de $\mathrm{F}_{\mathrm{ST}}=0$ indicam completa homogeneidade entre os grupos comparados, $\mathrm{F}_{\mathrm{ST}}=1$ completa diferenciação entre os grupos.

Quando o modelo SMM foi assumido, os alelos com repetições imperfeitas foram agrupados aos alelos com tamanhos mais próximos. 
Para avaliar se as frequiências genotípicas das STR estavam em equilíbrio de HardyWeinberg foi aplicado o teste exato de Fischer como o reformulado por Guo \& Thompson (1992), usando o programa ARLEQUIN.

As proporções de contribuição étnica de cada população parental para a população de Belém foram avaliadas por meio de dois estimadores: a) O primeiro é baseado nas frequiências alélicas observadas nos loci de STR analisados em Belém e nas freqüências alélicas das populações parentais (Europeus, Ameríndios e Africanos). Este método permite uma estimativa de mínimos quadrados das taxas de mistura genética usando probabilidades de identidade gênica (Chakraborty, 1985) modificado e adaptado para Windows por B. Bertoni, (Fac. Medicina, Univ de la República, Montevideo). Esta análise foi feita no programa ADMIX 95. b) O segundo estimador, é baseado no tempo de coalescencia dos alelos, levando em consideração informações moleculares (divergência entre os alelos), além das freqüências alélicas das populações híbrida e parental (Bertorelle \& Excoffier, 1998; modificado por Dupanloup \& Bertorelle, 2001). Estas proporções de mistura foram realizadas com o programa ADMIX 2.0. A significância destas estimativas foi obtida pelo método de randomização utilizando 10.000 replicatas (bootstraps). 


\section{RESULTADOS}

\subsection{Variantes de HPV-16}

\subsubsection{Distribuição das Variantes da LCR de HPV-16}

A análise de sequenciamento da LCR viral permite a identificação de variantes moleculares pertencentes a 5 ramos filogenéticos: europeu (E), asiático-americano (AA), africano 1 (Af-1), africano 2 (Af-2) e asiático (A) (Ho et al., 1993). A variabilidade na LCR na amostra total revelou 9 diferentes variantes pertencentes a 4 ramos filogenéticos (Junes, 2000). Estas correspondiam às variantes B-12, G-10, protótipo e Nova-2 (ramo E), B-2, B-14 e Nova1 (ramo AA), T-8 (ramo Af-1) e S21-A (ramo Af-2) (Tabela 1). As variantes mais freqüentes nos casos de CCU foram: B-2 $(39,5 \%)$, B12 $(19,8 \%)$ e o protótipo $(17,3 \%)$. As outras variantes foram encontradas em menor freqüência. Foram também observadas infecções por múltiplas variantes (Tabela 2). Nos casos foi observada uma freqüência de $43,2 \%$ de variantes AA, seguido por $42 \%$ de variantes do ramo E e $4,9 \%$ de variantes Af. Estes isolados foram agrupados de acordo com os ramos filogenéticos como $\mathrm{E}$ e não-E (variantes dos ramos Af-1, Af-2 e AA), como AA e não-AA (E, Af-1, Af-2) e também como protótipo e não-protótipo. A proporção de variantes do ramo E e não-E foi de $48 \%$ e $53 \%$, respectivamente. As variantes AA estiveram presentes em $41 \%$ das amostras e as não-AA em $48 \%$. Já as variantes protótipo foram freqüientes em $18 \%$ dos espécimes e as variantes não-protótipo em $71 \%$. Nos controles. 16 amostras foram positivas para HPV-16. Em 11 destes espécimes foi possível identificar 4 variantes de HPV-16 (B-2, protótipo, B-12 e G-10). A frequiência de variantes do ramo E foi de $82 \%(n=9)$ seguido de $18 \%(n=2)$ da variante do ramo asiático-americano $B-2$. 
Tabela 1. Padrão de substituição nucleotídica das variantes da LCR de HPV-16 encontradas em Belı (PA).

\begin{tabular}{|c|c|c|c|c|c|c|c|c|c|c|c|c|c|c|c|c|c|}
\hline & $\begin{array}{l}7 \\
4 \\
8 \\
5\end{array}$ & $\begin{array}{l}7 \\
4 \\
8 \\
9 \\
\end{array}$ & $\begin{array}{l}7 \\
5 \\
0 \\
7 \\
\end{array}$ & $\begin{array}{l}7 \\
5 \\
2 \\
1 \\
\end{array}$ & $\begin{array}{l}7 \\
5 \\
5 \\
2 \\
\end{array}$ & $\begin{array}{l}7 \\
6 \\
6 \\
9 \\
\end{array}$ & $\begin{array}{l}7 \\
6 \\
8 \\
9 \\
\end{array}$ & $\begin{array}{l}7 \\
7 \\
2 \\
9 \\
\end{array}$ & $\begin{array}{l}7 \\
7 \\
4 \\
3 \\
\end{array}$ & $\begin{array}{l}7 \\
7 \\
6 \\
4 \\
\end{array}$ & $\begin{array}{l}7 \\
7 \\
8 \\
6 \\
\end{array}$ & $\begin{array}{l}7 \\
7 \\
9 \\
2 \\
\end{array}$ & $\begin{array}{l}7 \\
8 \\
2 \\
6 \\
\end{array}$ & $\begin{array}{l}7 \\
8 \\
3 \\
4 \\
\end{array}$ & $\begin{array}{l}7 \\
8 \\
3 \\
7 \\
\end{array}$ & $\begin{array}{l}7 \\
8 \\
3 \\
9 \\
\end{array}$ & $\begin{array}{l}\mathrm{R} \\
\mathrm{a}\end{array}$ \\
\hline $\begin{array}{l}\text { Sitio de ligação } \\
\text { a fatores de } \\
\text { transcrição }\end{array}$ & GRE & Y1 & & YY1 & & & TEF-1 & & TEF-1 & & TEF-1 & & YY1 & & & Oct-1 & $\begin{array}{c}\mathrm{m} \\
\mathrm{o}\end{array}$ \\
\hline Protótipo & $\overline{\mathrm{A}}$ & G & $\mathrm{A}$ & $\mathrm{G}$ & $\mathrm{G}$ & $\mathrm{C}$ & $\mathrm{C}$ & A & $T$ & $\mathrm{C}$ & $\mathrm{C}$ & $\mathrm{C}$ & G & $G$ & $A$ & A & $\mathrm{E}$ \\
\hline B- 12 & . & . & . & A & . & . & . & - & . & $\cdot$ & . & . & . & $\cdot$ & $\cdot$ & $\cdot$ & $\mathrm{E}$ \\
\hline $\mathrm{G}-10$ & . & . & . & A & A & . & . & $\cdot$ & - & $\cdot$ & . & . & . & $\cdot$ & $\cdot$ & - & $\mathrm{E}$ \\
\hline Nova-2 & . & . & $\cdot$ & . & $\cdot$ & . & . & . & - & $\cdot$ & . & $\mathrm{T}$ & . & $\cdot$ & . & . & $\mathrm{E}$ \\
\hline B- 14 & $\mathrm{C}$ & $\mathrm{A}$ & $\mathrm{G}$ & A & . & $\mathrm{T}$ & A & $\mathrm{C}$ & . & $\mathrm{T}$ & $\mathrm{T}$ & . & , & . & . & . & $\mathrm{AA}$ \\
\hline B-2 & $\mathrm{C}$ & A & . & A & . & $\mathrm{T}$ & A & $\mathrm{C} / \mathrm{T}$ & G & $T$ & $\mathrm{~T}$ & . & . & . & . & . & $\mathrm{AA}$ \\
\hline Nova-1 & $\mathrm{C}$ & A & . & A & . & $\mathrm{T}$ & A & $\mathrm{C}$ & . & $\mathrm{T}$ & $\mathrm{T}$ & . & . & $T$ & . & . & $\mathrm{AA}$ \\
\hline T-8 & - & $\mathbf{A}$ & . & A & . & . & A & . & . & $\mathrm{T}$ & $\mathrm{T}$ & . & . & $T$ & . & . & Af- 1 \\
\hline $\mathrm{S}-21 \mathrm{~A}$ & $\mathrm{C}$ & $\mathrm{A}$ & . & A & . & $T$ & . & . & . & $T$ & $T$ & . & A & $\mathrm{T}$ & $\mathrm{C}$ & G & Af-2 \\
\hline
\end{tabular}

Cada linha representa uma variante genômica.

Os números no topo identificam as posições nucleoídicas onde as mutações foram detectadas no segmento 7478-7841 da LCR de HPV-16.

Europeu (E), africano (Af), asiático-americano (AA). Nova- 1 = relacionada à variante $\mathrm{ANb}$ 16; Nova-2 = relacionada à variante IND-5. 
Tabela 2. Freqüência das variantes da LCR de HPV-16 nas amostras de NIC III e CCU.

\begin{tabular}{|c|c|c|c|c|c|c|c|}
\hline \multirow[t]{2}{*}{$\begin{array}{c}\text { Ramo } \\
\text { Filogenético }\end{array}$} & \multirow[t]{2}{*}{ Variantes } & \multicolumn{2}{|c|}{$\begin{array}{l}\text { NIC III } \\
(n=18)\end{array}$} & \multicolumn{2}{|c|}{$\begin{array}{l}\mathrm{CCU} \\
(\mathrm{n}=63)\end{array}$} & \multicolumn{2}{|c|}{$\begin{array}{c}\text { Total } \\
(\mathrm{n}=81)\end{array}$} \\
\hline & & $N$ & $\%$ & $N$ & $\%$ & $\mathrm{~N}$ & $\%$ \\
\hline \multirow[t]{5}{*}{ Europeu } & Protótipo & 4 & 22,2 & 10 & 15,9 & 14 & 17,3 \\
\hline & $B-12$ & 2 & 11,1 & 14 & 22,2 & 16 & 19,8 \\
\hline & $\mathrm{G}-10$ & 0 & 0 & 2 & 3,2 & 2 & 2.5 \\
\hline & Nova-2 & 2 & 11,1 & 0 & 0 & 2 & 2.5 \\
\hline & Total & 8 & 44,4 & 26 & 41,3 & 34 & 42,0 \\
\hline \multirow{4}{*}{$\begin{array}{l}\text { Asiático- } \\
\text { Americano }\end{array}$} & B-2 & 4 & 22,2 & 28 & 44,4 & 32 & 39.5 \\
\hline & $B-14$ & 0 & 0 & 1 & 1,6 & 1 & 1.2 \\
\hline & Nova-1 & 2 & 11,1 & 0 & 0 & 2 & 2.5 \\
\hline & Total & 6 & 33,3 & 29 & 46,0 & 35 & 43.2 \\
\hline \multirow{3}{*}{$\begin{array}{l}\text { Africano-1 } \\
\text { Africano-2 }\end{array}$} & $\mathrm{T}-8$ & 0 & 0 & 1 & 1,6 & 1 & 1.2 \\
\hline & S21-A & 2 & 11,1 & 1 & 1,6 & 3 & 3.7 \\
\hline & Total & 2 & 11,1 & 2 & 3,2 & 4 & 4.9 \\
\hline & otótipo/B-2 & 1 & 5,6 & 1 & 1,6 & 2 & 2.5 \\
\hline & tótipo/G-10 & 1 & 5,6 & 0 & 0 & 1 & 1.2 \\
\hline *Prc & tipo/S21-A & 0 & 0 & 1 & 1,6 & 1 & 1.2 \\
\hline & ${ }^{*} \mathrm{~B}-2 / \mathrm{B}-12$ & 0 & 0 & 4 & 6,3 & 4 & 4.9 \\
\hline & Total & 2 & 11,1 & 6 & 9,5 & 8 & 9,9 \\
\hline
\end{tabular}

*Infecção por múltiplas variantes. 


\subsubsection{Análise do Polimorfismo na Posição 350 do Gene E6 de HPV-16}

A freqüência do polimorfismo do gene E6 350T $\rightarrow \mathrm{G}$ em 76 amostras HPV-16 positivas mostrou uma distribuição uniforme nesta amostra de CCU e NIC III. A substituição E6350T foi encontrada em 43,6\% $(n=34)$ das amostras e E6350G foi encontrada em $56,4 \%$ $(\mathrm{n}=44)$ dos espécimes (Junes, 2000). A freqüência do polimorfismo 350 $\rightarrow \mathrm{G}$ também foi estudada quanto à sua distribuição nas variantes da LCR de HPV-16. A presença da substituição $350 \mathrm{G}$ foi de $94,3 \%$ nos isolados do ramo AA (33/35). Já nos isolados não-AA, a freqüência deste polimorfismo foi de $25,6 \%(32 / 44)$, esta diferença foi significativa $(p<0,001)$. Todos os isolados dos ramos Af e E, incluindo o protótipo, hibridizaram com a sonda 350T, com exceção das amostras positivas para a variante B-12 que hibridizou em freqüência similar com as duas sondas. Dos isolados positivos para a variante B-2, apenas um hibridizou com a sonda $350 \mathrm{~T}$.

\subsection{Análise do mtDNA}

As amostras foram tipadas para os 9 sítios polimórficos do mtDNA (663 HaelII, 3.592 Hpal, 5.176 AluI, 13.259 HincII, 7.025 Alul. 12.308 HinfI, 13.366 BamHI, 13.704, BstNI e deleção de 9 pb). A primeira etapa na determinação da origem étnica consistiu na identificação dos haplótipos e haplogrupos (A, B, C, D, L. H, I, J, K, T, U, V) do mtDNA nas amostras normais e de CCU. De 397 amostras, 377 foram tipadas com sucesso. A Tabela 3 mostra os haplótipos e haplogrupos encontrados a partir das análises de RFLP. Um total de 7 haplótipos foi definido na amostra total. 
Tabela 3. Haplótipos e haplogrupos mitocondriais observados nas amostras de Belém.

\begin{tabular}{lccccccc}
\hline \multirow{2}{*}{ Sítios } & \multicolumn{7}{c}{ Haplótipos (Haplogrupos) } \\
\cline { 2 - 7 } & L3 (L)* & L & B & A & C & D & Não A-D \\
\hline Deleção 9 pb & - & + & + & - & - & - & - \\
3592 HpaI & + & + & - & - & - & - & - \\
663 HaeIII & - & - & - & + & - & - & - \\
13259 HincII & + & + & + & + & - & + & + \\
5176 AluI & + & + & + & + & + & - & + \\
\hline
\end{tabular}

*Este haplótipo pertence ao haplogrupo L, caracterizados pela mutação $3592 \mathrm{HpaI}$.

Em azul: mutações que definem os haplogrupos $A, B, C, D$ e L

Inclui todas as amostras selecionadas de esfregaços normais e de CCU.

As amostras que não apresentaram mutações específicas de ameríndios ou africanos (agrupadas como não A-D), foram posteriormente submetidas à analise por RFLP utilizando 4 marcadores de mtDNA específicos de haplogrupos europeus (7.025 AluI, 12.308 Hinfl, 13.366 BamHI, 13.704 BstNI) para uma melhor caracterização. Neste grupo, foram encontradas 5 combinações haplótipicas, todas de origem européia (Tabela 4). 
Tabela 4. Haplótipos mitocondriais de amostras agrupadas como não A-D.

\begin{tabular}{lccccc}
\hline \multirow{2}{*}{ Sítios } & \multicolumn{5}{c}{ Haplótipos (Haplogrupos não A-D) } \\
\cline { 2 - 6 } & I & II & III & IV & V \\
\hline 13704 Bst NI & + & + & + & + & - \\
7025 AluI & + & + & + & - & + \\
12308 Hinfl & + & + & - & + & + \\
13366 amHI & + & - & - & - & - \\
\hline
\end{tabular}

\subsubsection{Estimativa de Mistura Interétnica Baseada no mtDNA}

Estudos utilizando RFLP do mtDNA em várias populações humanas têm revelado um número estável de sítios polimórficos nas regiões codificadoras do mtDNA. Estes sítios definem grupos relacionados do mtDNA e são denominados haplogrupos, sendo a maioria destes específicos de cada continente.

$\mathrm{Na}$ Figura 4 encontram-se as freqüências de cada haplótipo e os respectivos haplogrupos mitocondriais observados em 377 espécimes tipados. 


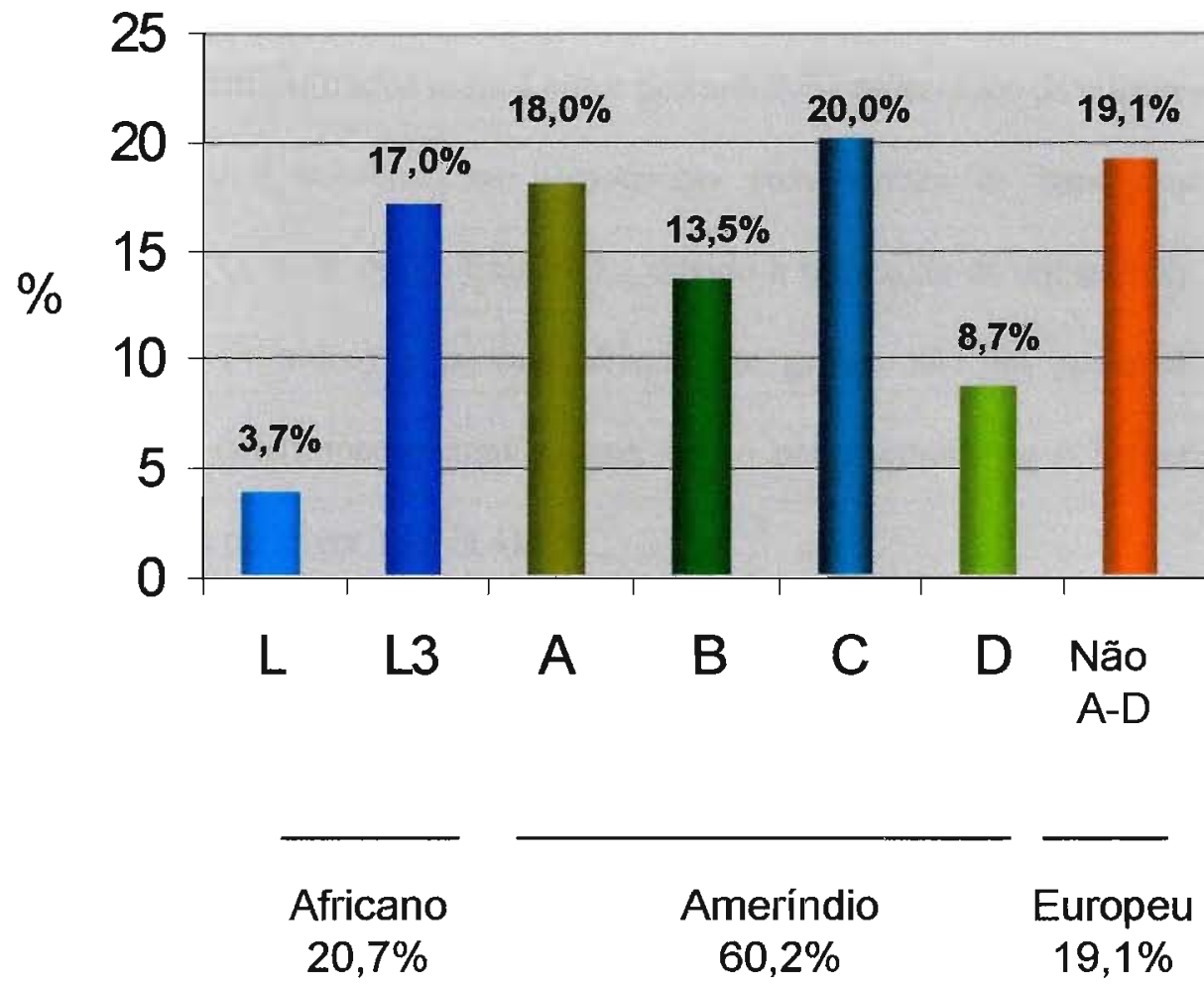

Figura 4. Freqüência dos haplogrupos do mtDNA observados nas amostras de Belém. Inclui um total de 377 amostras de esfregaços normais $(n=282)$ e de CCU $(n=95)$. 
Nesta amostra de Belém, dois haplótipos de origem africana foram encontrados em 78 indivíduos, o haplótipo L (3,7\%) e o L3 (17\%), ambos pertencentes ao haplogrupo L.

As linhagens A, B, C e D foram observadas em 227 indivíduos $(60,2 \%)$, sendo linhagens específicas de ameríndios. Cerca de 72 indivíduos $(19,1 \%)$ apresentaram linhagens do haplogrupo não A-D, provavelmente de origem européia. Para esclarecer a origem destas linhagens foram utilizados mais 4 sítios polimórficos específicos de europeus. A análise destes sítios revelou 4 combinações haplotípicas provenientes de haplogrupos específicos de europeus $(\mathrm{H}, \mathrm{U}, \mathrm{T}, \mathrm{K}$ ou $\mathrm{J})$. Entretanto, devido à utilização de um número reduzido de sítios polimórficos (4 sítios) para caracterizar este grupo, não foi possível classificar alguns haplótipos a determinados haplogrupos, como por exemplo, se o haplótipo $\mathrm{V}$ pertence ao haplogrupo K ou J (ver Tabela 4).

As estimativas de mistura interétnica foram obtidas pela simples contagem dos haplogrupos continente-específicos. Os resultados obtidos a partir do grupo de amostras total $(\mathrm{n}=377)$ demonstram que pelo menos $60,2 \%$ das linhagens mitocondriais da população de Belém são específicas de populações indígenas. Aproximadamente $20,7 \%$ e $19,1 \%$ das linhagens resultam da presença de haplogrupos africanos e europeus, respectivamente. $\mathrm{Na}$ Figura 5 encontra-se a distribuição étnica das amostras analisadas no estudo de associação com o HLA de acordo com o mtDNA. 


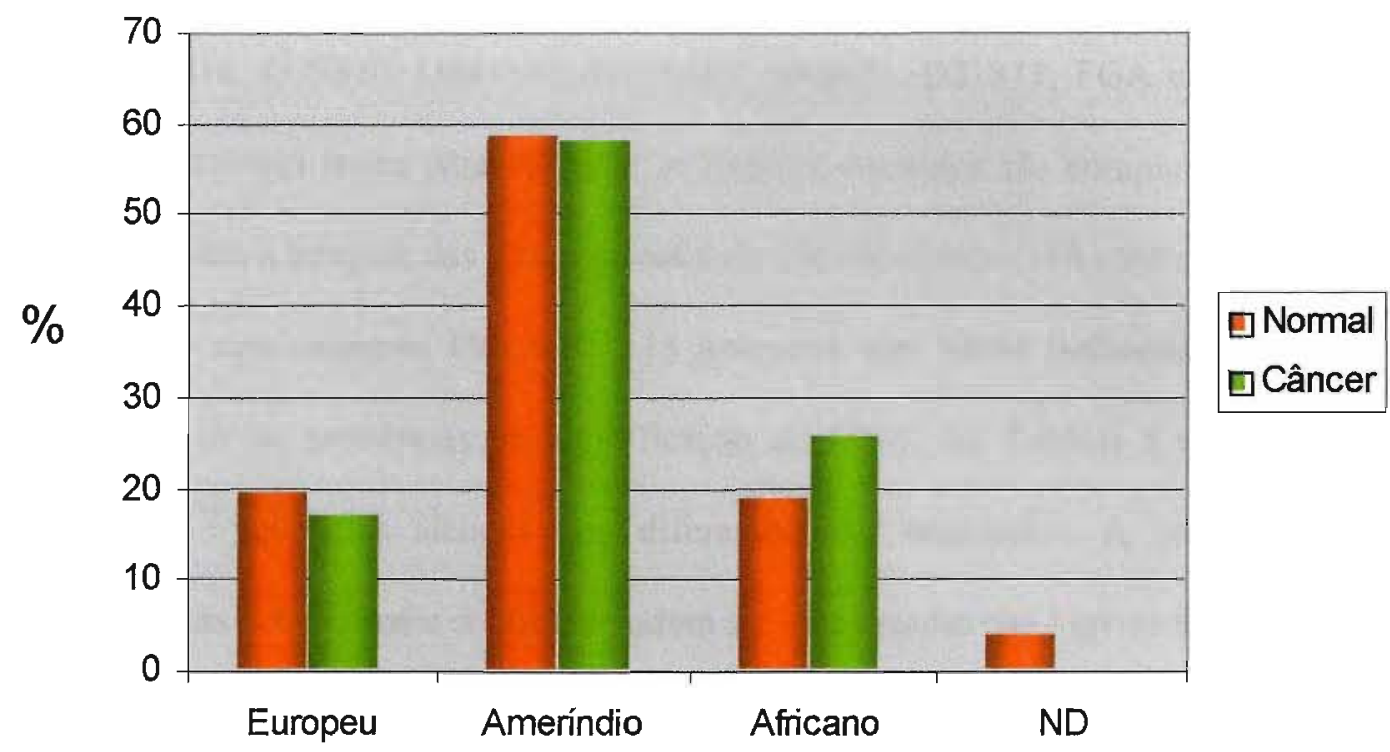

Figura 5. Contribuição étnica de acordo com o mtDNA entre casos e controles. $\mathrm{ND}=$ não definido. Um total de 382 amostras (95 casos e 287 controles) foi analisado no estudo de associação do HLA com o CCU, 11 amostras não definidas. 


\subsection{Análise da Estrutura Genética por STR}

Em adição aos dados de mtDNA, as freqüências polimórficas de 9 STR autossômicas (D3S1358, D5S818, D7S820, D8S1179, D13S317, D18S51, D21S11, FGA e VWA), foram utilizadas em diferentes testes para verificar se casos e controles são comparáveis. Das 397 amostras submetidas a tipagem das STR, um total de 286 espécimes (198 controles e 88 casos) foi caracterizado com sucesso. Cerca de 111 amostras não foram definidas devido à má qualidade do DNA ou problemas na amplificação do DNA. As Tabelas 5 e 6 mostram a distribuição das freqüências alélicas dos diferentes loci analisados. A comparação das freqüências alélicas entre casos e controles podem ser visualizadas nas Figuras 6 e 7. 
Tabela 5. Distribuição das freqüências alélicas de 9 STR nos casos de CCU e NIC III.

\begin{tabular}{|c|c|c|c|c|c|c|c|c|c|}
\hline Alelo & D3S1358 & VWA & $\mathrm{FGA}$ & D81179 & D21SII & D18S5I & D5S818 & D $13 \$ 317$ & D7S820 \\
\hline${ }^{*} \mathrm{n}$ & $n=174$ & $\mathrm{n}=170$ & $\mathrm{n}=158$ & $n=171$ & $n=172$ & $\mathrm{n}=170$ & $\mathrm{n}=171$ & $n=170$ & $=172$ \\
\hline 6 & & & & & & 0,002 & & & \\
\hline 7 & & & & & & - & 0,012 & & \\
\hline 8 & & & & & & - & 0,058 & 0.059 & 0,180 \\
\hline 9 & & & & 0,012 & & - & 0,135 & 0,165 & 0.076 \\
\hline 10 & & & & 0,093 & & 0,006 & 0,064 & 0.094 & $0,244^{*}$ \\
\hline II & & 0.006 & & 0.041 & & 0.012 & $0,269^{*}$ & $0.247^{*}$ & $0.233^{*}$ \\
\hline 12 & & - & & 0,145 & & 0,094 & $0,292^{*}$ & $0.259 *$ & $0,250^{*}$ \\
\hline 13 & & 0.006 & & $0,267^{*}$ & & 0.135 & 0,158 & 0,124 & 0,012 \\
\hline 14 & 0,091 & 0,076 & & $0,256^{*}$ & & $0,171^{*}$ & 0.006 & 0,053 & 0,006 \\
\hline 15 & $0,426^{*}$ & 0.076 & & 0,145 & & 0,165 & - & & \\
\hline 15.2 & - & - & & - & & - & - & & \\
\hline 16 & $0,267^{*}$ & $0,341^{*}$ & & 0,035 & & 0,065 & 0,006 & & \\
\hline 17 & $0,159^{*}$ & $0,241^{*}$ & & & & $0,194^{*}$ & & & \\
\hline 18 & 0,040 & $0,176^{*}$ & 0,006 & & & 0,088 & & & \\
\hline 18.2 & - & - & - & & & - & & & \\
\hline 19 & 0,006 & 0.059 & 0,101 & & & 0.029 & & & \\
\hline 20 & & 0,012 & 0.119 & & & 0.018 & & & \\
\hline 21 & & 0,006 & 0,094 & & & 0.012 & & & \\
\hline 22 & & & $0,138^{*}$ & & & - & & & \\
\hline 22.2 & & & 0,006 & & & - & & & \\
\hline 23 & & & $0,145^{*}$ & & & 0,006 & & & \\
\hline 23.2 & & & - & & & - & & & \\
\hline 24 & & & $0,151^{*}$ & & & & & & \\
\hline 25 & & & $0,138^{*}$ & & & & & & \\
\hline 26 & & & 0,088 & & & & & & \\
\hline 27 & & & 0,006 & & 0,035 & & & & \\
\hline 28 & & & & & 0,110 & & & & \\
\hline 29 & & & & & $0,203^{*}$ & & & & \\
\hline 29.2 & & & & & - & & & & \\
\hline 30 & & & & & $0,238^{*}$ & & & & \\
\hline 30.2 & & & & & 0,017 & & & & \\
\hline 31 & & & & & 0,122 & & & & \\
\hline 31.2 & & & & & 0,093 & & & & \\
\hline 32 & & & & & - & & & & \\
\hline 32.2 & & & & & 0,122 & & & & \\
\hline 33 & & & & & 0,006 & & & & \\
\hline 33.2 & & & & & 0,035 & & & & \\
\hline 34 & & & & & - & & & & \\
\hline 34.2 & & & & & 0,006 & & & & \\
\hline 35 & & & & & 0,012 & & & & \\
\hline nd & 0.011 & & 0,006 & 0,006 & & & & & \\
\hline Tota! & 1,000 & 0.999 & 0.998 & 1.000 & 0,999 & 1.001 & 1.000 & 1.001 & 1,001 \\
\hline
\end{tabular}

*Frequiências alélicas mais elevadas em cada locus de STR.

${ }^{*} 2 \mathrm{n}$ 
Tabela 6. Distribuição das freqüências alélicas de 9 STR nos controles.

\begin{tabular}{|c|c|c|c|c|c|c|c|c|c|}
\hline Alelo & D3S1358 & vWA & $\mathrm{FGA}$ & D81179 & D21S11 & DI8S5] & D5S818 & D13S317 & D7S820 \\
\hline${ }_{n}$ & $\mathrm{n}=396$ & $n=396$ & $n=396$ & $n=396$ & $n=396$ & $n=396$ & $n=396$ & $n=396$ & $=396$ \\
\hline \multicolumn{10}{|l|}{6} \\
\hline 7 & & & & & & & 0.083 & & 0.013 \\
\hline 8 & & & & 0.003 & & & 0,030 & 0.071 & 0.101 \\
\hline 9 & & & & 0.003 & & & 0,063 & 0.184 & 0.131 \\
\hline 10 & & & & 0.078 & & 0.008 & 0,053 & 0.063 & $0,258^{*}$ \\
\hline 11 & & 0,003 & & 0.061 & & - & $0,313^{*}$ & $0.250^{*}$ & $0,258^{*}$ \\
\hline 12 & & - & & 0,129 & & 0,116 & $0,311 *$ & $0.235^{*}$ & $0,220^{*}$ \\
\hline 13 & & 0.005 & & $0.283 *$ & & 0,109 & 0,131 & 0.124 & 0,018 \\
\hline 14 & 0,076 & 0,058 & & $0.288^{*}$ & & $0,220^{*}$ & 0,015 & 0,073 & 0,003 \\
\hline 15 & $0,381^{*}$ & 0,119 & & 0,129 & & $0.164^{*}$ & & & \\
\hline 15.2 & 0,003 & - & & - & & . & & & \\
\hline 16 & $0,268^{*}$ & $0.323^{*}$ & & 0.023 & & 0,098 & & & \\
\hline 17 & 0.192 & $0.285^{*}$ & 0.005 & 0.005 & & 0,144 & & & \\
\hline 18 & 0,066 & 0.149 & 0,015 & & & 0,056 & & & \\
\hline 18.2 & - & - & 0,005 & & & - & & & \\
\hline 19 & 0,015 & 0.053 & 0.076 & & & 0,040 & & & \\
\hline 20 & & - & 0,078 & & & 0,023 & & & \\
\hline 21 & & 0.005 & $0,134^{*}$ & & & 0.015 & & & \\
\hline 22 & & & 0,114 & & & - & & & \\
\hline 22.2 & & & 0,005 & & & - & & & \\
\hline 23 & & & 0,114 & & & - & & & \\
\hline 23.2 & & & 0,003 & & & - & & & \\
\hline 24 & & & $0,192 *$ & & & 0,003 & & & \\
\hline 25 & & & $0,131^{*}$ & & & 0,003 & & & \\
\hline 26 & & & 0,106 & & & 0,003 & & & \\
\hline 27 & & & 0,008 & & 0.023 & & & & \\
\hline 28 & & & 0,013 & & 0,141 & & & & \\
\hline 29 & & & 0,003 & & $0,225^{*}$ & & & & \\
\hline 29.2 & & & & & - & & & & \\
\hline 30 & & & & & $0,245^{*}$ & & & & \\
\hline 30.2 & & & & & 0,028 & & & & \\
\hline 31 & & & & & 0,056 & & & & \\
\hline 31.2 & & & & & 0.093 & & & & \\
\hline 32 & & & & & 0,013 & & & & \\
\hline 32.2 & & & & & 0,104 & & & & \\
\hline 33 & & & & & - & & & & \\
\hline 33.2 & & & & & 0.056 & & & & \\
\hline 34 & & & & & - & & & & \\
\hline 34.2 & & & & & 0,008 & & & & \\
\hline 35 & & & & & 0,010 & & & & \\
\hline \multicolumn{10}{|l|}{ nd } \\
\hline Total & 1.001 & 1.000 & 1.002 & $\mathrm{I} .002$ & 1.002 & 1.002 & 0,999 & 1.000 & 1.002 \\
\hline
\end{tabular}

*Freqüèncias alélicas mais elevadas em cada locus de STR.

$\stackrel{*}{ } 2 \mathrm{n}$ 


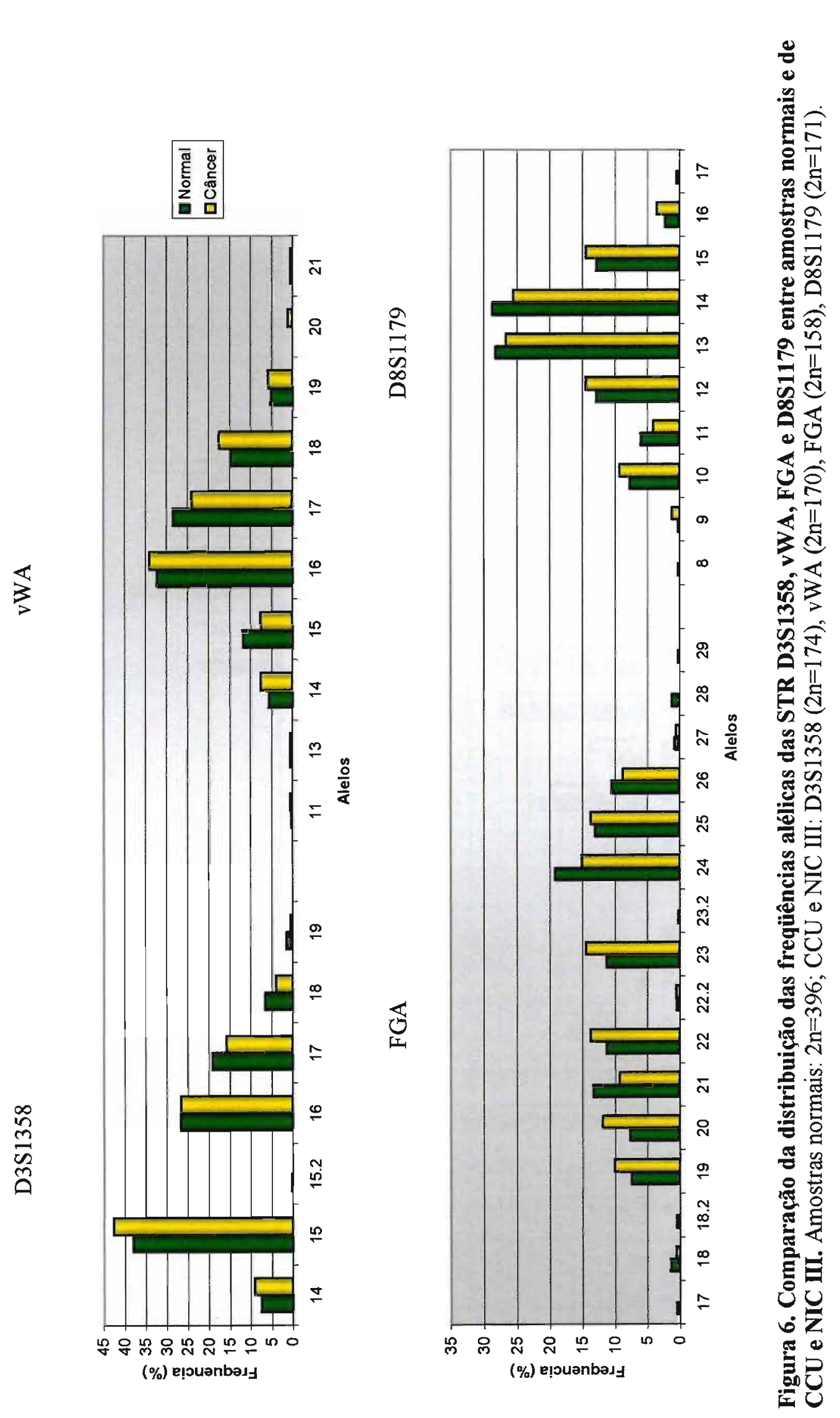


BIBLIOTECA

INSTITUTO DE QUIMICA

Unversidade de São Paulo
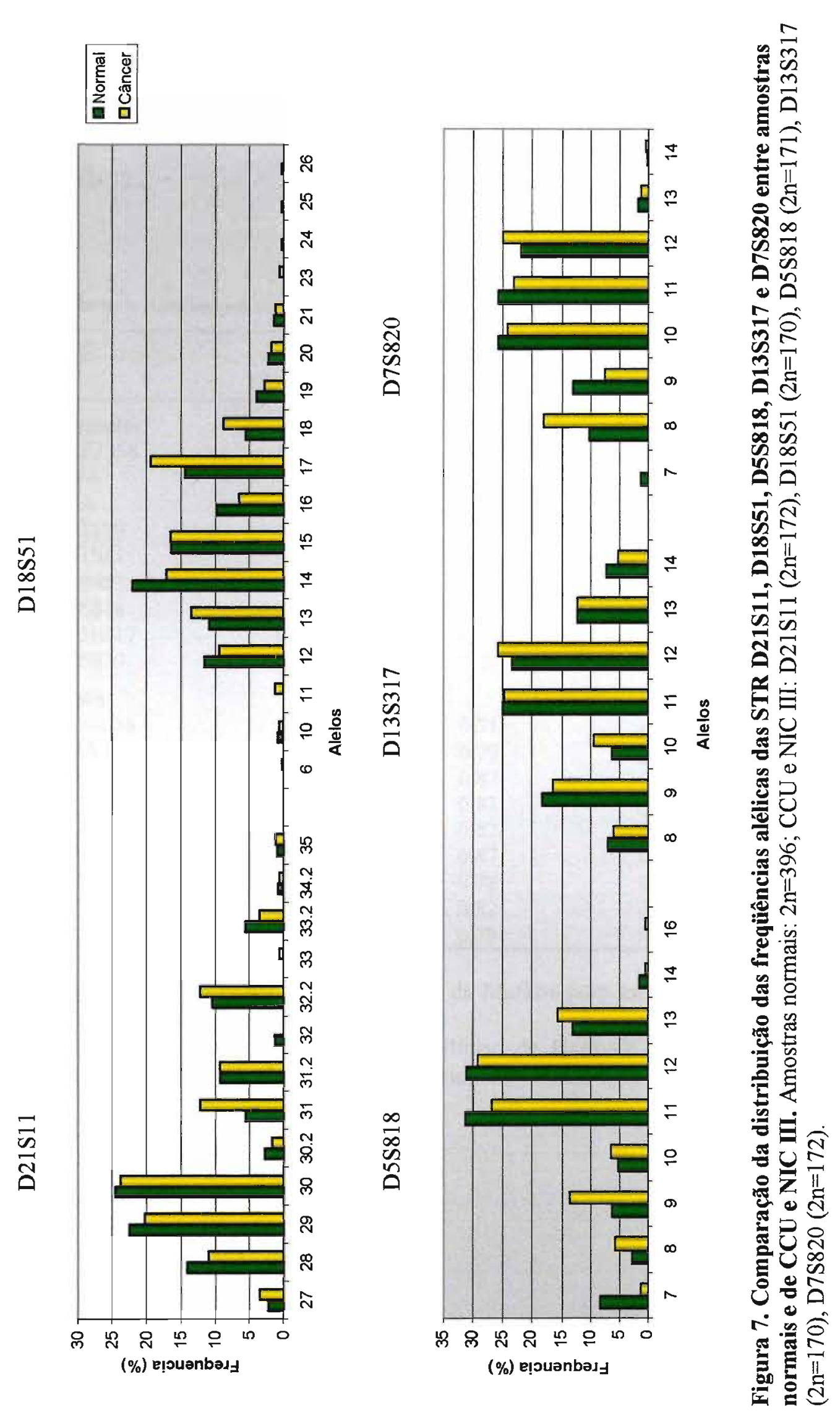
Para determinar se as freqüências genotípicas dos loci de STR analisados desviaram-se do equilíbrio de Hardy-Weinberg foi realizado o teste de Guo \& Thompson (1992), o qual analisa a adequação das frequêencias genotípicas observadas com seus respectivos equilíbrios de Hardy-Weinberg. Foram observados desvios significativos do equilíbrio de HardyWeinberg para os loci vWA e D13S317, o locus D81179 foi marginalmente significativo (Tabela 7).

Tabela 7. Análise por locus do equilíbrio de Hardy-Weinberg entre casos e controles.

\begin{tabular}{lcccc}
\hline Loci & $\begin{array}{c}* \text { Heter. } \\
\text { Observada }\end{array}$ & $\begin{array}{c}\text { Heter. } \\
\text { Esperada }\end{array}$ & Valores de $p^{\varphi}$ & $\begin{array}{l}\text { Desvio } \\
\text { Padrão }\end{array}$ \\
\hline Controles & & & & \\
D3S1358 & 0,76 & 0,74 & 0,378 & 0,0014 \\
vWA & 0,78 & 0,77 & 0,077 & 0,0011 \\
FGA & 0,83 & 0,88 & 0,334 & 0,0007 \\
D81179 & 0,76 & 0,80 & 0,467 & 0,0011 \\
D21S11 & 0,82 & 0,81 & 0,458 & 0,0009 \\
D18S51 & 0,85 & 0,86 & 0,605 & 0,0011 \\
D5S818 & 0,75 & 0,78 & 0,068 & 0,0006 \\
D13S317 & 0,83 & 0,82 & 0,871 & 0,0009 \\
D7S820 & 0,84 & 0,79 & 0,903 & 0,0010 \\
Casos & & & & \\
D3S1358 & 0,69 & 0,71 & 0,971 & 0,0006 \\
vWA & 0,71 & 0,79 & $\underline{0,010}$ & 0,0002 \\
FGA & 0,83 & 0,87 & 0,844 & 0,0009 \\
D81179 & 0,85 & 0,81 & $\underline{0,053}$ & 0,0005 \\
D21S11 & 0,74 & 0,82 & 0,097 & 0,0006 \\
D18S51 & 0,84 & 0,87 & 0,766 & 0,0007 \\
D5S818 & 0,70 & 0,78 & 0,384 & 0,0007 \\
D13S317 & 0,65 & 0,82 & $\underline{0,013}$ & 0,0003 \\
D7S820 & 0,73 & 0,79 & 0,873 & 0,0008 \\
\hline
\end{tabular}

* Heterozigosidade;

Teste exato de Fischer usando a cadeia de Markov para todos os Loci (Guo \& Thompson, 1992);

$\varphi$ Valores de significância para o equilíbrio de Hardy-Weinberg, onde $p>0,05$ está em equilíbrio e $p<0,05$ não está em equilíbrio. 
É possivel que o desequilibrio de Hardy-Weinberg observado nos referidos loci tenha decorrido do fato de que muitos dos alelos observados têm freqüência reduzida. Essa é uma propriedade intrínseca aos loci de VNTR que geralmente segregam um grande número de alelos, sendo na sua grande maioria alelos raros (Chakraborty, 1992). Entretanto, ao considerar apenas os alelos com frequiência igual ou superior a $2 \%$, não foram observados desvios significativos do equilíbrio de Hardy-Weinberg. É importante também ressaltar que estes loci não se encontram em desequilíbrio de ligação.

\subsubsection{Empregando Freqüências Genotípicas da População Híbrida}

A diferenciação genética entre casos e controles foi estimada usando AMOVA. Os resultados mostram que a diferença genética dentro do grupo como um todo é maior do que a diferença genética observada entre casos e controles. Sendo observada uma percentagem de variação de $100,32 \%$ e $-0,32 \%$, respectivamente. O índice de fixação considerando todos os loci apresentou resultado negativo, $\mathrm{F}_{\mathrm{ST}}=-0,0032$, indicando que não há diferenças significativas entre casos e controles (Tabela 8).

Tabela 8. Diferenciação genética na população de Belém

\begin{tabular}{lccc}
\hline $\begin{array}{l}\text { Fonte da } \\
\text { Variação }\end{array}$ & $\begin{array}{c}\text { Componentes } \\
\text { de Variança }\end{array}$ & $\begin{array}{c}\text { Percentagem de } \\
\text { variação }\end{array}$ & $\begin{array}{c}\mathrm{F}_{\text {ST }} \\
\text { Total }\end{array}$ \\
\hline Interpopulação & $-0,0831$ & $-0,30$ & \\
Intrapopulação & 26,2064 & 100,32 & $-0,0032$ \\
\hline
\end{tabular}




\subsubsection{Empregando Frequiências alélicas das Populações Híbrida e Parentais}

A estimativa de contribuição étnica é baseada na distribuição diferencial das freqüências alélicas de cada locus levando em consideração as freqüências alélicas das populações parentais (Shriver et al., 1997). Para tanto, foi construído um banco de dados de freqüências alélicas das populações que originaram a cidade de Belém. A organização destes dados foi baseada na literatura e incluem amostras de origem européia (Entrala, et al., 1998; Gusmão et al., 2000; Geada et al., 2000; Amorim et al. 2001; Sanz et al., 2001; Pérez-Miranda et al., 2005), ameríndia (Hutz, et al., 2002) e africana (Destro-Bisol et al., 2000; Pérez-Lezaun et al., 2000; Alves et al., 2001; Farfán et al., 2001; Geada et al., 2003; Tofanelli et al., 2003).

A análise das STR pelo método de identidade gênica (Chakraborty et al., 1975) demonstra que $37 \%$ dos casos são de origem ameríndia, seguido por $34 \%$ de europeu e $29 \%$ de africano. Em relação aos controles, cerca de $45 \%$ são de origem européia, 32\% de origem ameríndia e $23 \%$ de origem africana. Os resultados mostram uma pequena inversão na contribuição étnica entre casos e controles, onde os ameríndios são encontrados em maior freqüência nos casos (37\%) e os europeus são encontrados em maior frequiência nos controles $(45 \%)$.

Outra análise foi realizada, desta vez usando o método sugerido por Bertorelle \& Excoffier (1998). A taxa de mutação assumida para as STR foi de $10^{-3} /$ locus/gameta/geração e o tempo de miscigenação de 400 anos, período em que a cidade de Belém foi fundada. Utilizando este método, a contribuição étnica observada neste grupo de amostra de Belém foi de $32,4 \%$ de europeus, $35,4 \%$ de ameríndio e $32,2 \%$ de africanos nos casos. A contribuição nos controles foi quase idêntica, com $32,3 \%$ de contribuição européia, $35,3 \%$ de ameríndios e $32,4 \%$ de africanos. A Tabela 9 mostra a contribuição étnica usando diferentes abordagens. 
Tabela 9. Proporções de ancestralidade do DNA nuclear e mtDNA

\begin{tabular}{rcccc}
\hline & \multicolumn{2}{c}{ Casos } & \multicolumn{2}{c}{ Controles } \\
\cline { 2 - 5 } Ancestralidade & $\%$ & & \\
\cline { 2 - 5 } & Proporção & Erro Padrão & Proporção & Erro padrão \\
\hline STR Método 1 & & & & \\
Européia & 34,0 & 0,004 & 45,0 & 0,021 \\
Ameríndia & 37,0 & 0,002 & 32,0 & 0,025 \\
Africana & 29,0 & 0,004 & 23,0 & 0,010 \\
STR Método 2 & & & & \\
Européia & 32,4 & 0,003 & 32,3 & 0,002 \\
Ameríndia & 35,4 & 0,004 & 35,3 & 0,003 \\
Africana & 32,2 & 0,003 & 32,4 & 0,002 \\
mtDNA & & & & \\
Européia & 16,8 & - & 19,2 & - \\
Ameríndia & 57,9 & - & 58,5 & - \\
Africana & 25,3 & - & 18,5 & - \\
\hline
\end{tabular}

Método 1: Chakraborty (1985).

Método 2: Bertorelle \& Excoffier (1998).

\subsection{Análise dos Genes HLA-DQB1 e HLA-DRB1 e o Desenvolvimento de CCU}

Este estudo compreendeu uma amostra proveniente de Belém, capital do Estado do Pará, uma área que apresenta uma das maiores taxas de incidência do câncer cervical no Brasil.

Com o objetivo de avaliar uma possível associação entre o polimorfismo de genes HLA de classe II e o risco de CCU, um total de 95 biópsias de CCU e 297 esfregaços normais foram selecionados para este estudo. Algumas amostras foram eliminadas por problemas de amplificação do DNA ou na hibridização. Desta forma, foram analisados 95 CCU (casos) e um grupo controle constituído por: 190 esfregaços cervicais HPV negativos e 97 esfregaços HPV positivos. A Tabela 10 mostra a distribuição das variáveis sociodemográficas de idade e grupo étnico entre os casos e controles. A diferença de idade entre casos e controles foi 
significantemente diferente, com uma média de 50,2 e 36,9 anos, respectivamente $(p<0,001)$. Já a distribuição dos três grupos étnicos entre casos e controles foi estatisticamente comparável $(p=0,426)$, apesar da maior proporção de mulheres africanas nos casos.

Para fins de análise os casos foram divididos em dois grupos: i) todos os casos: que inclui pacientes com neoplasia intraepitelial cervical de grau III (NIC III ou carcinoma in situ) e pacientes com carcinoma epidermóide invasor do colo uterino (CCU); ii) CCU: inclui somente pacientes com carcinoma epidermóide invasor (Tabelas 11 e 12). Nas Tabelas 11 e 12 as distribuições dos grupos e alelos HLA-DQB1 e HLA-DRB1 entre casos e controles são comparados quanto ao risco de desenvolvimento de CCU. As amostras também foram estratificadas de acordo com a condição de infecção por HPV: i) CCU e NIC III HPV-16 positivos; ii) somente CCU HPV-16 positivo (Tabelas 13 e 14). Os controles também foram divididos em 2 grupos: i) mulheres com citologia normal positivas para qualquer tipo de HPV; ii) mulheres com citologia normal HPV-16 positivas. A comparação desta análise foi feita utilizando os controles HPV negativos (Tabelas 17-19). 
Tabela 10. Distribuição sócio-demográfica no estudo caso-controle.

\begin{tabular}{llccc}
\hline Variáveis & Casos & $\begin{array}{c}\text { Controles } \\
\mathrm{n}=95\end{array}$ & $\begin{array}{c}\text { Vaior de } \\
\mathrm{p}^{\mathrm{b}}\end{array}$ \\
\hline Idade em anos & Média & 50,2 & 36,9 & $\mathrm{p}<0,001$ \\
& Mediana & 49,0 & 37,0 & \\
& Desv. Padrão & 14,0 & 4,7 & \\
& Ameríndio & 51,6 & 36,8 & $\mathrm{p}<0,001$ \\
& Europeu & 50,7 & 37,0 & $\mathrm{p}<0,002$ \\
& Africano & 46,9 & 37,4 & $\mathrm{p}<0,004$ \\
Grupo Étnico & & & \\
& Europeu & $16(16,8 \%)$ & $55(19,2 \%)$ & \\
& Ameríndio & $55(57,9 \%)$ & $168(58,5 \%)$ & \\
& Africano & $24(25,3 \%)$ & $53(18,5 \%)$ & \\
& ND & 0 & $11(3,8 \%)$ & $\mathrm{p}=0,426$ \\
\hline
\end{tabular}

${ }^{a}$ Baseado na análise do polimorfismo do $\mathrm{mtDNA} ; \mathrm{ND}=$ não definido.

${ }^{\text {b }}$ Teste do Qui-quadrado 


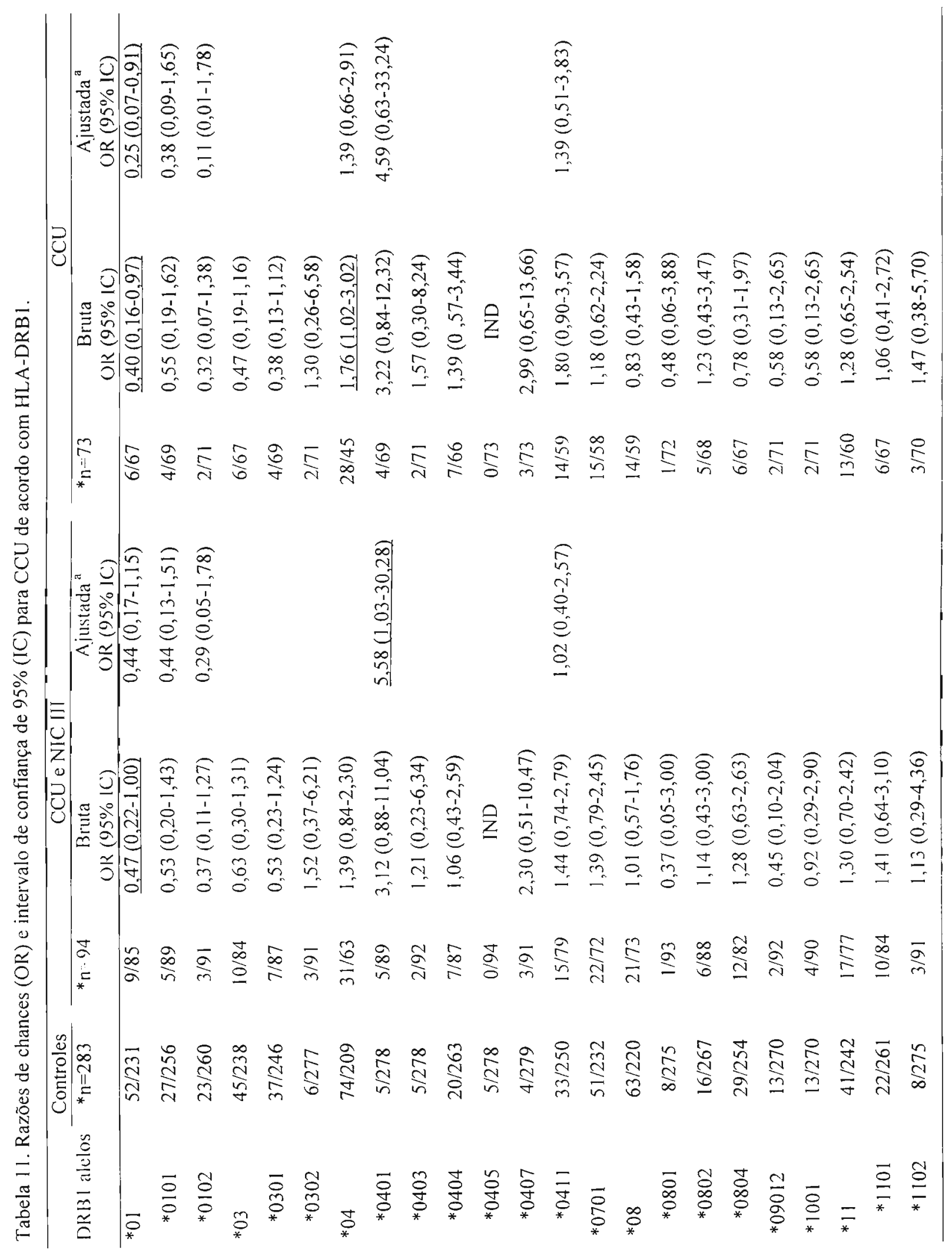




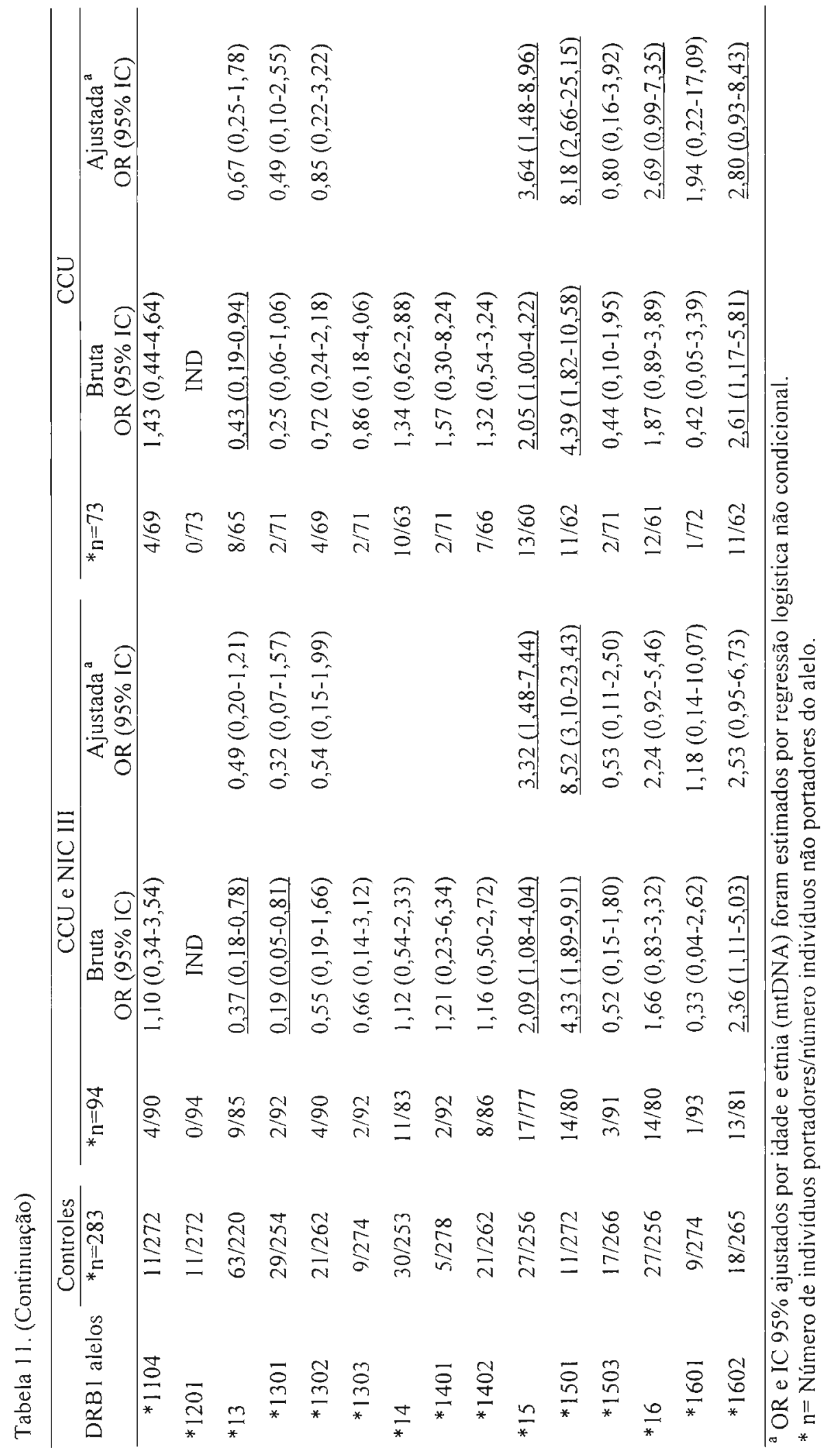




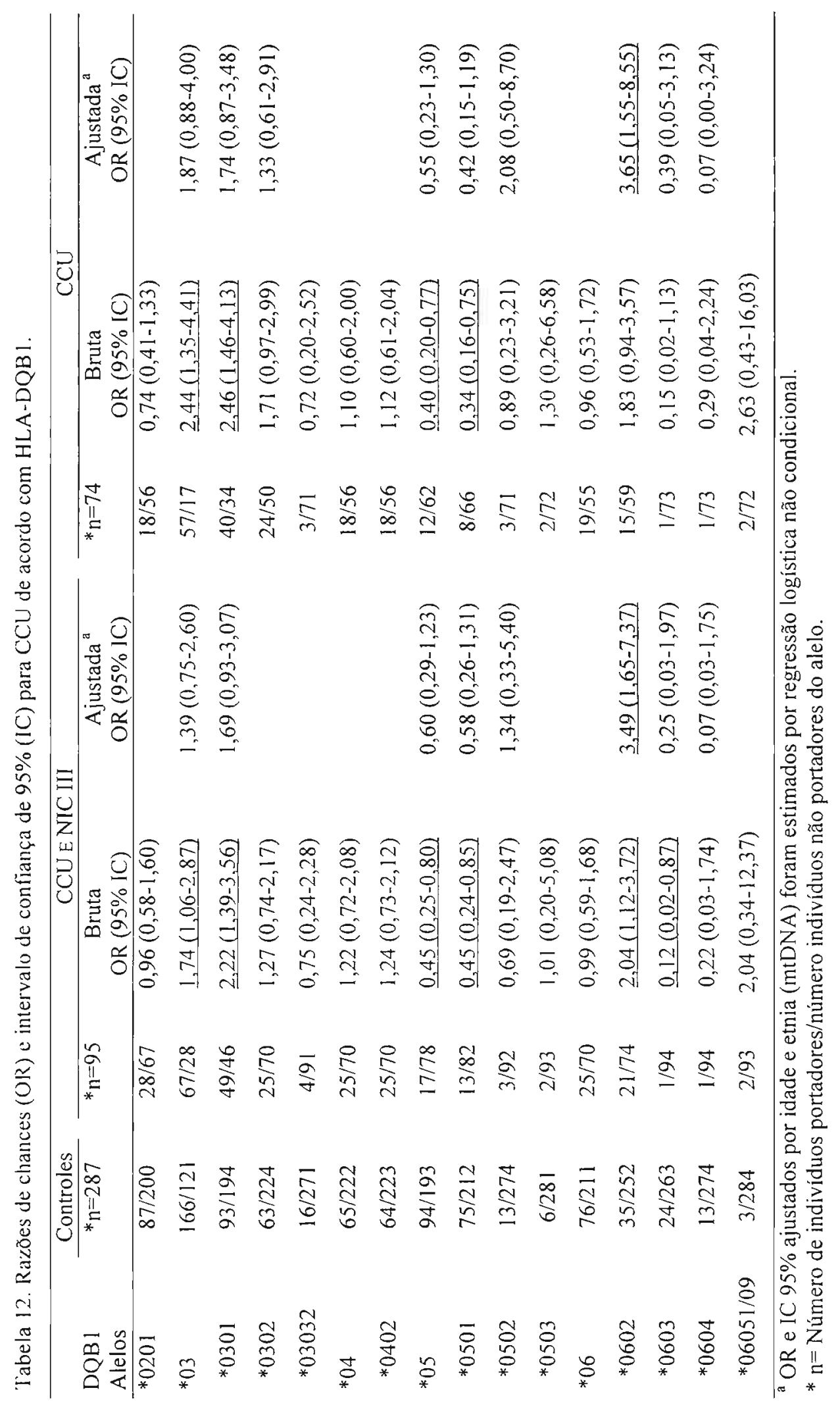


A análise bruta dos dados de HLA-DRB1 demonstrou um aumento da freqüência dos alelos dos grupos HLA-DRB1*01 e DRB1*13 (especialmente DRB1*1301) nos controles e após o ajuste por idade e etnia esta diferença não foi significativa. Entretanto, quando as amostras de $\mathrm{CCU}$ foram analisadas separadamente o grupo $\mathrm{DRB}{ }^{*} 01$ revelou um efeito protetor que foi mais acentuado após o ajuste por idade e etnia $(\mathrm{OR}=0,25 ; \mathrm{IC}: 0,07-0,91)$. O mesmo não foi observado para os alelos do grupo DRB1*13 (Tabela 11).

Um risco aumentado de desenvolvimento de CCU foi observado para o alelo DRB $1 * 0401 \quad(\mathrm{OR}=3,12)$. Este risco praticamente dobrou após o ajuste por idade e etnia $(\mathrm{OR}=5,58 ; \mathrm{IC}: 1,03-30,28)$. Já na análise incluindo apenas amostras de $\mathrm{CCU}$, este risco permaneceu elevado mas não foi significativo ( $O R=4,59 ; \mathrm{IC}: 0,63-33,24)$.

Os alelos do grupo DRB1*15 também foram positivamente associados aos casos de CCU e NIC III (OR=3,32; IC: 1,48-7,44), e este risco se manteve quando analisados apenas os casos de CCU (OR=3,64; IC: 1,48-8,96). Neste estudo, o grupo DRB1*15 incluiu os alelos DRB $1 * 1501$ e DRB ${ }^{*} 1503$, entretanto, riscos elevados foram atribuídos somente ao alelo DRB $1 * 1501$, tanto nas amostras de CCU e NIC III $(\mathrm{OR}=8,52$; IC: $3,10-23,43)$ quanto nas amostras de $\mathrm{CCU}(\mathrm{OR}=8,18 ; \mathrm{IC}: 2,66-25,15)$.

O grupo $\mathrm{DRBl}^{*} 16$ apresentou tendências de associação positiva com 0 desenvolvimento de $\mathrm{CCU}$ nos dois grupos de amostra $(\mathrm{OR}=2,24 ; \mathrm{IC}: 0,92-5,46$ e $\mathrm{OR}=2,69$; IC: 0,99-7,35). Sendo uma importante contribuição a do alelo DRB $1 * 1602$ (Tabela 11 ).

$\mathrm{Na}$ análise bruta dos genes HLA-DQB1 observou-se um aumento da freqüência dos alelos do grupo $\mathrm{DQB} 1 * 03$ nos casos, principalmente do alelo $\mathrm{DQB} 1 * 0301 \quad(\mathrm{OR}=2,22$ e $\mathrm{OR}=2,46$ ). Entretanto, após o ajuste por idade e etnia esses resultados não foram significativos. Efeito inverso foi observado para os alelos do grupo DQB1*05, especialmente o alelo DQBI*0501 (Tabela 12). 
Um risco elevado de desenvolvimento de CCU foi atribuído ao alelo DQB1*0602. A magnitude desta associação praticamente dobrou após o ajuste nos dois grupos de casos $(\mathrm{OR}=3,49 ; \mathrm{IC}: 1,65-7,37$ e $\mathrm{OR}=3,65 ; \mathrm{IC}: 1,55-8,55)$. Este alelo encontra-se em desequilíbrio de ligação com DRB1*1501. Já o alelo DQB1*0603, o qual está ligado a DRB1*1301, apresentou uma maior proporção nos controles, entretanto, não foi observado um efeito protetor do mesmo após o ajuste (OR=0,25; IC: 0,03-1,97 e $\mathrm{OR}=0,39 ; \mathrm{IC}: 0,05-3,13)$.

Para verificar se as associações observadas foram dependentes do tipo de HPV, as OR para os alelos HLA-DRB1 e DQB1 foram estimadas considerando somente os casos HPV-16 positivos (Tabelas 13 e 14). Este foi o tipo de HPV mais freqüente nesta amostra $(85,3 \%)$. 


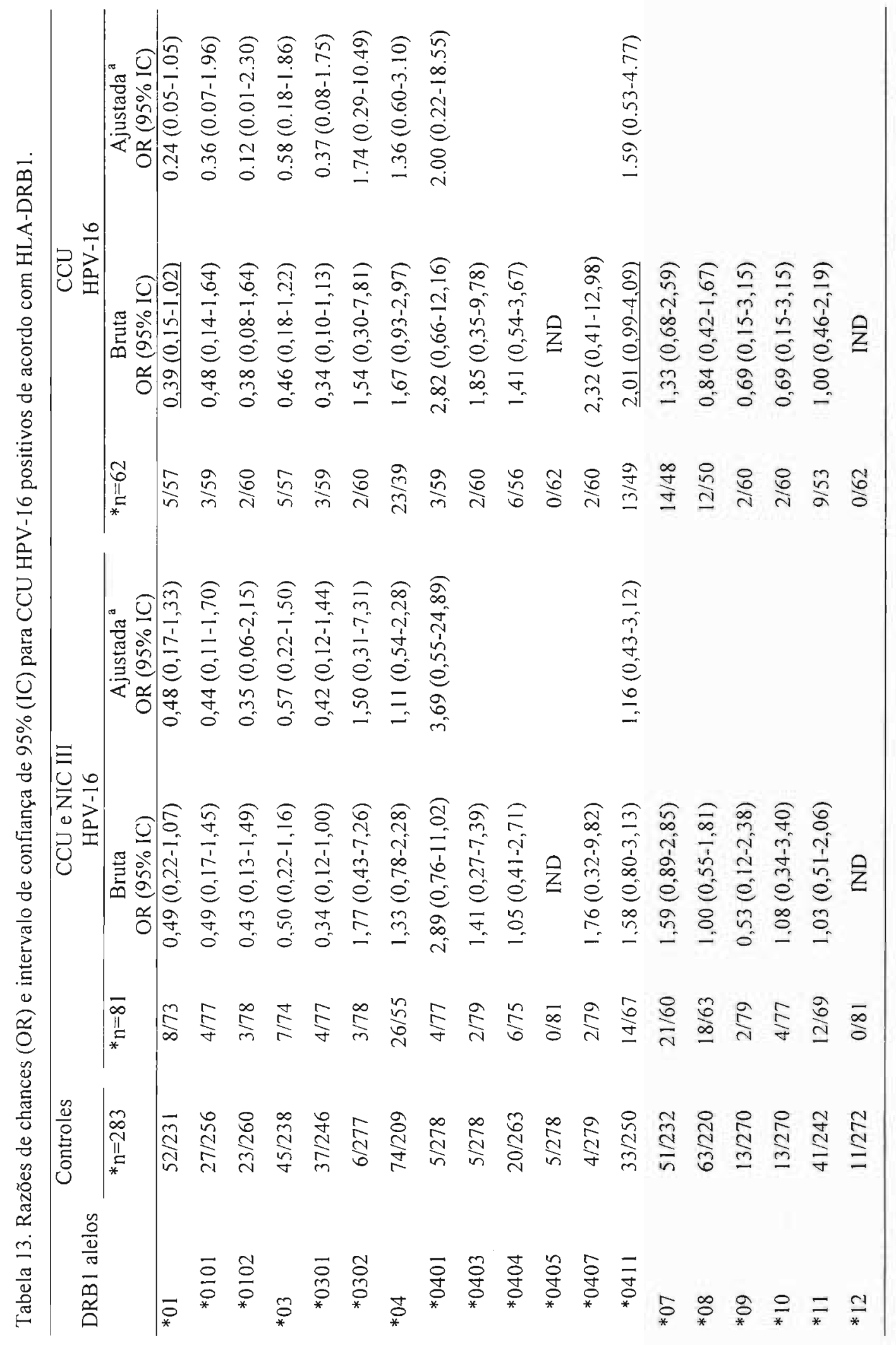




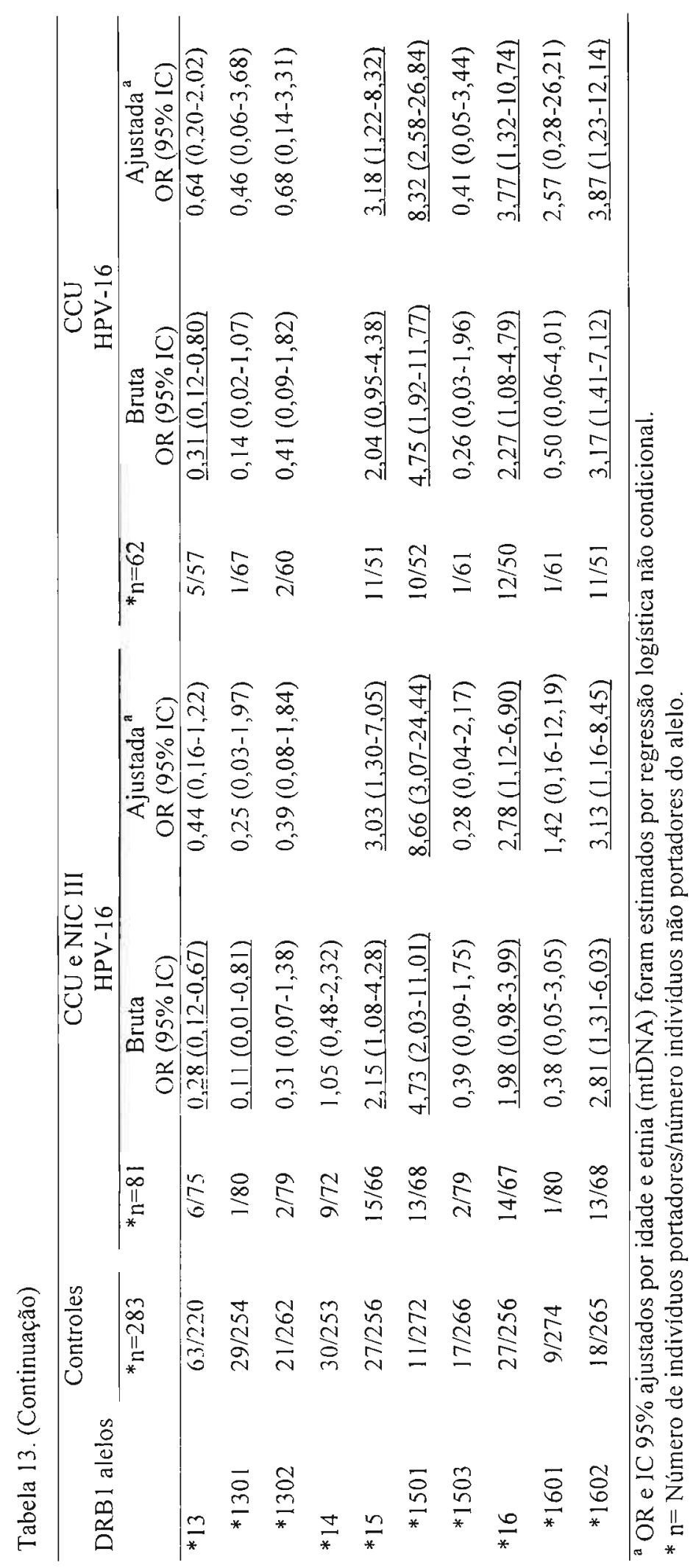




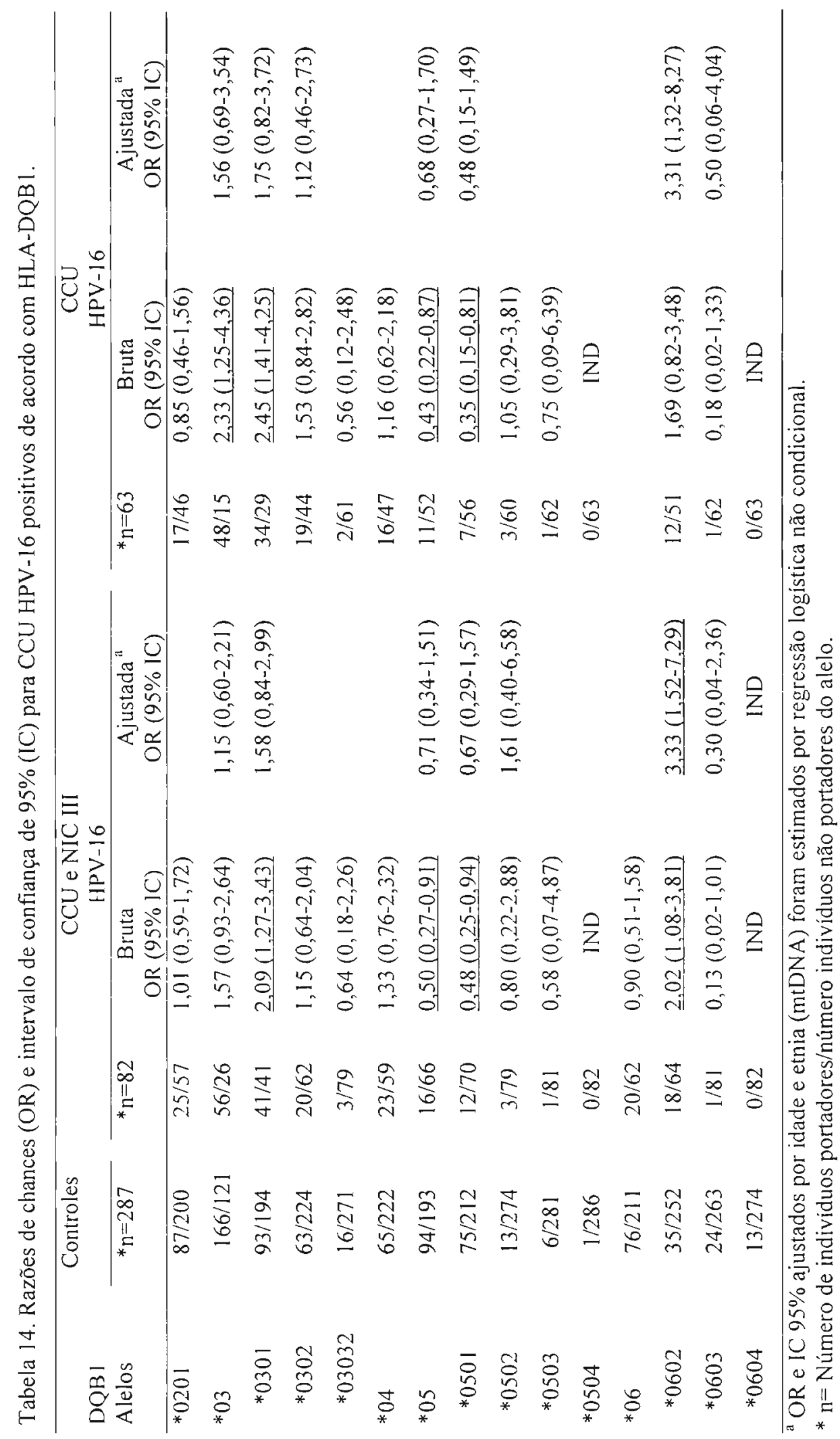


O padrão de associação dos genes HLA-DQB1 e DRB1 para casos HPV-16 positivos não diferiu do observado nas análises que incluíam todas as amostras.

Nesta análise não foi observado um efeito protetor do grupo $\mathrm{DRB} 1 * 01(\mathrm{OR}=0,24$; IC: 0,05-1,05). O alelo DRB ${ }^{*} 0401$ permaneceu com um risco elevado de desenvolvimento de CCU, entretanto, a associação observada na análise incluindo todos os casos foi diluída $(\mathrm{OR}=3,69 ; \mathrm{IC}: 0,55-24,89)$ (Tabela 13).

A análise bruta do alelo DRB1*0411 nos casos só de CCU apresentou uma associação positiva marginal com o $\mathrm{CCU}(\mathrm{OR}=2,01 ; \mathrm{IC}: 0,99-4,09)$, mas após os ajustes por idade e etnia a OR ficou próxima da unidade, perdendo a significância.

A magnitude das associações envolvendo o alelo $\mathrm{DRBI}^{*} 1501$ permaneceu a mesma nos casos HPV-16 positivos. Já os riscos observados para o alelo DRB1*1602 foram significativamente maiores tanto nas amostras que incluíam todos os casos $(\mathrm{OR}=3,13$; IC: 1,16-8,45) quanto no grupo só de $\mathrm{CCU}(\mathrm{OR}=3,87$; IC: 1,23-12,14).

Sabe-se que alelos de diferentes genes HLA encontram-se em diferentes desequilíbrios de ligação. Assim, com o objetivo de separar tais efeitos entre os genes DRB1 e DQB1, foram investigadas as associações dos haplótipos DRB1-DQB1 mais freqüentes encontrados na população de Belém. Na Tabela 15 está apresentada a análise bruta dos dados utilizando diferentes estratificações dos casos. A Tabela 16 mostra os dados ajustados por idade e etnia de acordo com o mtDNA. 


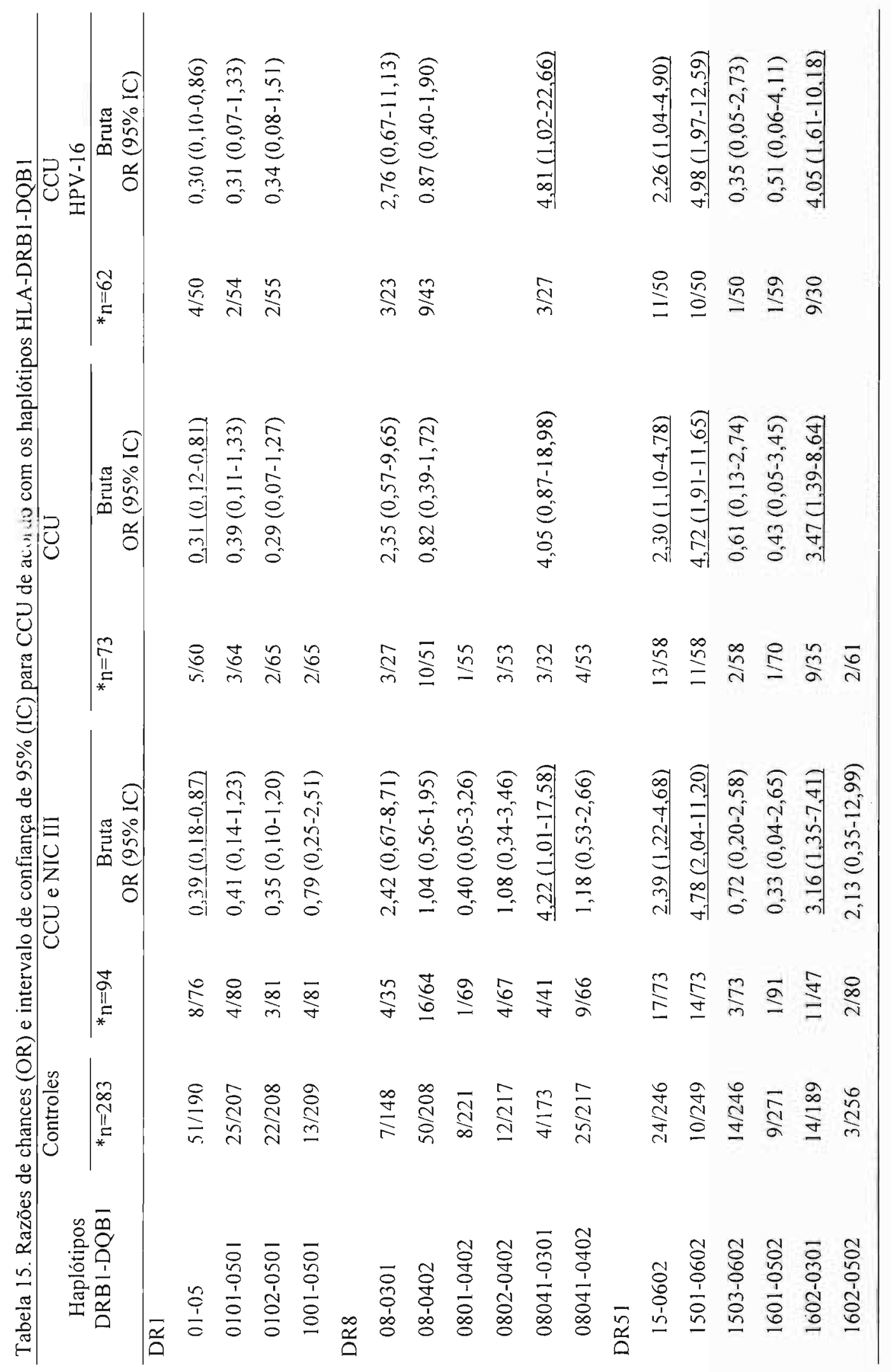




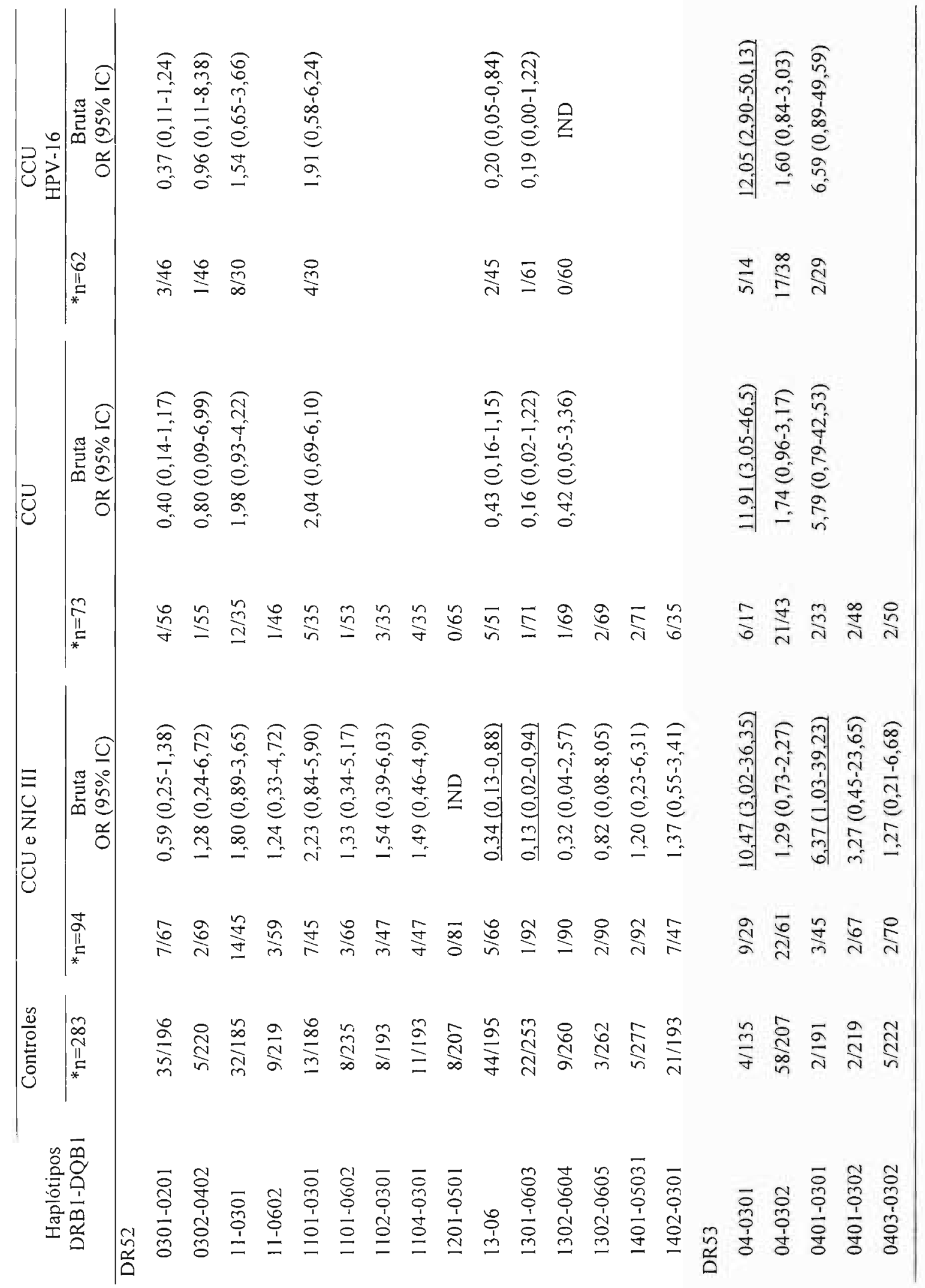




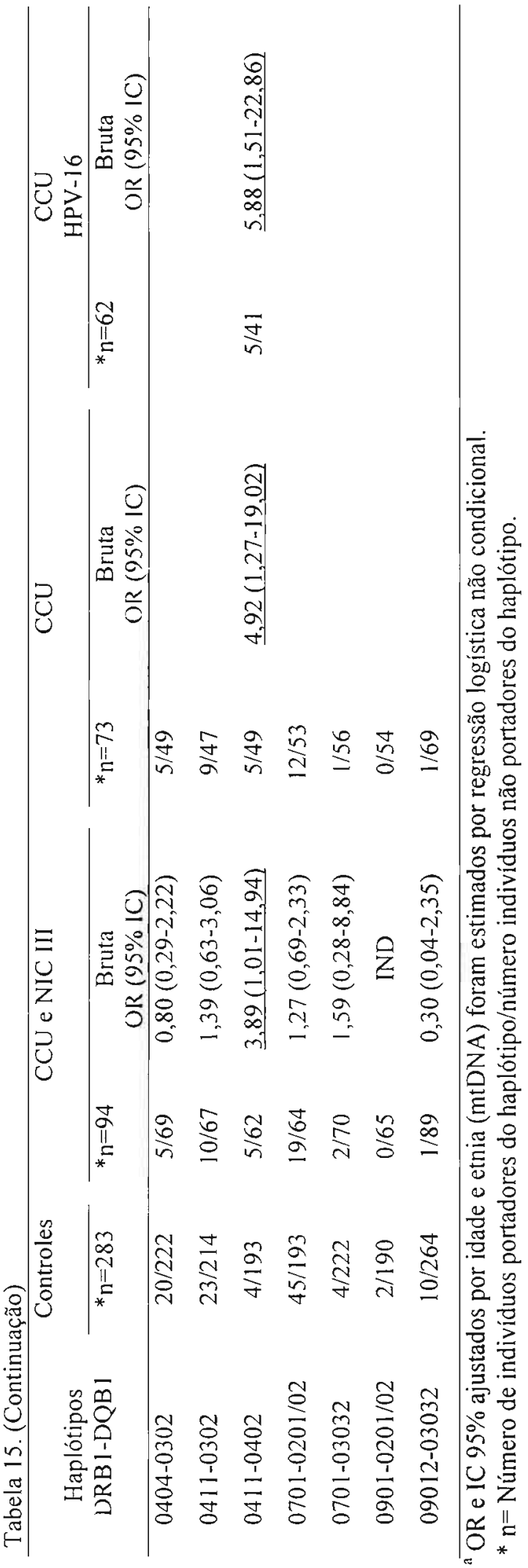




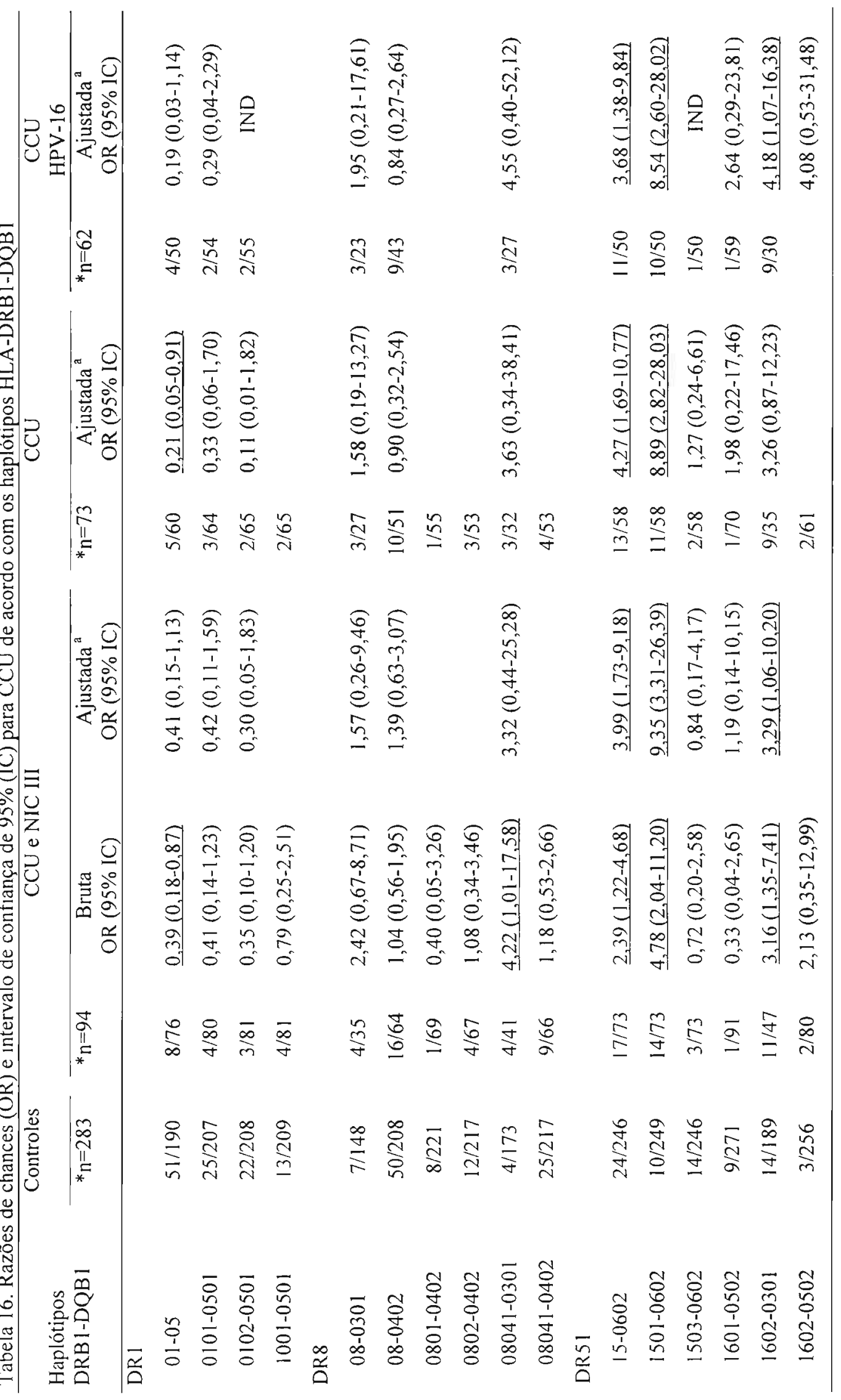




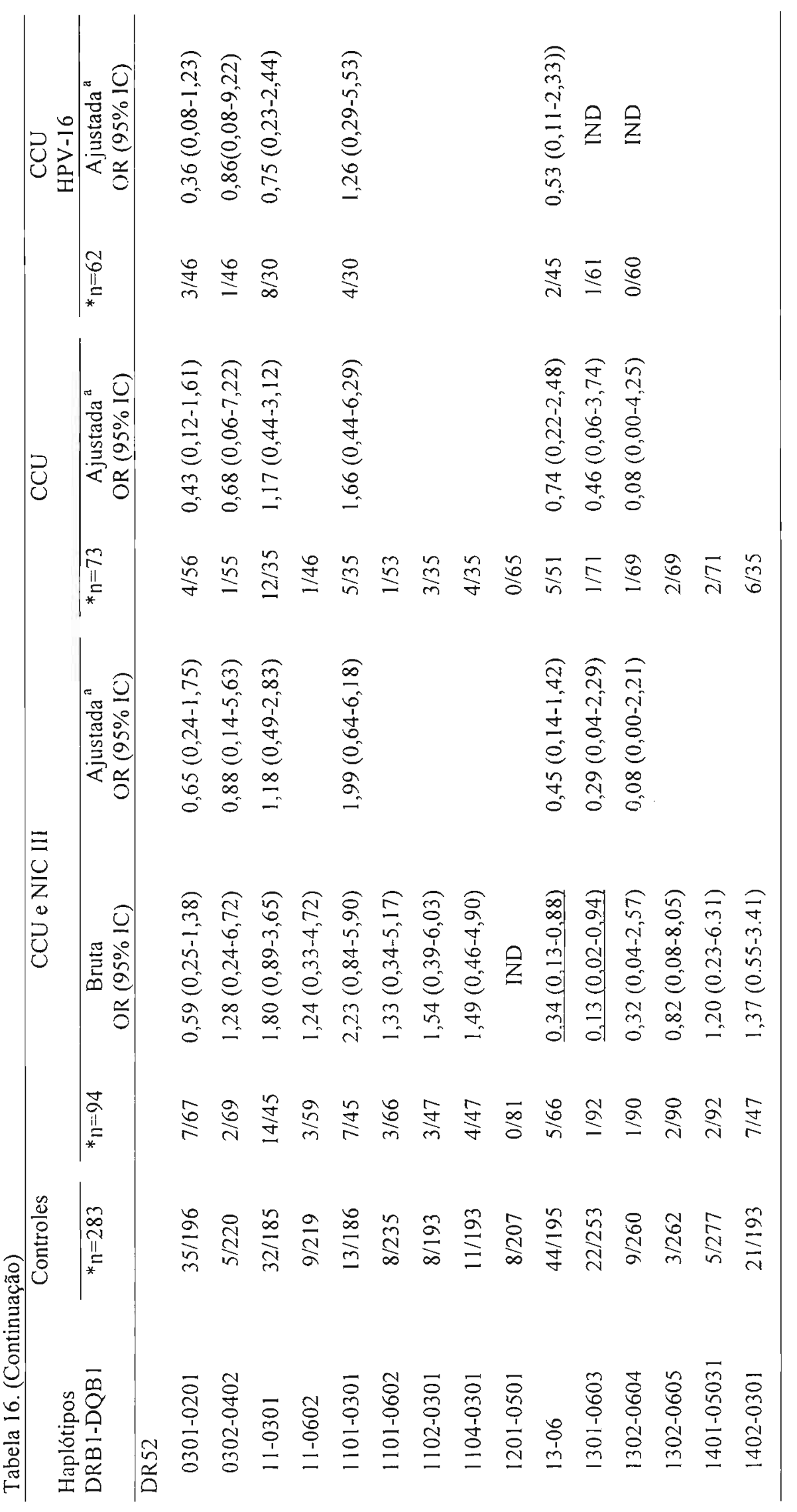




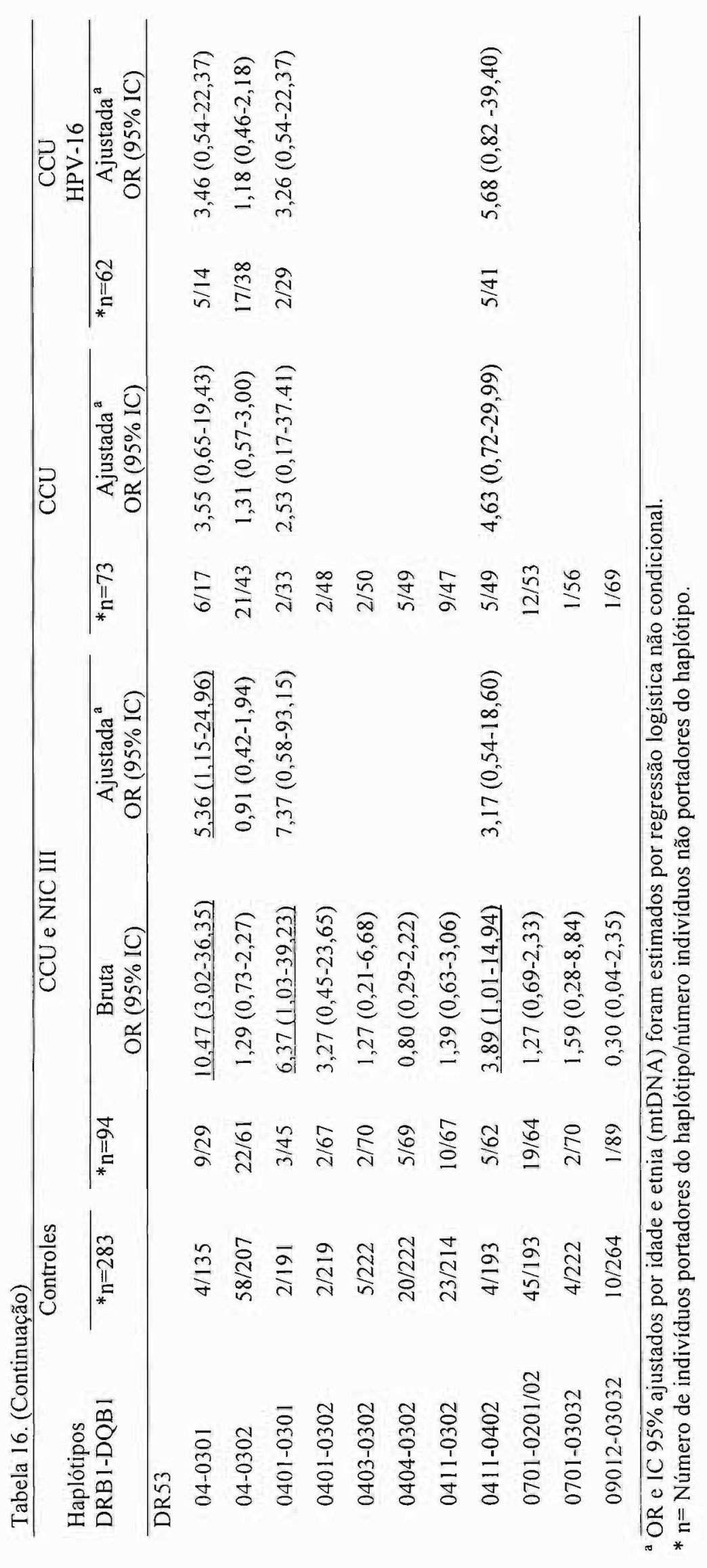


A análise bruta revelou um risco diminuído do haplótipo DRB1*01-DQB1*05 no desenvolvimento de CCU. Após os ajustes esse efeito foi significativo somente nos casos de $\mathrm{CCU}(\mathrm{OR}=0,21 ; 0,05-0,91)$. Para todos os alelos do grupo $\mathrm{DRB} 1 * 01$ foram obtidos valores de OR abaixo da unidade. O mesmo foi observado para os haplótipos do grupo DRB1*13 (DRB1*13-DQB 1*06 e DRB 1*1301-DQB1*0603) entretanto, após o ajuste, o efeito protetor não foi estatisticamente significativo (Tabelas 15 e 16).

Os haplótipos DRB1*1101-DQB1*0301, DRB1*08-DQB1*0301 e DRB1*08041DQB1*0301 apresentaram riscos de 2,23 a 4,22. Contudo nenhum destes haplótipos foi significativamente associado ao CCU.

A análise bruta do haplótipo DRB1*04-DQB1*0301 revelou um risco de 10,47 vezes de desenvolvimento de CCU. Após o ajuste, este risco diminuiu pela metade, no entanto, ainda foi significativo na análise do grupo total de casos $(\mathrm{OR}=5,35$; IC: $1,15-24,96)$. Este risco tendeu a cair nos casos que continham somente CCU e/ou CCU HPV-16 positivos, perdendo o poder estatístico. Resultados parecidos foram observados para o haplótipo DRB1*0401DQB1*0301. Ao contrário, o haplótipo DRB1*0411-DQB1*0402 apresentou riscos elevados que variaram de 3,89 (IC: 1,01-14,94) na análise bruta a 5,68 (IC: 0,82-39,40) na analise ajustada, contudo não foi significativo (Tabela 16).

Uma forte associação do haplótipo DRB1*1602-DQB1*0301 com o CCU foi observada $(\mathrm{OR}=3,29 ; \mathrm{IC}: 1,06-10,20)$ na amostra total de casos. O risco foi maior no grupo de casos HPV-16 positivos ( $\mathrm{OR}=4,08$; IC: $0,53-31,48)$. Esta associação foi perdida quando amostras com diagnóstico de CIN III foram retiradas da análise.

Um forte risco de desenvolvimento de CCU foi associado aos haplótipos envolvendo o grupo DRB1*15 (OR=2,39; IC: 1,22-4,68). A magnitude da associação entre o haplótipo DRB $1 * 1501-\mathrm{DQB} 1 * 0602$ e CCU dobrou após o ajuste por idade e etnia, aumentando de 4,78 (IC: 2.04-11,20) para 9,35 (IC: 3,31-26,39) no grupo total de casos. Este risco permaneceu 
elevado nos grupos de mulheres só com $\mathrm{CCU}(\mathrm{OR}=8,89 ; \mathrm{IC}: 2,82-28,03)$ e/ou CCU HPV-16 positivos (OR=8,54; IC: 2,60-28,02).

A distribuição dos alelos e haplótipos HLA também foi avaliada quanto ao status de infecção para HPV nos controles. As Tabelas 17 e 18 mostram a distribuição dos alelos de DRB1 e DQB1 respectivamente. 


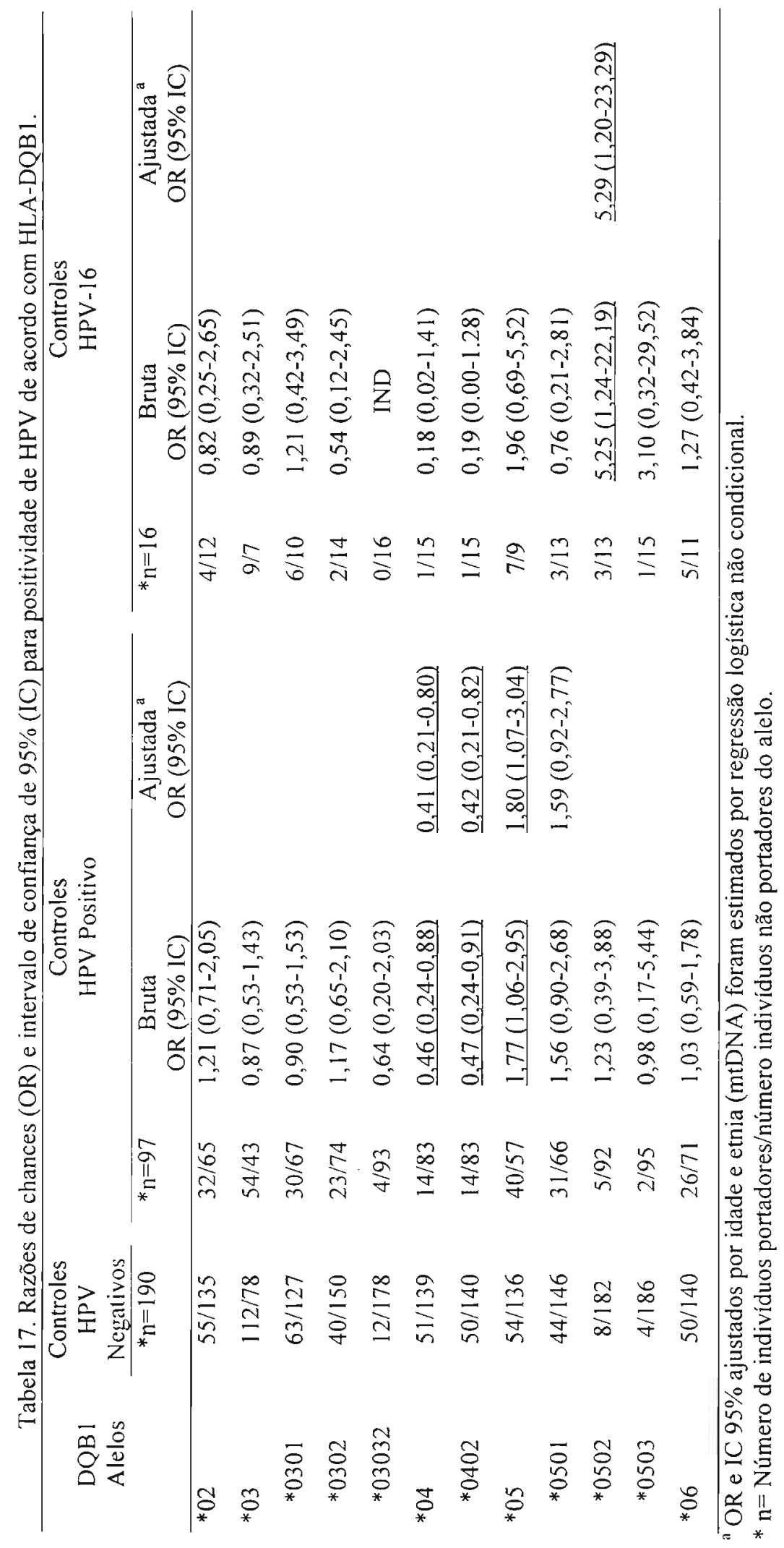




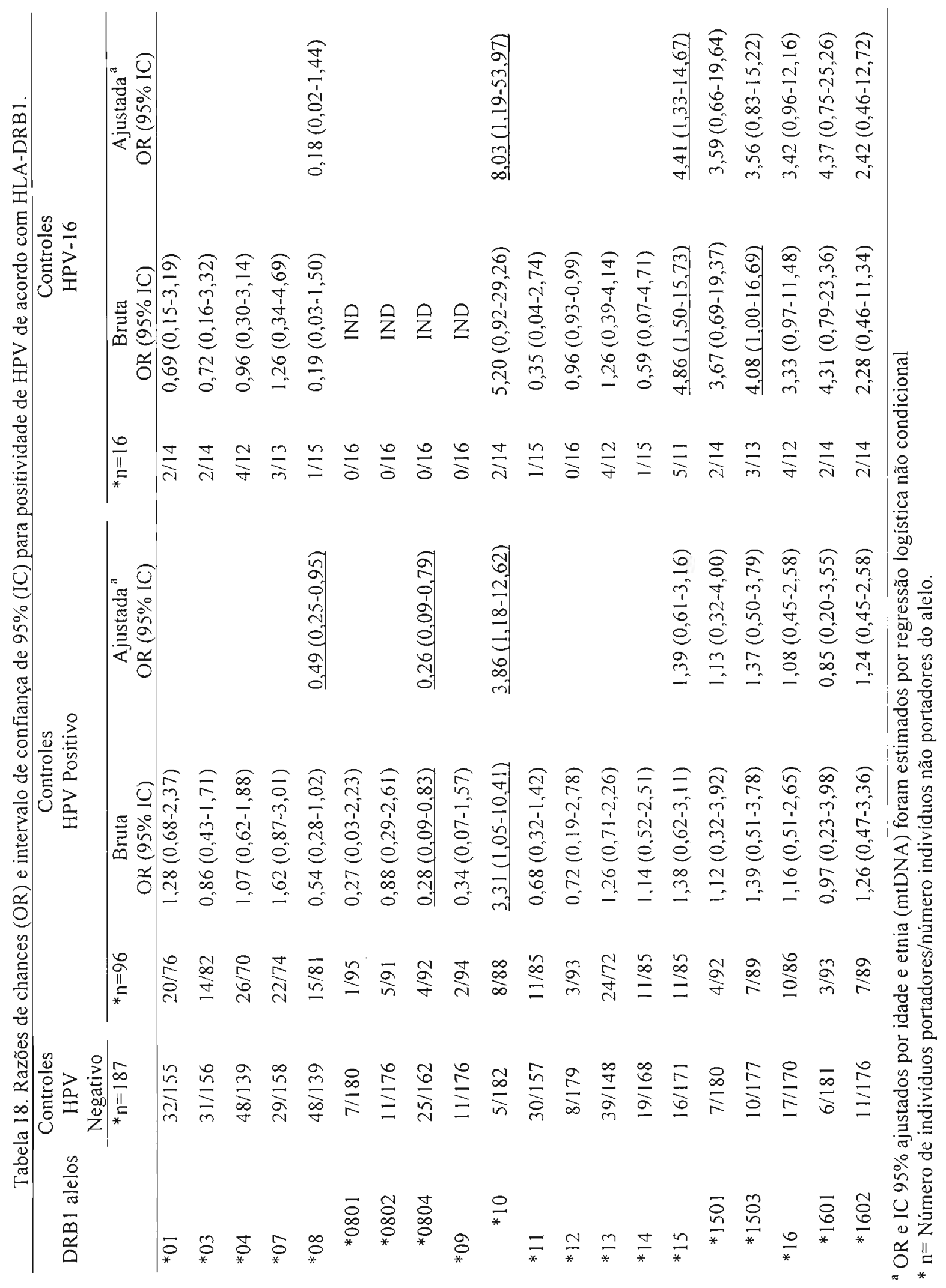


A análise de DQB1 revelou um forte efeito protetor à infecção por todos os tipos de HPV em mulheres portadoras do grupo DQB $1{ }^{*} 04$, especialmente portadoras do alelo $\mathrm{DQB} 1 * 0402 \quad(\mathrm{OR}=0,42 ; \mathrm{IC}: 0,21-0,82)$. Este efeito não foi verificado quando somente os controles HPV-16 positivos foram analisados (Tabela 17).

Uma associação positiva foi observada para portadoras do grupo DQB ${ }^{*} 05(\mathrm{OR}=1,80$; IC: $1,07-3,04)$ positivas para qualquer tipo de HPV. Entretanto, esta associação não foi observada quando somente mulheres HPV-16 positivas foram analisadas. O efeito maior desta associação foi devido ao alelo $\mathrm{DQB} 1 * 0501(\mathrm{OR}=1,59$; IC: $0,92-2,77)$. Por outro lado, o alelo DQB 1*0502 apresentou uma forte associação com o desenvolvimento de CCU em mulheres HPV-16 positivas (OR=5,29; IC: $1,20-23,29)$.

O grupo DRB $1 * 08$ apresentou uma associação negativa à infecção por todos os tipos de HPV $(\mathrm{OR}=0,49 ; \mathrm{IC}: 0,25-0,95)$. Todos os alelos deste grupo apresentaram $\mathrm{OR}$ abaixo da unidade, com o alelo DRB $1 * 0804$ apresentado uma forte associação negativa $(O R=0,26$; IC: 0,09-0,79). Alelos de DRB $1 * 08$ encontram-se em desequilíbrio de ligação com alelos do grupo DQB ${ }^{*} 04$.

O grupo DRB1*10 foi fortemente associado com o status de infecção para todos os tipos de HPV (OR=3,86; IC: 1,18-12,62). A margnitude desta associação dobrou nos casos HPV-16 positivos (OR=8,03; IC: 1,19-53,97). Uma tendência de associação positiva foi encontrada em portadoras do grupo DRB $1 * 16$ positivas para HPV-16 $(\mathrm{OR}=3,42$; IC: 0,96 12,16). A Tabela 19 mostra a distribuição dos haplótipos DRB1-DQB1 entre os controles positivos para qualquer tipo de HPV e os controles HPV-16 positivos. 


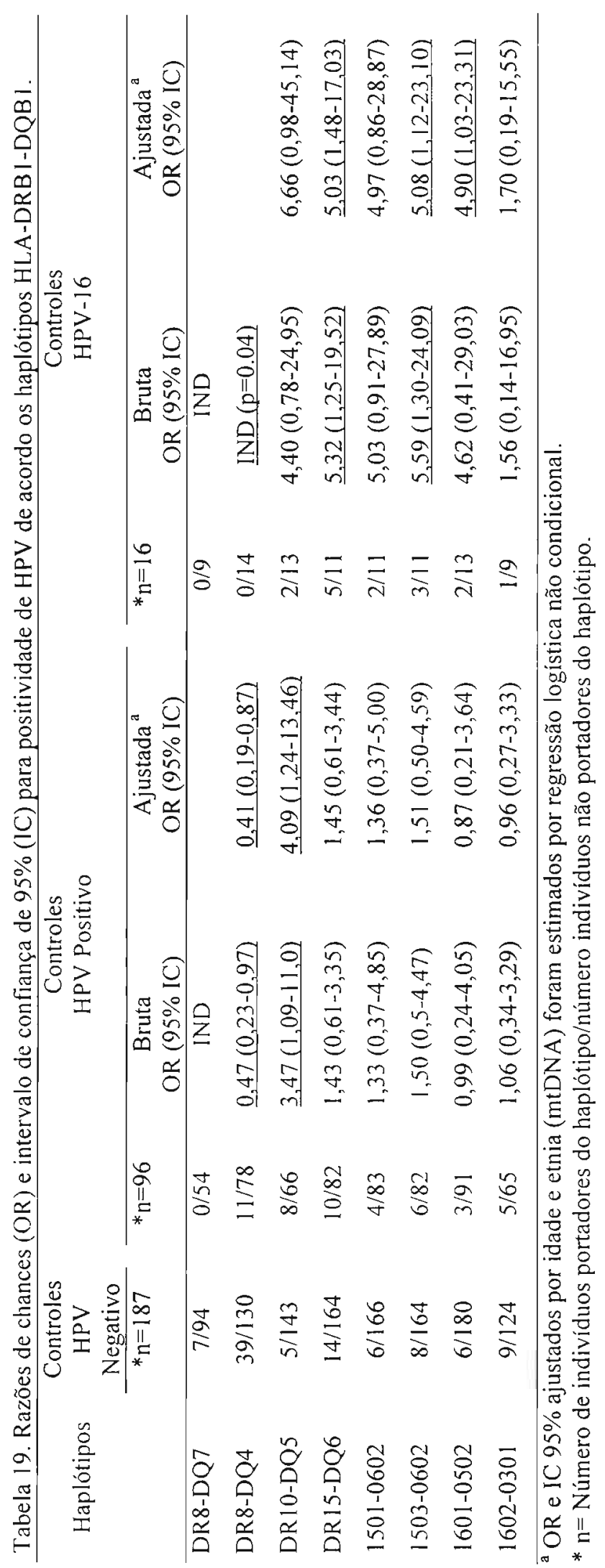


A análise conjunta dos genes DRB1 e DQB1 nos controles revelou uma associação negativa do haplótipo DRB 1*08-DQB1*04 com a positividade para HPV, sendo independente do tipo de HPV (Tabela 19). Vale ressaltar que este haplótipo foi ausente entre as pacientes normais HPV-16 positivas $(\mathrm{p}=0,04)$.

Forte associação positiva foi observada entre o haplótipo DRB1*10-DQB1*05 e o risco de infecção por qualquer tipo de HPV $(\mathrm{OR}=4,09$; IC: 1,24-13,46), este risco permaneceu entre mulheres HPV-16 positivas mas não foi significativo ( $\mathrm{OR}=4,40 ; \mathrm{IC}: 0,78-24,95)$.

Foi observada uma alta susceptibilidade à infecção por HPV-16 em mulheres portadoras do haplótipo $\mathrm{DRB} 1 * 15-\mathrm{DQB} 1 * 06(\mathrm{OR}=5,32 ; \mathrm{IC}: 1,25 ; 19,52)$, principalmente do haplótipo $\mathrm{DRBI}^{*} 1503-\mathrm{DQB} 1 * 0602(\mathrm{OR}=5,59 ; \mathrm{IC}: 1,30 ; 24,09)$. Neste grupo de amostra, DRB1*1501-DQB1*0602 apresentou uma OR de 5,59 mas não foi estatisticamente significativa (IC: 0,91-27,89). O mesmo efeito foi observado para o haplótipo DRB $1^{*} 1601$ DQB $1 * 0502(\mathrm{OR}=12.37$; IC: $0,90-170,7)$.

Neste estudo, o fator idade foi um importante fator de confusão. Desta forma, foi realizada uma análise estratificada por idade em três categorias: $\leq 34,35-44$ e $\geq 45$ anos de idade. Os resultados desta análise encontram-se na Tabela 20. 


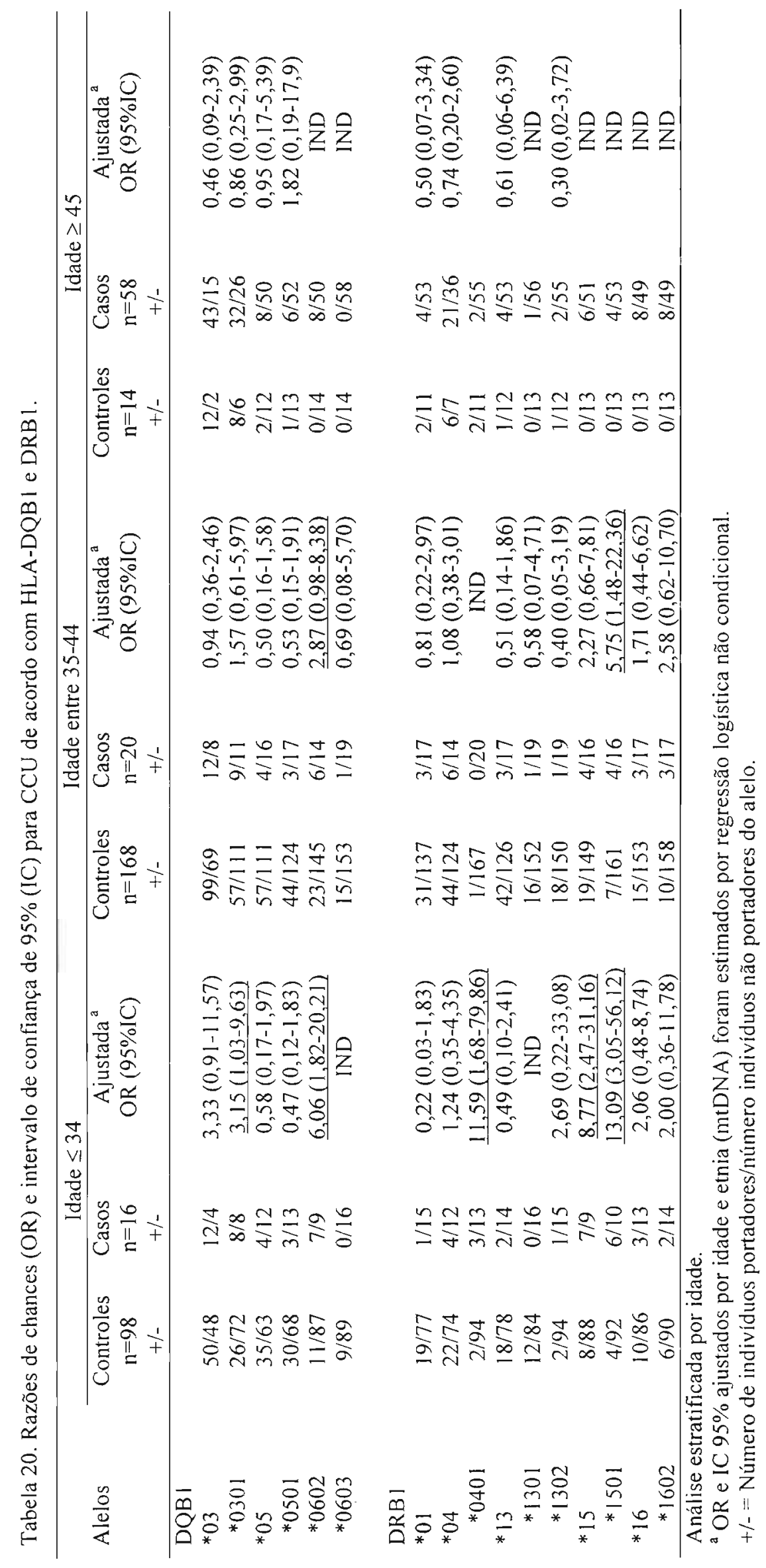


Esta análise demonstrou dados bastante informativos nos grupos de mulheres com idade $\leq 34$ anos e no grupo com idade entre 35-44 anos. Fortes associações positivas envolvendo os alelos DQB1*0301, DQB1*0602, DRB1*0401 e DR*1501 foram encontradas. Foi observado um risco 3,15 vezes maior de desenvolvimento de CCU em portadoras do alelo DQB1*0301 (IC: 1,03-9,63) com idade menor que 34 anos. Este risco foi diluído nas análises envolvendo mulheres mais velhas (Tabela 19). Já o alelo DQB1 *0602 foi associado a um risco duas vezes maior $(\mathrm{OR}=6,06 ; \mathrm{IC}: 1,82-20,21)$ neste grupo de amostras. Este alelo também apresentou uma tendência de associação positiva no grupo de mulheres com idade entre 35-44 anos, entretanto, este risco foi quase 3 vezes menor $(2,87$; IC: $0,98-8,38)$.

A magnitude da associação entre pacientes portadoras do alelo DRB $1 * 0401$ com o CCU foi de 11,59 (IC: 1,68-79,86). Devido ao pequeno número de amostras portando este alelo, não foi possível realizar análises no grupo composto por mulheres com idade maior que 35 anos. Por outro lado, o alelo DRB1*1501 apresentou um forte risco de infecção tanto no grupo de mulheres com idade $\leq 34$ anos ( $\mathrm{OR}=13,09$; IC: $3,05-56,12$ ) quanto no grupo com idade entre 35-44 anos (OR=5,75; IC: 1,48-22,36), apesar do risco ter diminuído pela metade.

Outra análise foi realizada, desta vez estratificando os grupos de amostras em dois grupos de idade: idade $<40$ e idade $>40$ anos (Tabela 21 ). 
Tabela 21. Razões de chances (OR) e intervalo de confiança de $95 \%$ (IC) para CCU de acordo col HLA-DQB1 e DRB1.

\begin{tabular}{|c|c|c|c|c|c|c|}
\hline \multirow[b]{2}{*}{ Alelos } & \multicolumn{3}{|c|}{ Idade $\leq 40$} & \multicolumn{3}{|c|}{ Idade $>40$} \\
\hline & $\begin{array}{c}\text { Controles } \\
n=208 \\
+/-\end{array}$ & $\begin{array}{c}\text { Casos } \\
n=27 \\
+/-\end{array}$ & $\begin{array}{c}\text { Ajustada } \\
\text { OR }(95 \% \mathrm{IC})\end{array}$ & $\begin{array}{c}\text { Controles } \\
\mathrm{n}=72 \\
+/-\end{array}$ & $\begin{array}{c}\text { Casos } \\
\mathrm{n}=67 \\
+/-\end{array}$ & $\begin{array}{c}\text { Ajustada }^{\text {a }} \\
\text { OR }(95 \% \mathrm{IC})\end{array}$ \\
\hline \multicolumn{7}{|l|}{ DQB 1} \\
\hline *03 & $118 / 90$ & $17 / 10$ & $1.30(0.56-3.00)$ & $43 / 29$ & $50 / 17$ & $1.81(0.86-3.79)$ \\
\hline *0301 & $65 / 143$ & $13 / 14$ & $2.16(0.95-4.92)$ & $26 / 46$ & $36 / 31$ & $1.94(0.97-3.87)$ \\
\hline$* 05$ & $74 / 134$ & $8 / 19$ & $0.75(0.31-1.81)$ & $20 / 52$ & $8 / 59$ & $\underline{0.39(0.15-0.97)}$ \\
\hline *0501 & $660 / 148$ & $6 / 21$ & $0.68(0.26-1.77)$ & $15 / 57$ & $6 / 61$ & $0.43(0.15-1.21)$ \\
\hline *0602 & $25 / 183$ & $8 / 19$ & $3.04(1.19-7.78)$ & $9 / 63$ & $13 / 54$ & $1.83(0.70-4.76)$ \\
\hline *0603 & $18 / 190$ & $1 / 26$ & $0.41(0.05-3.29)$ & $6 / 66$ & $0 / 67$ & $\underline{\operatorname{ND}}(p=0.017)$ \\
\hline \multicolumn{7}{|l|}{ DRB 1} \\
\hline *01 & $37 / 169$ & $4 / 23$ & $0.77(0.25-2.37)$ & $15 / 56$ & $4 / 62$ & $0.25(0.08-0.81)$ \\
\hline *04 & $54 / 152$ & $6 / 21$ & $0.80(0.31-2.12)$ & $18 / 53$ & $25 / 41$ & $1.73(0.83-3.61)$ \\
\hline$* 0401$ & $3 / 203$ & $3 / 24$ & $8.62(1.61-46.15)$ & $2 / 69$ & $2 / 64$ & $1.04(0.14-7.67)$ \\
\hline$* 13$ & $48 / 158$ & $5 / 22$ & $0.67(0.24-1.90)$ & $13 / 58$ & $4 / 62$ & $0.28(0.08-0.94)$ \\
\hline$* 1301$ & $22 / 184$ & $1 / 26$ & $0.27(0.03-2.16)$ & $6 / 65$ & $1 / 65$ & $0.19(0.02-1.65)$ \\
\hline$* 1302$ & $14 / 192$ & $2 / 25$ & $1.05(0.22-4.96)$ & $7 / 64$ & $2 / 64$ & $0.26(0.05-1.31)$ \\
\hline$* 15$ & $18 / 188$ & $8 / 19$ & $4.50(1.68-12.07)$ & $9 / 62$ & $9 / 57$ & $1.17(0.42-3.26)$ \\
\hline$* 1501$ & $8 / 198$ & $7 / 20$ & $\underline{8.35(2.67-26.13)}$ & $3 / 68$ & $7 / 59$ & $2.58(0.63-10.49)$ \\
\hline$* 16$ & $22 / 184$ & $6 / 21$ & $2.26(0.81-6.26)$ & $3 / 68$ & $8 / 58$ & $2.96(0.74-11.88)$ \\
\hline$* 1602$ & $13 / 193$ & $5 / 22$ & $2.94(0.94-9.22)$ & $3 / 68$ & $8 / 58$ & $2.96(0.74-11.88)$ \\
\hline
\end{tabular}

Análise estratificada por idade.

${ }^{a}$ OR e JC $95 \%$ ajustados por idade e etnia (mtDNA) foram estimados por regressão logística não condicional.

$+/==$ Número de individuos portadores/número indivíduos não portadores do alelo. 
A análise estratificada por idade dividindo os casos em dois grupos (idade $\leq 40$ e idade $>40$ anos) revelou tanto associações positivas quanto associações negativas, algumas delas não foram observadas anteriormente.

Com exceção de DQB1*0301, no grupo de mulheres com idade $\leq 40$ anos foram encontradas as mesmas associações vistas na análise incluindo mulheres com idade $\leq 35$ anos. Sendo observados riscos positivos para os alelos DQB1*0602, DRB1*0401, DRB1*1501 (Tabela 21). Entretanto, apesar dos riscos permanecerem elevados, houve uma diminuição nos valores de OR.

Um efeito protetor foi observado envolvendo os grupos DRB $1 * 01(\mathrm{OR}=0,25 ; \mathrm{IC}: 0,08$ 0,81) e DRB $1^{*} 13\left(\mathrm{OR}=0,28\right.$; IC: 0,08-0,94). O alelo DQB ${ }^{*} 0501$ está e em desequilíbrio de ligação com alelos do grupo DRB $1 * 01$. E neste grupo de amostras foi encontrada uma associação negativa do grupo $\mathrm{DQB} 1 * 05$ (OR=0,39: IC: 0,15-0,97). Já os alelos do grupo DRB1*13 estão ligados a alelos do grupo DQB $1 * 06$, principalmente o alelo DQB $1 * 0603$. Este por sua vez não foi encontrado no grupo de mulheres com idade $>40$ anos $(p=0,017)$; contudo, foi observada uma baixa frequência deste alelo nos controles $(9,1 \%)$. 


\subsubsection{Análise dos Genes HLA-DQB1 e HLA-DRB1 e as Variantes Moleculares de HPV-}

16

Foram também investigadas as associações entre genes HLA em pacientes de portados das variantes moleculares de HPV-16. A comparação entre variantes de HPV-16 nos grupos de casos e controles não foi possível, devido ao pequeno número de mulheres HPV-16 positivas $(n=16)$ no grupo controle. Assim, os dados aqui apresentados resultam da comparação da distribuição dos grupos HLA entre pacientes com CCU portadoras de variantes de HPV-16 e controles. Foram realizadas análises agrupando as amostras de acordo com o classificação filogenética das variantes (E, AA) ou de acordo com a presença da substituição na posição nucleotídica 350 do gene E6 de HPV-16 $(350 \mathrm{~T} \rightarrow \mathrm{G})$. As variantes mais freqüentes também foram analisadas individualmente (B2, B12 e protótipo). As Tabelas 22-26 mostram a distribuição das variantes da LCR de HPV-16 nos casos de acordo com HLA-DRB1 e DQB1. 
Tabela 22. Razões de chances (OR) e intervalo de confiança de $95 \%$ (IC) para CC positivos para variantes AA de acordo com HLA-DRb1 e DQB1.

\begin{tabular}{|c|c|c|c|c|}
\hline \multirow{2}{*}{ HLA } & \multirow{2}{*}{$\begin{array}{c}\text { Casos } \\
\text { AA } \\
\text { Positivos } \\
* n=39\end{array}$} & \multicolumn{3}{|c|}{ Controles } \\
\hline & & $*^{n}=283$ & $\begin{array}{c}\text { Bruta } \\
\text { OR }(95 \% \text { IC })\end{array}$ & $\begin{array}{c}\text { Ajustada }^{a} \\
\text { OR }(95 \% \text { IC) }\end{array}$ \\
\hline \multicolumn{5}{|l|}{$\overline{\text { DRB1 }}$} \\
\hline$*_{01}$ & $3 / 36$ & $52 / 231$ & $0,37(0,11-1,25)$ & $0.20(0.03-1.52)$ \\
\hline$*_{03}$ & $6 / 33$ & $45 / 238$ & $0,96(0,38-2,43)$ & \\
\hline$* 0302$ & $3 / 36$ & $6 / 277$ & $3.85(0.92-16.06)$ & $3.09(0.61-15.66)$ \\
\hline$* 04$ & $12 / 27$ & $74 / 209$ & $1,25(0,61-2,60)$ & \\
\hline *0411 & $6 / 33$ & $33 / 250$ & $1.38(0.54-3.53)$ & \\
\hline$* 07$ & $12 / 27$ & $51 / 232$ & $2,02(0,96-4,26)$ & $1.05(0.37-2.92)$ \\
\hline$*_{08}$ & $6 / 33$ & $63 / 220$ & $0,63(0,25-1,58)$ & \\
\hline *09 & $1 / 38$ & $13 / 270$ & $0,55(0,07-4,30)$ & \\
\hline$* 10$ & $2 / 37$ & $13 / 270$ & $1.12(0,24-5,17)$ & \\
\hline$* 11$ & $6 / 33$ & $4 I / 242$ & $1,07(0,42-2,72)$ & \\
\hline$* 12$ & $0 / 39$ & $11 / 272$ & IND & \\
\hline$* 13$ & $1 / 38$ & $63 / 220$ & $0.09(0.01-0.68)$ & $0.18(0.02-1.44)$ \\
\hline$* 1301$ & $0 / 39$ & $29 / 254$ & IND & \\
\hline$* 1302$ & $0 / 39$ & $21 / 262$ & IND & \\
\hline$* 14$ & $7 / 32$ & $30 / 253$ & $1,84(0,75-4,54)$ & \\
\hline$* 15$ & $7 / 32$ & $27 / 256$ & $2,07(0,84-5,15)$ & $2.02(0.65-6.28)$ \\
\hline *1501 & $6 / 33$ & $11 / 272$ & $4.50(1.56-12.95)$ & $5.09(1.39-18.63)$ \\
\hline *I6 & $9 / 30$ & $27 / 256$ & $2.84(1.22-6.61)$ & $\underline{5.86(1.88-18.31)}$ \\
\hline$* 1602$ & $8 / 31$ & $18 / 265$ & $\underline{3.80(1.53-9.46)}$ & $5.98(1.74-20.48)$ \\
\hline DQB 1 & $n=40$ & $n=287$ & & \\
\hline$* 02$ & $15 / 25$ & $87 / 200$ & $1.38(0,69-2.74)$ & \\
\hline *03 & $27 / 13$ & $166 / 121$ & $1.51(0.75-3.05)$ & $1.27(0.52-3.12)$ \\
\hline$* 04$ & $11 / 29$ & $65 / 222$ & $1.30(0.61-2.73)$ & \\
\hline$* 05$ & $9 / 31$ & $94 / 193$ & $0,60(0,27-1,30)$ & $0.78(0.28-2.13)$ \\
\hline$* 0501$ & $5 / 35$ & $75 / 212$ & $0.40(0.15-1.07)$ & $0.44(0.12-1.65)$ \\
\hline$* 06$ & $8 / 32$ & $76 / 211$ & $0,69(0,31-1,57)$ & \\
\hline *0602 & $8 / 32$ & $35 / 252$ & $1.80(0.77-4.22)$ & $2.30(0.80-6.65)$ \\
\hline$* 0603$ & $0 / 40$ & $24 / 263$ & $p=0.056$ & \\
\hline$* 07$ & $19 / 21$ & $93 / 194$ & $1,89(0,97-3,68)$ & $1.58(0.67-3.73)$ \\
\hline *08 & $11 / 29$ & $63 / 224$ & $1.35(0,64-2.85)$ & \\
\hline *09 & $1 / 39$ & $16 / 271$ & $0,43(0,06-3,37)$ & \\
\hline
\end{tabular}

${ }^{a}$ OR e IC $95 \%$ ajustados por idade e etnia (mtDNA) foram estimados por regressão logística não condicional.

* $n=$ Número de individuos portadores/número individuos não portadores do alelo. 
Tabela 23. Razões de chances (OR) e intervalo de confiança de 95\% (IC) para CC positivos para variantes B-2 (ramo AA) de acordo com HLA-DRB1 e DQB1.

\begin{tabular}{|c|c|c|c|c|}
\hline \multirow{3}{*}{ HLA } & \multirow{2}{*}{$\begin{array}{c}\text { Casos } \\
\text { B2 } \\
\text { Positivos }\end{array}$} & \multicolumn{3}{|c|}{ Controles } \\
\hline & & & & \\
\hline & ${ }^{*} \mathrm{n}=36$ & ${ }^{*} n=283$ & $\begin{array}{c}\text { Bruta } \\
\text { OR }(95 \% \text { IC })\end{array}$ & $\begin{array}{c}\text { Ajustada }^{\mathrm{a}} \\
\text { OR }(95 \% \text { IC })\end{array}$ \\
\hline \multicolumn{5}{|l|}{ DRB 1} \\
\hline$* 01$ & $3 / 33$ & $52 / 231$ & $0,40(0.12-1,37)$ & $0.23(0.03-1.78)$ \\
\hline$* 03$ & $5 / 31$ & $45 / 238$ & $0,85(0,32-2,31)$ & \\
\hline$* 0302$ & $2 / 34$ & $6 / 277$ & $2.72(0.53-13.99)$ & \\
\hline$* 04$ & $11 / 25$ & $74 / 209$ & $1,24(0,58-2,65)$ & \\
\hline *0411 & $6 / 30$ & $33 / 250$ & $1.52(0.59-3.91)$ & \\
\hline$* 07$ & $11 / 25$ & $51 / 232$ & $2,00(0,93-4,33)$ & $0.91(0.30-2.74)$ \\
\hline$* 08$ & $5 / 31$ & $63 / 220$ & $0,56(0,21-1,51)$ & \\
\hline *09 & $1 / 35$ & $13 / 270$ & $0,59(0,07-4,67)$ & \\
\hline$* 10$ & $2 / 34$ & $13 / 270$ & $1,22(0,26-5,65)$ & \\
\hline$* 11$ & $5 / 31$ & $41 / 242$ & $0.95(0.35-2.59)$ & \\
\hline *12 & $0 / 36$ & $11 / 272$ & IND & \\
\hline$* 13$ & $1 / 35$ & $63 / 220$ & $0.10(0.01-0.74)$ & $0.20(0.03-1.61)$ \\
\hline *1301 & $0 / 36$ & $29 / 254$ & IND & \\
\hline$* 1302$ & $0 / 36$ & $21 / 262$ & IND & \\
\hline$* 14$ & $6 / 30$ & $30 / 253$ & $1,69(0,65-4,38)$ & \\
\hline *15 & $7 / 29$ & $27 / 256$ & $\underline{2.29(0.92-5.72)}$ & $2.32(0.73-7.35)$ \\
\hline${ }^{*} 1501$ & $6 / 30$ & $11 / 272$ & $\pm .95(1.71-14.33)$ & $5.84(1.57-21.77)$ \\
\hline$* 16$ & $9 / 27$ & $27 / 256$ & $\underline{3.16(1,35-7,41)}$ & $\underline{6.96(2.16-22.47)}$ \\
\hline$* 1602$ & $8 / 28$ & $18 / 265$ & $\pm .21(1.68-10.55)$ & $6.83(1.95-23.98)$ \\
\hline DQB 1 & $n=37$ & $\mathrm{n}=287$ & & \\
\hline$* 02$ & $14 / 23$ & $87 / 200$ & $1,40(0,69-2,85)$ & \\
\hline$* 03$ & $25 / 12$ & $166 / 121$ & $1,52(0,73-3,14)$ & \\
\hline$* 04$ & $9 / 28$ & $65 / 222$ & $1,10(0.49-2,44)$ & \\
\hline$* 05$ & $9 / 28$ & $94 / 193$ & $0,66(0.30-1.45)$ & \\
\hline$* 0501$ & $5 / 32$ & $75 / 212$ & $0.44(0.17-1.18)$ & $0.51(0.13-1.96)$ \\
\hline *06 & $7 / 30$ & $76 / 211$ & $0.65(0,27-1,54)$ & \\
\hline$* 0602$ & $7 / 30$ & $35 / 252$ & $1.68(0.69-4.11)$ & $2.07(0.66-6.46)$ \\
\hline$* 0603$ & $0 / 37$ & $24 / 263$ & IND & \\
\hline$* 07$ & $17 / 20$ & $93 / 194$ & $1,77(0,89-3,54)$ & $1.44(0.58-3.59)$ \\
\hline$* 08$ & $11 / 26$ & $63 / 224$ & $1,50(0,70-3,21)$ & \\
\hline *09 & $1 / 36$ & $16 / 271$ & $0,47(0,06-3,65)$ & \\
\hline
\end{tabular}

${ }^{a}$ OR e IC $95 \%$ ajustados por idade e etnia (mtDNA) foram estimados por regressão logística não condicional.

* $n=$ Número de indivíduos portadores/número indivíduos não portadores do alelo. 
Tabela 24. Razões de chances (OR) e intervalo de confiança de $95 \%$ (IC) para CC positivos para variantes do ramo E de acordo com HLA-DRB1 e DQB1.

\begin{tabular}{|c|c|c|c|c|}
\hline \multirow{2}{*}{ HLA } & \multirow{2}{*}{$\begin{array}{c}\text { Casos } \\
\text { E } \\
\text { Positivos } \\
{ }^{*} n=39\end{array}$} & \multicolumn{3}{|c|}{ Controles } \\
\hline & & $*_{n}=283$ & $\begin{array}{c}\text { Bruta } \\
\text { OR }(95 \% \text { IC })\end{array}$ & $\begin{array}{c}\text { Ajustada } \\
\text { OR }(95 \% \text { IC) }\end{array}$ \\
\hline \multicolumn{5}{|l|}{ DRB 1} \\
\hline$* 01$ & $3 / 36$ & $52 / 231$ & $0,37(0,11-1,25)$ & $0.70(0.19-2.52)$ \\
\hline$* 03$ & $0 / 39$ & $45 / 238$ & $\underline{I N D}(p=0.015)$ & \\
\hline$* 04$ & $13 / 26$ & $74 / 209$ & $1,41(0.69-2,89)$ & \\
\hline$* 0401$ & $2 / 37$ & $5 / 278$ & $3.01(0.56-16.05)$ & \\
\hline *0411 & $7 / 32$ & $33 / 250$ & $1.66(0.68-4.05)$ & \\
\hline$* 0701$ & $9 / 30$ & $51 / 232$ & $1,36(0,61-3,05)$ & \\
\hline$* 08$ & $12 / 27$ & $63 / 220$ & $1,55(0,74-3,24)$ & \\
\hline *0804 & $8 / 31$ & $29 / 254$ & $2.26(0.95-5.38)$ & $2.77(0.89-8.61)$ \\
\hline$* 09012$ & $1 / 38$ & $13 / 270$ & $0,55(0,07-4,30)$ & \\
\hline$* 1001$ & $3 / 36$ & $13 / 270$ & $1,73(0,47-6,37)$ & \\
\hline$* 11$ & $6 / 33$ & $41 / 242$ & $1,07(0,42-2,72)$ & \\
\hline$* 1201$ & $0 / 39$ & $11 / 272$ & IND & \\
\hline$* 13$ & $4 / 35$ & $63 / 220$ & $0,40(0,14-1,16)$ & $0.47(0.13-1.69)$ \\
\hline *1301 & $1 / 38$ & $29 / 254$ & $0.23(0.03-1.74)$ & $0.47(0.06-3.80)$ \\
\hline *1302 & $2 / 37$ & $21 / 262$ & $0.67(0.15-2.99)$ & $0.71(0.14-3.54)$ \\
\hline *14 & $3 / 36$ & $30 / 253$ & $0,70(0,20-2,42)$ & \\
\hline$* 15$ & $7 / 32$ & $27 / 256$ & $2,07(0,83-5.15)$ & $2.85(0.99-8.69)$ \\
\hline$* 1501$ & $6 / 33$ & $11 / 272$ & $\underline{4.50(1.56-12.95)}$ & $6.77(1.91-23.91)$ \\
\hline$* 16$ & $6 / 33$ & $27 / 256$ & $1,72(0,66-4.48)$ & $1.39(0.38-5.04)$ \\
\hline *1602 & $6 / 33$ & $18 / 265$ & $2.68(0.99-7.22)$ & $1.72(0.45-6.60)$ \\
\hline DQ & $\mathrm{n}=39$ & $n=287$ & & \\
\hline$* 0201 / 02$ & $8 / 31$ & $87 / 200$ & $0,59(0,26-1,34)$ & \\
\hline *03 & $28 / 11$ & $166 / 121$ & $1,85(0,89-3.87)$ & $1.04(0.43-2.52)$ \\
\hline$* 04$ & $12 / 27$ & $65 / 222$ & $1,52(0,73-3,16)$ & \\
\hline$* 05$ & $7 / 32$ & $94 / 193$ & $0,45(0,19-1,05)$ & $0.91(0.33-2.48)$ \\
\hline$* 0501$ & $7 / 32$ & $75 / 212$ & $0.62(0.26-1.46)$ & $1.31(0.47-3.62)$ \\
\hline *06 & $11 / 28$ & $76 / 211$ & $1,09(0,52-2,30)$ & \\
\hline *0602 & $9 / 30$ & $35 / 252$ & $2.16(0.95-4.93)$ & $3.33(1.24-8.91)$ \\
\hline *0603 & $1 / 38$ & $24 / 263$ & $0.29(0.04-2.19)$ & $0.60(0.07-4.87)$ \\
\hline$* 0604$ & $0 / 39$ & $13 / 274$ & IND & \\
\hline$* 07$ & $21 / 18$ & $93 / 194$ & $\underline{2.43(1.24-4.79)}$ & $1.49(0.63-3.47)$ \\
\hline$* 08$ & $8 / 31$ & $63 / 224$ & $0,92(0,40-2,09)$ & \\
\hline *09 & $2 / 37$ & $16 / 271$ & $0,92(0,20-4,14)$ & \\
\hline
\end{tabular}

${ }^{a}$ OR e IC $95 \%$ ajustados por idade e etnia (mtDNA) foram estimados por regressão logística não condicional.

* $\mathrm{n}=$ Número de indivíduos portadores/número indivíduos não portadores do alelo. 
Universidade de São Paulo

Tabela 25. Razões de chances (OR) e intervalo de confiança de $95 \%$ (IC) para CC positivos para variantes protótipo (ramo E) de acordo com HLA-DRBl e DQB1.

\begin{tabular}{|c|c|c|c|c|}
\hline \multirow{4}{*}{ HLA } & \multirow{4}{*}{$\begin{array}{c}\text { Casos } \\
\text { Protótipo } \\
\text { Positivos } \\
{ }^{*} n=17\end{array}$} & \multicolumn{3}{|c|}{ Controles } \\
\hline & & & & \\
\hline & & ${ }^{*} \mathrm{n}=283$ & Bruta & Ajustada $^{a}$ \\
\hline & & & OR $(95 \%$ IC $)$ & OR $(95 \%$ IC) \\
\hline \multicolumn{5}{|l|}{$\overline{\text { DRB1 }}$} \\
\hline$* 01$ & $3 / 14$ & $52 / 231$ & $0,95(0,26-3,43)$ & \\
\hline$* 03$ & $0 / 17$ & $45 / 238$ & IND & \\
\hline$* 04$ & $7 / 10$ & $74 / 209$ & $1,98(0,72-5,38)$ & \\
\hline$* 0401$ & $0 / 17$ & $5 / 278$ & IND & \\
\hline$* 0411$ & $3 / 14$ & $33 / 250$ & $1.62(0.44-5.95)$ & \\
\hline *0701 & $2 / 15$ & $51 / 232$ & $0,61(0,13-2,73)$ & \\
\hline$* 08$ & $4 / 13$ & $63 / 220$ & $1,07(0,34-3,41)$ & \\
\hline$* 0804$ & $3 / 14$ & $29 / 254$ & $1.88(0.51-6.92)$ & \\
\hline *09012 & $0 / 17$ & $13 / 270$ & IND & \\
\hline$* 1001$ & $1 / 16$ & $13 / 270$ & $1,30(0,16-10,55)$ & \\
\hline *11 & $2 / 15$ & $41 / 242$ & $0,79(0,17-3,57)$ & \\
\hline$* 1201$ & $0 / 17$ & $11 / 272$ & IND & \\
\hline$* 13$ & $2 / 15$ & $63 / 220$ & $0,46(0,10-2,09)$ & \\
\hline$* 1301$ & $1 / 16$ & $29 / 254$ & $0.55(0.07-4.28)$ & \\
\hline *1302 & $1 / 16$ & $21 / 262$ & $0.78(0.10-6.17)$ & \\
\hline$* 14$ & $1 / 16$ & $30 / 253$ & $0,53(0,07-4,12)$ & \\
\hline$* 15$ & $6 / 11$ & $27 / 256$ & $\underline{5,17(1,77-15,09)}$ & $4.48(1.34-15.06)$ \\
\hline *1501 & $5 / 12$ & $11 / 272$ & $10.30(2.38-38.52))$ & $9.92(2.42-40.61)$ \\
\hline$* 16$ & $3 / 14$ & $27 / 256$ & $2,03(0,55-7,52)$ & \\
\hline *1602 & $3 / 14$ & $18 / 265$ & $3.15(0.83-11.99)$ & \\
\hline DQB1 & $\mathrm{n} 17$ & $\mathrm{n}=287$ & & \\
\hline *0201/02 & $1 / 16$ & $87 / 200$ & $0,14(0,02-1,10)$ & $0.13(0.02-1.09)$ \\
\hline$* 03$ & $6 / 11$ & $166 / 121$ & $1,33(0,48-3,71)$ & \\
\hline$*_{04}$ & $6 / 11$ & $65 / 222$ & $1,86(0,66-5,23)$ & \\
\hline$* 05$ & $4 / 13$ & $94 / 193$ & $0,63(0,20-1,99)$ & \\
\hline$* 0501$ & $4 / 13$ & $75 / 212$ & $0.87(0.28-2.75)$ & \\
\hline$* 06$ & $8 / 9$ & $76 / 211$ & $2,47(0,92-6,63)$ & \\
\hline$* 0602$ & $6 / 11$ & $35 / 252$ & $\underline{3.93(1.37-11.29)}$ & $4.29(1.28-14.32)$ \\
\hline$* 0603$ & $1 / 16$ & $24 / 263$ & $0.68(0.09-5.38)$ & \\
\hline$* 0604$ & $0 / 17$ & $13 / 274$ & IND & \\
\hline$* 07$ & $8 / 9$ & $93 / 194$ & $1,85(0,69-4,96)$ & \\
\hline$* 08$ & $4 / 13$ & $63 / 224$ & $1,09(0,34-3,47)$ & \\
\hline$* 09$ & $0 / 17$ & $16 / 271$ & IND & \\
\hline
\end{tabular}

${ }^{\mathrm{a}}$ OR e IC $95 \%$ ajustados por idade e etnia (mtDNA) foram estimados por regressão logística não condicional.

* $\mathrm{n}=$ Número de indivíduos portadores/número indivíduos não portadores do alelo. 
Tabela 26. Razões de chances (OR) e intervalo de confiança de $95 \%$ (IC) para CC positivos para variantes B-12 (ramo E) de acordo com HLA-DRB1 e DQB1.

\begin{tabular}{|c|c|c|c|c|}
\hline \multirow{3}{*}{ HLA } & Casos & \multicolumn{3}{|c|}{ Controles } \\
\hline & Positivos & & & \\
\hline & ${ }^{*} n=18$ & ${ }^{*} \mathrm{n}=283$ & $\begin{array}{c}\text { Bruta } \\
\text { OR }(95 \% \text { IC })\end{array}$ & $\begin{array}{c}\text { Ajustada }^{\mathrm{a}} \\
\text { OR }(95 \% \text { IC })\end{array}$ \\
\hline \multicolumn{5}{|l|}{ DRB 1} \\
\hline$* 01$ & $0 / 18$ & $52 / 231$ & IND & \\
\hline *03 & $0 / 18$ & $45 / 238$ & IND & \\
\hline *04 & $5 / 13$ & $74 / 209$ & $1,08(0,37-3,15)$ & \\
\hline *0411 & $4 / 14$ & $33 / 250$ & $2,16(0,67-6,97)$ & \\
\hline$* 0701$ & $5 / 13$ & $51 / 232$ & $1,75(0,60-5,13)$ & \\
\hline *08 & $7 / 11$ & $63 / 220$ & $2,22(0,83-5,97)$ & \\
\hline$* 09012$ & $1 / 17$ & $13 / 270$ & $1,22(0,15-9,90)$ & \\
\hline$* 1001$ & $1 / 17$ & $13 / 270$ & $1,22(0,15-9,90)$ & \\
\hline$* 11$ & $4 / 14$ & $41 / 242$ & $1,69(0,53-5,38)$ & \\
\hline$* 1201$ & $0 / 18$ & $11 / 272$ & IND & \\
\hline$* 13$ & $2 / 16$ & $63 / 220$ & $0,44(0,10-1,95)$ & \\
\hline *1301 & $0 / 18$ & $29 / 254$ & IND & \\
\hline *1302 & $1 / 17$ & $21 / 262$ & $0.73(0.09-5.78)$ & \\
\hline$* 14$ & $2 / 16$ & $30 / 253$ & $1,05(0,23-4,81)$ & \\
\hline$* 15$ & $0 / 18$ & $27 / 256$ & IND & \\
\hline$* 16$ & $3 / 17$ & $27 / 256$ & $1.90(0.52-6.97)$ & \\
\hline$* 1602$ & $3 / 17$ & $18 / 265$ & $2.94(0.78-11.11)$ & \\
\hline DQB 1 & $\mathrm{n}=18$ & $n=287$ & & \\
\hline *0201/02 & $5 / 13$ & $87 / 200$ & $0,88(0,31-2,56)$ & \\
\hline$* 03$ & $14 / 4$ & $166 / 121$ & $2,55(0,82-7,94)$ & \\
\hline$* 04$ & $5 / 13$ & $65 / 222$ & $1,31(0,45-3,82)$ & \\
\hline${ }^{*} 05$ & $2 / 16$ & $94 / 193$ & $0,26(0.06-1.14)$ & \\
\hline$* 0501$ & $2 / 16$ & $75 / 212$ & $0.35(0.08-1.57)$ & \\
\hline$* 06$ & $2 / 16$ & $76 / 211$ & $0,35(0,08-1,54)$ & \\
\hline$* 0602$ & $2 / 16$ & $35 / 252$ & $0.90(0.20-4.08)$ & \\
\hline$* 0603$ & $0 / 18$ & $24 / 263$ & IND & \\
\hline$*^{*} 07$ & $11 / 7$ & $93 / 194$ & $3,28(1.23-8.73)$ & $1.91(0.48-7.59)$ \\
\hline$* 08$ & $4 / 14$ & $63 / 224$ & $1,02(0,32-3,19)$ & \\
\hline$* 09$ & $1 / 17$ & $16 / 271$ & $0,99(0,12-7,97)$ & \\
\hline
\end{tabular}

${ }^{\mathrm{a}}$ OR e IC $95 \%$ ajustados por idade e etnia (mtDNA) foram estimados por regressão logística não condicional.

* $\mathrm{n}=$ Número de indivíduos portadores/número indivíduos não portadores do alelo. 
A análise dos genes HLA mostrou riscos positivos de desenvolvimento de CCU para portadoras do alelo $\mathrm{DRB} 1 * 1501(\mathrm{OR}=8,52 ; \mathrm{IC}: 3,10-23,43)$ e portadoras do alelo $\mathrm{DRB} 1 * 1602$ quando positivas para HPV-16 (OR=3,13; IC: 1,16-8,45). Riscos semelhantes foram encontrados quando casos portadores das variantes de HPV-16 foram comparados. Foi observado um risco 5.09 vezes maior (IC: $1,39-18,63$ ) de mulheres positivas para variantes do ramo filogenético AA. portadoras do alelo DRB1*1501. desenvolverem CCU. Valor de OR semelhante foi observado em portadoras do alelo de origem indigena $\mathrm{DRB} 1^{*} 1602$ positivas para as mesmas variantes $(\mathrm{OR}=5,98 ; \mathrm{IC}: 1,74-20,48)$ (Tabela 22). Resultados parecidos foram observados quando somente mulheres positivas para variantes B-2 (do ramo AA) foram analisadas, sendo o efeito nesta última comparação mais pronunciado tanto para DRB $1 * 1501$ $(\mathrm{OR}=5,84 ; \mathrm{IC}: 1,57-21,77)$ quanto para $\mathrm{DRB} 1^{*} 1602(\mathrm{OR}=6,83 ; \mathrm{IC}: 1,95-23,98)$ (Tabela 23).

Nenhuma associação foi encontrada entre portadoras dos alelos de DQB1 positivas para variantes AA e o CCU.

A análise das variantes do ramo E mostrou uma tendência de associação positiva com o desenvolvimento de CCU entre pacientes portadoras do grupo DRB $1 * 15(\mathrm{OR}=2,85$; IC: 0,99-8,69), sendo observado um risco positivo significativo para o alelo DRB1*1501 $(\mathrm{OR}=6,77$; IC: 1,91-23,91) (Tabela 24). O alelo DQB1*0602, o qual está em desequilíbrio de ligação com DRBI*1501, também apresentou o mesmo efeito em mulheres positivas para variantes do ramo $\mathrm{E}(\mathrm{OR}=3,33$ (IC: $1,24-8,91)$.

Mulheres com infecção por variantes protótipo (ramo E) também apresentaram um risco elevado de $\mathrm{CCU}$, quando estas eram portadoras do alelo $\mathrm{DRB} 1 * 1501 \quad(\mathrm{OR}=9,92 ; \mathrm{IC}$ : 2,42-40,61). Neste grupo de mulheres com variantes protótipo, o alelo DQBI*0201 apresentou uma tendência de um efeito protetor contra o $\operatorname{CCU}(\mathrm{OR}=0.13$; IC: 0,02-1,09) (Tabela 25).

Não foram observadas associações específicas de alelos HLA com o CCU em mulheres positivas da variante B-12 (ramo E) (Tabela 26). 
Assim, os maiores riscos de desenvolvimento de CCU envolvendo o alelo DRB1*1501 podem ser atribuídos às variantes do ramo $\mathrm{E}$, especialmente a variante protótipo. $\mathrm{E}$ os maiores riscos de CCU em pacientes portadoras do alelo $\mathrm{DRB} 1 * 1602$ podem ser atribuídos às variantes AA, principalmente as variantes B-2, uma vez que esta constitui a maioria das variantes do ramo AA..

Foi sugerido anteriormente que a variante $350 \mathrm{G}$ do gene E6 apresenta maior capacidade de persistência do genoma viral (Londesborough et al., 1996). Esta posição do gene E6 também foi analisada no presente estudo e os resultados encontram-se nas Tabelas 27 e 28 . 


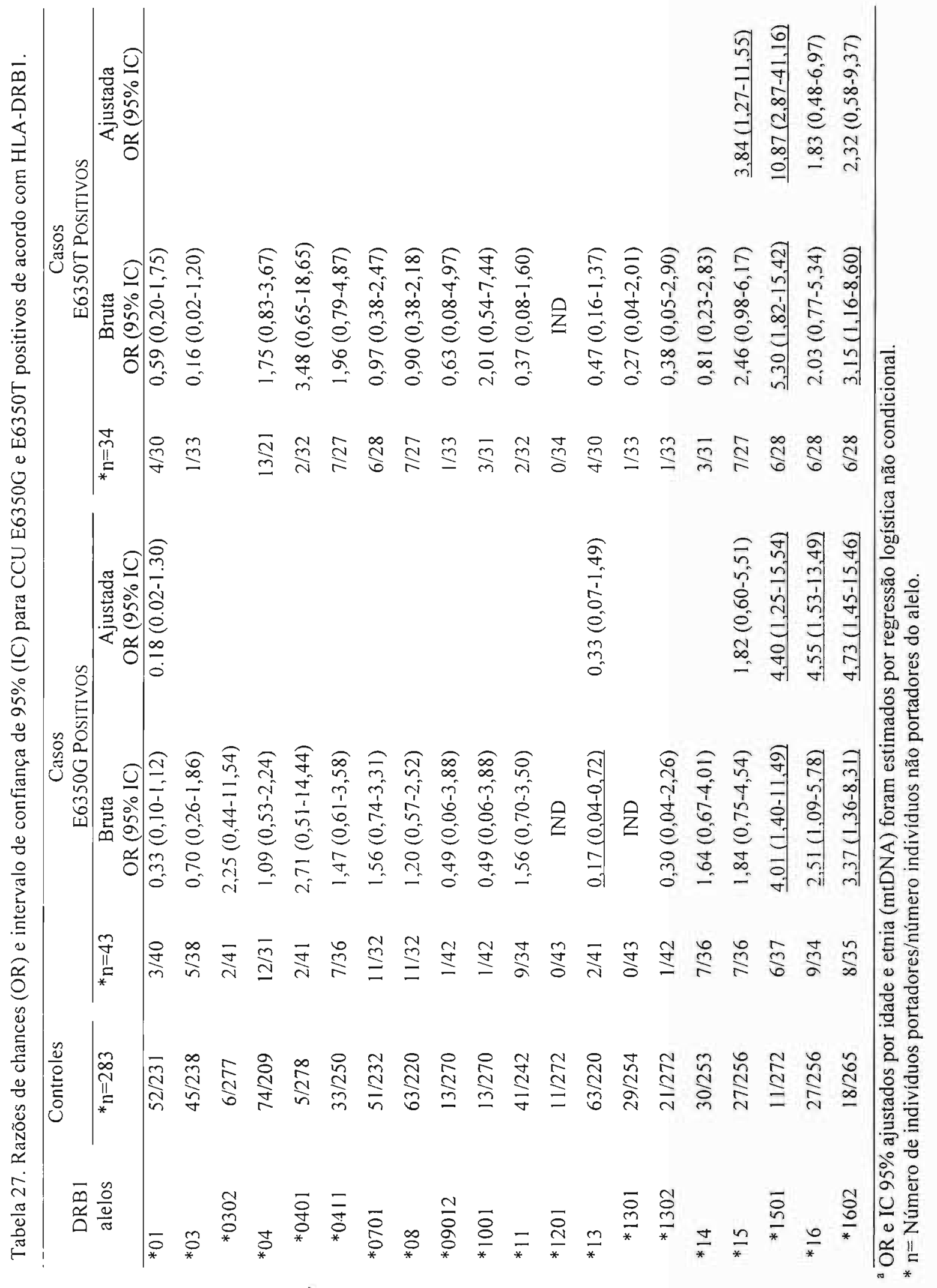




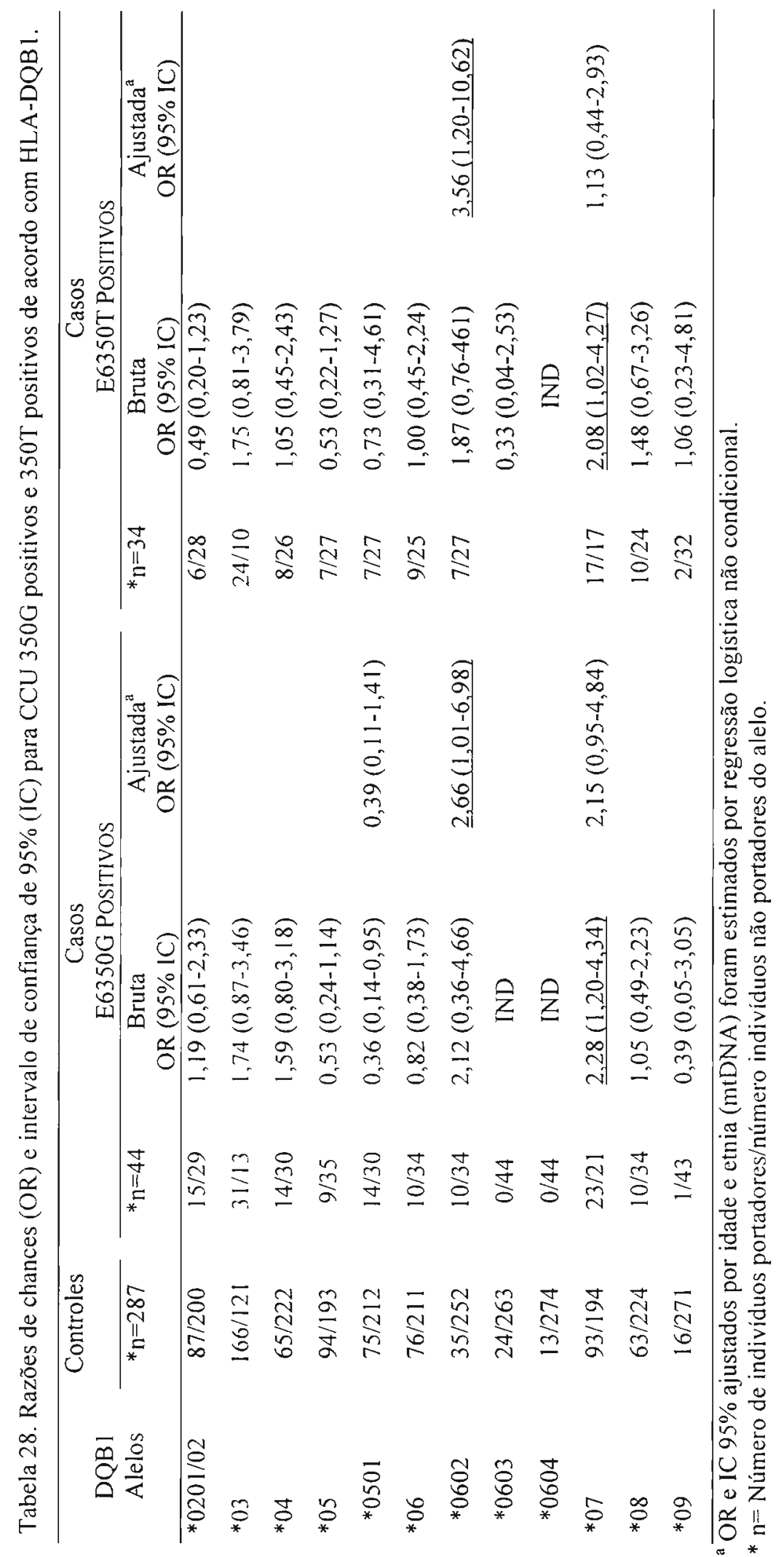


Associações positivas com o CCU foram encontradas envolvendo o grupo DRB $1 * 15$ e mulheres portadoras das variantes E6350T ( $\mathrm{OR}=3,84$; IC:1,27-11,55). Um efeito duas vezes maior foi observado para portadoras do alelo $\mathrm{DRB} 1^{*} 1501$, apesar da imprecisão das estimativas, como indicam as amplitudes dos intervalos de confiança (OR=10,87; IC:2,8741,16) (Tabela 27).

Em mulheres positivas para a variante E6350G, o alelo DRB1*1501 também apresentou uma associação positiva com $\mathrm{CCU}(\mathrm{OR}=4,40$; IC:1,25-15,54). Entretanto, o risco observado foi quase três vezes menor quando comparado ao risco encontrado para mulheres portadoras das variantes $\mathrm{E} 6350 \mathrm{~T}(\mathrm{OR}=10,87$; IC:2,87-41,16). As pacientes positivas para as variantes E6350G e portadoras do alelo DRB1*1602 também apresentaram alta susceptibilidade ao desenvolvimento de $\mathrm{CCU}(\mathrm{OR}=4,73$; IC:1,45-15,46). Já o grupo DQ7 (*0301), o qual está em desequilíbrio de ligação com $\mathrm{DRBI}^{*} 1602$, não foi associado positivamente com o CCU, após o ajuste por idade e etnia.

Um elevado risco de susceptibilidade também foi observado para portadoras do alelo $\mathrm{DQB} 1 * 0602(\mathrm{OR}=3,56 ; \mathrm{IC}: 1,20-10,62)$ tanto no grupo de mulheres positivas para as variantes E6350T quanto no grupo de mulheres com variantes E6350G. Este se encontra em desequilíbrio de ligação com $\mathrm{DRB} 1 * 1501$ que também associou com $\mathrm{CCU}$ nos dois grupos de amostras (Tabela 28). 


\section{DISCUSSÃO}

\subsection{Estudos do tipo Caso-Controle versus Etnia}

Estudos de associação comparam amostras de indivíduos não consangüíneos entre si, afetados pela doença, com indivíduos não afetados da população em geral. Para evitar associações espúrias, o grupo controle deve ser o mais semelhante possível ao grupo de casos: tanto em relação ao período e local de obtenção de amostras quanto a sua composição étnica. Para verificar se a distribuição de alelos HLA entre pacientes com CCU difere da distribuição da população livre de doença, o grupo controle utilizado para comparação com os casos foi coletado em regiões e períodos de tempo próximos dos casos de CCU.

O conhecimento da composição étnica da população envolvida em estudos de associação genética é de extrema importância. uma vez que estas associações podem ser expúrias devido à diferença na prevalência de alguns alelos, neste caso HLA, nas diferentes populações. A maioria dos estudos realiza ajustes estatísticos utilizando a cor da pele em relação a este importante fator de confusão. Entretanto, ainda assim algum erro classificatório pode ocorrer, principalmente se populações com elevado grau de mistura étnica forem consideradas. Hoggart e col. (2003) sugerem que estudos de associação genética do tipo casocontrole deveriam, pelo menos, ser verificados quanto à distância genética entre casos e controles.

Este é o primeiro trabalho que utiliza marcadores genéticos para a definição de grupo étnico em estudos que envolvem associações entre HLA e CCU. Os marcadores genéticos selecionados neste trabalho são baseados em sítios de restrição de fragmentos do mtDNA, os quais são classicamente utilizados nos estudos de definição da estrutura genética de populações humanas, tendo indicado boa diferenciação entre as populações estudadas (Horai 
et al., 1993;Torroni et al., 1993; Torroni et al. 1994; Batista-dos-Santos et al., 1999). A utilização de marcadores do DNA nuclear é adequada para populações com elevada miscigenação como indicam estudos realizados na população brasileira (Zago et al., 1996; Vallinoto et al., 1998; Silva et al., 1999; Batista-dos-Santos et al., 1999).

A historiografia da população de Belém mostra que a miscigenação foi característica marcante desde a sua fundação. De acordo com os registros históricos a miscigenação de ameríndios com europeus durou aproximadamente 150 anos. A partir da segunda metade do século XVIII a cidade começou a receber um significativo fluxo de africanos e nordestinos, o que durou aproximadamente 60 anos (Figueiredo, 2003).

Os dados de estimativas de mistura interétnica (de acordo com o mtDNA), da amostra total analisados para os genes HLA, demonstram que a população de Belém estudada apresenta uma maior contribuição indígena $(60,2 \%)$ seguida pela contribuição africana $(20,7 \%)$ e européia $(19,1 \%)$. O elevado componente indígena na população de Belém sugere que a amostra estudada segue o padrão de povoamento ocorrido nesta região. Portanto, encontram-se de acordo com os registros histórico da população de Belém.

Em 1999, Rodrigues estimou a contribuição étnica da população de Belém utilizando 5 VNTR. Os resultados foram similares aos nossos, com alguma variação nas proporções ( $41 \%$ ameríndio, $34 \%$ europeus e $25 \%$ africanos).

As análises de contribuição étnica do presente estudo usando o DNA nuclear sugerem uma maior contribuição européia entre os controles ( $32 \%$ ameríndio. $45 \%$ europeu e $23 \%$ africano). Uma maior contribuição ameríndia foi encontrada nos casos (37\% ameríndio, $34 \%$ europeu, 29\% africano). Entretanto, apesar das diferenças nas proporções observadas, a participação de cada etnia entre casos e controles é semelhante. tanto pela análise do mtDNA quanto pela análise do DNA nuclear. Estas diferenças não foram significativas em ambas as análises ( $\mathrm{p}=0,426$ e FST= -0,0032, respectivamente). 
$\mathrm{Na}$ análise do mtDNA também foi observada uma maior contribuição de africanos nos casos $(25,3 \%)$ quando comparados aos controles $(18,5 \%)$. O que poderia ter ocorrido devido a diferenças socioeconômicas. Os resultados do censo de 2000 mostram uma marcante diferença econômica associada à classificação cor/etnia, onde a renda mensal de pessoas definidas como negro é $60 \%$ mais baixa do que a renda de pessoas definidas como branco. Além disso, em todas as regiões do mundo o CCU apresenta uma consistente associação com o baixo nível sócio econômico (Franceschi, et al., 2005), advinda da falta de acesso a programas de rastreamento da doença, os quais permitem precoce detecção e tratamento.

\subsection{Associações entre HLA de classe II e CCU}

O grande número de polimorfismos dos alelos HLA gera variações no sítio de reconhecimento do antígeno presente na superfície celular. Estas variações poderiam conferir susceptibilidade ou resistência às infecções por HPV e progressão neoplásica das lesões. A análise da distribuição dos alelos de DRB1 revelou uma significativa associação negativa entre o grupo $\mathrm{DRB} 1 * 01$ e $\mathrm{CCU}(\mathrm{OR}=0,25$, IC: $0,7-0,91)$. Este efeito foi observado em mulheres com idade maior que 40 anos. Um efeito protetor do alelo DRB $1^{*} 0101$ foi anteriormente descrito em mulheres da cidade de João Pessoa (PB) após o ajuste por diferentes variáveis (Maciag et al., 2000).

$\mathrm{Na}$ análise bruta, o grupo $\mathrm{DRB} 1 * 13$ apresentou proteção moderada nos grupos contendo todos os casos ou somente $\mathrm{CCU}$, mas não foi estatisticamente significativa após o ajuste por idade e etnia ( $\mathrm{OR}=0,49$ e $\mathrm{OR}=0,67$, respectivamente). Entrento, este grupo mostrou um efeito protetor contra o CCU em mulheres com idade maior que 40 anos. Tendências de associação foram observadas para o alelo DRB1*1302 em João Pessoa (Maciag et al., 2000). Um efeito protetor significativo do grupo $\mathrm{DRB} 1^{*} 13$ foi observado em populações de mulheres 
brancas: hispânica (Apple et al., 1994; 1995), francesa (Sastre-Garau et al., 1996), sueca (Sanjeevi et al., 1996) e americana (Hildesheim et al., 1998). Os alelos DRB1*1301 e DRB 1 *1302 são comuns tanto em populações africanas quanto em populações européias (Fernandez-Viña et al., 1992), o que poderia explicar resultados concordantes entre diferentes populações.

Foi observada uma forte susceptibilidade de desenvolvimento de CCU em portadoras do alelo DRB1*0401 (OR=5,58; IC: 1,03-30,28). A magnitude desta associação dobrou em mulheres jovens com idade $\leq 34$ anos ( $\mathrm{OR}=11,59$; IC: 1,68-79,86). Entretanto, na análise restrita a casos HPV-16 positivos esta associação não foi observada, provavelmente, devido à baixa freqüência de DRB $1 * 0401$ em Belém. Este resultado foi contrário em mulheres brancas americanas, onde houve um risco significativo maior nos casos HPV-16 positivos comparados aos casos HPV-16 negativos (Madeleine et al., 2002).

O alelo DQB1*0602, o qual está ligado a DRB1*1501, também foi associado positivamente com o CCU nos diferentes grupos de amostras. Associações deste tipo foram observadas em um estudo conduzido na Tanzânia onde a população é constituída principalmente por negros (Wank et al., 1993) e em mulheres suecas (Beskow et al., 2001). Em contraste, esta associação não foi observada em um estudo realizado na população de negros residentes nos Estados Unidos (Gregoire et al., 1994).

Análise dos controles mostrou uma associação positiva entre a infecção por HPV e os alelos do grupo DR*15, este efeito também foi observado em João Pessoa (Maciag et al., 2000). Um risco aumentado de desenvolvimento de CCU foi observado em portadoras do grupo DR15 (OR=3,32, IC: 1,48-7,44). A magnitude da associação entre o alelo DRB1*1501 para todos os casos de CCU debrou após o ajuste por idade e etnia, aumentando de 4,33 (IC: 1,89-9,91) para 8,52 (IC: 3,10-23,43). Os riscos de susceptibilidade ao desenvolvimento de CCU observados para o grupo DRB1*15 são bem mais fortes no grupo de pacientes com idade 
inferior a 40 anos. O que poderia estar correlacionado com variáveis de comportamento tais como número de parceiros e início da atividade sexual. A associação positiva entre os alelos do grupo DR15 e o CCU também foi observada em João Pessoa (OR=2,24, IC: 1,29-3,90), com um efeito pronunciado para DRB1*1503. Este alelo é prevalente em populações africanas mas não em populações européias, nas quais o alelo DRB1*1501 é mais freqüente (Moraes et al., 1993). Em estudos de várias populações, maiores riscos tanto de desenvolvimento de CCU quanto de suas lesões precursoras foram atribuídos aos alelos do grupo DRB $1 * 15$.

Estas associações estão descritas entre mulheres suecas (Sanjeevi et al., 1996; Beskow et al., 2001), e mestiças (de origem européia e ameríndia) do Novo México (EUA), particularmente o alelo DRB1*1501 (Apple et al., 1994;1995).

A maioria dos estudos de diferentes populações descreve associações positivas de $\mathrm{DRB} 1 * 15$ com o $\mathrm{CCU}$, indicando que este grupo confere suscetibilidade ao CCU. Uma vez que DRB1*15 está em desequilíbrio de ligação com o alelo DQB $1 * 0602$, uma possibilidade seria que o efeito fosse atribuído ao alelo de DQB1 ou, ainda, resultaria de efeito aditivo dos 2 loci. Apesar do risco 2 vezes maior de DRB1*15 quando comparado a DQB1*0602, nesta :mostra, não foi possível estimar o efeito de cada alelo no risco, uma vez que DRB 1 * 15 estava em desequilíbrio de ligação absoluto com DQB1*0602. Já o alelo DQB1*0602 foi encontrado ligado a outros alelos o que poderia diminuir o efeito do mesmo no risco de doença. No entanto, em estudos anteriores foi possível observar que a contribuição de DQB 1 *0602 parece ser menor (revisado por Maciag \& Villa, 1999; Maciag et al., 2000).

Beskow e col. (2001) sugerem que o papel do haplótipo DRB1*1501-DQB1*0602 estaria relacionado à inabilidade de eliminar a infecção pelo HPV, uma vez que a freqüência de portadoras deste haplótipo é maior entre mulheres que apresentam infecções persistentes de longa duração pelo HPV quando comparadas às mulheres com infecções persistentes de curta duração. Mais recentemente, Arias-Pulido e col. (2004) demonstraram uma elevada perda de 
heterozigose em pacientes portadoras do haplótipo DRB1*1501-DQB1*0602 quando comparadas a portadoras de haplótipos que conferem baixo risco de desenvolvimento de CCU. Foi sugerido também que a perda de heterozigose ocorreria em eventos iniciais do processo de carcinogênese, por ter sido observada tanto no $\mathrm{CCU}$ quanto em suas lesões precursoras (carcinoma in situ) (Arias-Pulido et al., 2004).

O grupo DR16 apresentou tendência de associação positiva no grupo de amostras de $\mathrm{CCU}(\mathrm{OR}=2,69$ IC: 0,99-7,35), especialmente o alelo DRBI*1602 (OR=2,80, IC: 0,93-8,43). Esta associação foi consistente no grupo restrito a pacientes com CCU HPV-16 positivas $(\mathrm{OR}=3,87 \mathrm{IC}: 1,23-12,14)$. Interessante que $\mathrm{DRB} 1 * 1602$ é um alelo tipicamente encontrado em populações ameríndias da América do Sul. Recentemente, um estudo realizado em uma população boliviana dos Andes também reportou uma associação positiva entre este alelo e risco de CCU HPV positivos (Cervantes et al., 2003).

Quando foi realizada a estratificação por idade das amostras, foi possível observar um risco de susceptibilidade de desenvolvimento de CCU em mulheres com idade $\leq 34$ anos portadoras de $\mathrm{DQB1}{ }^{* 0301}(\mathrm{OR}=3,15 ; \mathrm{IC}: 1,03-9,63)$. Na população de Belém o alelo DQB $1 * 0301$ foi encontrado em desequilíbrio de ligação com 7 diferentes alelos de DRB1. principalmente DRB $1 * 1602$ e DRB1*0401. Estes também foram associados positivamente ao CCU. Em um estudo realizado em outra população brasileira da cidade de João Pessoa (PB), não foi encontrada qualquer associação envolvendo o grupo DQB1*03 ou alelos individuais deste grupo (Maciag et al., 2000). Naquela população DQB1*0301 foi encontrado ligado a 11 alelos de DRB1. Assim, é possível que mesmo tendo sido encontrado em alta freqüência em João Pessoa, o efeito de DQB1*0301 tenha sido diluído devido ao seu desequilíbrio de ligação com um número elevado de diferentes alelos. Deve-se considerar também, as diferenças na contribuição étnica entre as duas regiões brasileiras. 
Associações positivas entre alelos do grupo $\mathrm{DQB} 1{ }^{*} 03$ e o risco de CCU são freqüentes em diferentes populações (David et al.,.1992; Vandelvede et al., 1993; Gregoire et al., 1994; Nawa et al., 1995). Em um estudo realizado na Inglaterra foi observado um maior risco de desenvolvimento de NIC entre as pacientes portadoras do alelo DQB1*0301 (Odunsi et al., 1996). Entretanto, outros trabalhos não encontram associação deste grupo (Wank et al., 1993). Resultados contraditórios também podem ser um indicativo de que tais populações possuem características intrínsecas nas quais interações ambientais e fatores ligados ao hospedeiro podem ser diferentes.

Apesar de DQB 1*0301 não ter sido encontrado associado ao CCU individualmente nas análises envolvendo todos os casos. Este alelo foi encontrado em duas associações haplótipicas importantes envolvendo o grupo DRB1*04 e o alelo DRB1*1602. Um elevado risco foi encontrado para o haplótipo DRB $1 * 0401-\mathrm{DQB} 1 * 0301$ (OR=5,36; IC: 1,15-24-96), sendo restrito ao grupo com todos os casos (que inclui NIC III). Em um estudo anterior, este haplótipo também foi associado positivamente a tumores contendo o DNA de HPV-16 (Madeleine et al., 2002). Associações positivas envolvendo o haplótipo DRB1*0401DQB1*0301 foram vistas tanto em NIC I e III (Odunsi et al., 1996) quanto em CCU (Cuzick et a., 2000; Madeleine et al., 2002). Este haplótipo é representativo de populações européias.

O haplótipo DRBI*1602-DQB1*0301 é considerado um marcador de etnia porque é encontrado unicamente em populações indígenas das Américas (Tsuneto et al., 2003). Sabe-se que a população de Belém possui uma contribuição marcante de ameríndios na sua formação. Desta forma, foi possível encontrar uma associação positiva do haplótipo DRB1*1602DQB $1 * 0301$ com CCU. Os riscos foram de 3,29 vezes (IC: 1,06-10,20) no grupo total de casos e de 4,18 no grupo restrito ao CCU HPV-16 positivo. Uma OR de 3,26 vezes foi encontrada no grupo de mulheres com CCU, no entanto esse valor não foi significativo (IC: 0,87-12,23). Esta é a única associação envolvendo este haplótipo, contudo um risco de 
susceptibilidade para o alelo DRB $1 * 1602$ também foi observado em outra população de origem ameríndia (Cervantes, et al., 2003). Em outros grupos étnicos, o alelo DRB1*1602 é encontrado mais freqüentemente ligado a $\mathrm{DQB} 1 * 0502$. Este por sua vez foi associado ao risco de infecção por HPV-16.

Um efeito protetor foi encontrado contra a infecção por HPV em mulheres portadoras do alelo DRB $1 * 0804$. Este alelo tem sido encontrado em populações indígenas da América do Sul. O alelo DRB $1^{*} 08042$ tem sido identificado em ameríndios. Já o alelo DRB1*08041 é encontrado em países do sub-saara (Tsuneto et al., 2003).

Em Belém, foi encontrada uma associação negativa entre o grupo DQB 1*05 e o CCU em mulheres com idade maior que 40 anos. No estudo realizado em João Pessoa também foi observado um efeito protetor deste grupo (Maciag et al., 2000). Odunsi e col. (1996) descreveram associações negativas de DQB $1 * 0501$ com as lesões precursoras do CCU. Este se encontra em desequilíbrio de ligação com os alelos do grupo DR1 e DR10. Em Belém, foi possível encontrar um efeito protetor do haplótipo DRB1*01-DQB1*05 no grupo de mulheres com CCU. Um efeito parecido foi observado em mulheres inglesas (Odunsi et al., 1996). Além disso, foi demonstrado em outra população brasileira um efeito protetor do haplótipo DRB1*01-DQB1*0501 contra infecção persistente de HPV de longa duração (Maciag et al., 2002).

A comparação dos diversos estudos de associação envolvendo genes HLA e o CCU, nem sempre é possível. Além das diferenças nos tamanhos amostrais e das técnicas empregadas na análise dos genes HLA, as freqüências alélicas são distintas na população em geral das diferentes regiões geográficas. Entretanto, mesmo com essas limitações, é possível observar tendências comuns entre os diversos estudos (revisado por Souza \& Villa, 2003). Muitos estudos investigaram possíveis associações entre alelos e haplótipos HLA e risco de CCU ou infecção por HPV. Os genes mais comumente investigados são HLA-DRB1 e DQB1, 
mas os métodos de análise também podem ser diferentes: os primeiros estudos utilizaram tipagens sorológicas, enquanto atualmente a maioria dos estudos utiliza métodos baseados em PCR. Outra fonte de variação entre os diferentes estudos pode ser o tipo de lesão analisada: alguns analisam casos de CCU invasivo, outros lesões precursoras de diferentes graus. Frente a tais limitações, muitos resultados parecem contraditórios. Deve-se considerar que o CCU é uma doença de caráter multifatorial, e que múltiplos genes podem participar no seu desenvolvimento. Características relacionadas ao vírus tais como variabilidade genética entre diferentes tipos de HPV podem também influenciar no controle da resposta imune, levando a infecções persistentes por HPV oncogênicos, o principal fator de risco para o desenvolvimento do CCU.

\subsection{Variantes de HPV-16 e HLA de Classe II no desenvolvimento de CCU}

As variantes moleculares de HPV-16 foram identificadas a partir da LCR viral, uma vez que esta é uma região com maior variabilidade e está sob menor pressão seletiva, o que a torna mais informativa quando comparada a regiões codificadora. A região analisada neste trabalho não interage diretamente com o complexo HLA e célula T. Entretanto, tem sido demonstrado que as substituições nucleotídicas vistas na LCR viral são compativeis filogeneticamente com a variabilidade encontrada nas regiões codificadoras do genoma viral.

Um dos nossos objetivos foi verificar a distribuição das variantes moleculares de HPV16 entre casos e controles. Porém, não foi possível realizar essa comparação devido ao pequeno número de mulheres com citologia normal HPV-16 positivas $(n=16)$. Contudo, foi possível verificar a distribuição dos alelos HLA entre casos portadores de diferentes variantes de HPV-16 comparados à distribuição da população livre de doença (grupo controle). 
As estratificações das amostras por ramo filogenético ou por variantes individuais revelaram associações estatisticamente significativas com o $\mathrm{CCU}$ envolvendo tanto as variantes do ramo AA quanto às do ramo $\mathrm{E}$. Devido ao pequeno número de amostras, não foi possível realizar a estratificação de acordo com as as variantes do ramo Af.

Quando a freqüência dos alelos ou grupos HLA foi contrastada entre casos HPV-16 positivos e controles, foi encontrada uma alta susceptibilidade ao $\mathrm{CCU}$ entre mulheres portadoras dos alelos $\mathrm{DRB} 1 * 1501$ e $\mathrm{DRB} 1 * 1602$ positivas para as variantes do ramo AA. O mesmo foi visto na análise individual das variantes $\mathrm{B}-2$, o isolado do ramo AA predominante neste grupo de amostras.

Interessante que o risco de susceptibilidade ao CCU encontrado para o alelo de origem ameríndia DRB1*1602 foi restrito ao grupo de variantes AA, particularmente a variante B-2. Este trabalho é o primeiro a mostrar uma associação positiva entre DRB1*1602 e o CCU em mulheres com variantes do ramo AA. É provável que este resultado não seja encontrado em outro grupo étnico onde a variabilidade genética tanto do HLA quanto do HPV pode ser diferente.

As variantes européias não apresentaram riscos significativos de desenvolvimento de CCU envolvendo o alelo DRB $1 * 1602$. Por outro lado, foram observados riscos elevados em portadoras do alelo $\mathrm{DRB} 1^{*} 1501(\mathrm{OR}=6,77)$. Na análise individual, a magnitude desta associação foi quase duas vezes maior para portadoras do HPV-16 protótipo (OR=9.92). Além disso, o risco de desenvolvimento de $\mathrm{CCU}$ envolvendo o alelo $\mathrm{DRB}$ *1501 $^{*}$ foi consideravelmente maior para as variantes protótipo quando comparado ao risco observado para as variantes do ramo AA $(\mathrm{OR}=5,09)$. Por outro lado, nenhuma associação significativa entre alelos HLA e o CCU foi observada no grupo de mulheres positivas para as variantes européias B-12. De fato, esta variante não foi encontrada em mulheres portadoras do alelo 
DRB $1 * 1501$. Desta forma, podemos sugerir que o risco elevado de CCU envolvendo o alelo $\mathrm{DRB} 1^{*} 1501$ é atribuído principalmente ao protótipo e à variante asiático-americana B-2.

Com relação ao alelo DQB 1 *0201, não foi observada uma associação de risco com o CCU. Entretanto, tendências de um efeito protetor foram achadas entre mulheres portadoras de $\mathrm{DQB} 1 * 0201$ positivas para a variante protótipo $(\mathrm{OR}=0,13 ; \mathrm{IC}: 0,02-1,09)$. Este alelo também mostrou um risco diminuído de desenvolvimento de $\mathrm{CCU}$ em mulheres africanas-americanas e norueguesas (Gregoire et al., 1994; Helland et al., 1994).

Na população analisada neste estudo, o alelo DQB $1 * 0602$ apresentou um alto risco de CCU. Esta associação foi consistente somente no grupo de mulheres portando variantes do ramo $\mathrm{E}$, mais especificamente as variantes protótipo $(\mathrm{OR}=4.29)$. Este alelo está em desequilíbrio de ligação com $\mathrm{DRB} 1 * 1501$. Entretanto, ao contrário do observado para DRB $1 * 1501$, não foi vista uma associação positiva de DQB $1 * 0602$ com variantes do ramo AA. Provavelmente devido ao fato de DQB ${ }^{*} 0602$ estar ligado a dois outros alelos de DRB I neste grupo de amostras, favorecendo assim estimativas imprecisas para este alelo. Um estudo anterior realizado na Tanzânia com amostras predominantemente de origem africana, mostrou uma associação positiva entre DQB1*0602 e CCU (Wank et al., 1993). O mesmo efeito foi observado em mulheres suecas (Beskow et al., 2001).

Tem sido sugerida a ocorrência da perda de heterozigose envolvendo o haplótipo DRB1*1501-DQB1*0602 em eventos iniciais do processo de carcinogênese (Arias-Pulido et al., 2004). Por conseguinte, foi demonstrado que mulheres portadoras dos alelos DRB $1 * 1501$ e DQB1*0602 foram mais freqüentes no grupo de mulheres com infecção de longa duração, indicando que esses alelos de classe II contribuem para a inabilidade de eliminar a infecção por HPV (Beskow et al., 2001). Também foi evidenciado que a variante européia 131G do gene E6 de HPV-16 altera um sítio de ligação do peptídeo com a molécula de classe I HLAB7, podendo influenciar no reconhecimento e na resposta pelas células $T$ citotóxicas, o que 
levaria à evasão da resposta imune (Ellis et al., 1995). Somados a estes achados, e de acordo com os riscos elevados de CCU envolvendo a variante asiático americana B-2 e o protótipo (ramo E) na população de Belém, podemos supor que fatores como a perda de heterozigose dos alelos DRB1*1501 e DQB ${ }^{*} 0602$ e a variabilidade do HPV poderiam contribuir para a susceptibilidade destes alelos ao desenvolvimento de CCU.

Os resultados de HLA obtidos para as variantes de HPV-16 (principalmente as variantes $\mathrm{AA}$ ) na população de Belém são corroborados pelos dados epidemiológicos obtidos no nosso grupo, onde foi evidenciada uma maior capacidade de persistência das variantes nãoeuropéias (Villa et al., 2000). Além disso, tem sido demonstrado que as variantes AA apresentam maior atividade transcricional quando comparadas às variantes do ramo $\mathrm{E}$ ou As. Com a variante B-12 apresentando uma atividade quase similar ao controle (Veress et al., 1999; Kozuka et al., 2000).

A maioria das substituições nucleotídicas nas variantes de HPV não origina substituição de aminoácidos. Supõe-se que alterações mais relevantes encontrem-se em regiões antigênicas ou em regiões que interfiram na atividade funcional das proteínas. Londesborough e col. (1996) descreveram que uma substituição na posição 350 do gene E6 $(\mathrm{T} \rightarrow \mathrm{G})$ estaria associada à persistência do genoma viral. Esta substituição gera uma mudança no aminoácido 83 da proteína E6 de leucina para valina. A estratificação das amostras de acordo com as variantes da posição $\mathrm{E} 6350 \mathrm{~T} \rightarrow \mathrm{G}$ mostrou que portadoras do alelo DRB1*1501 apresentam um elevado risco de CCU tanto quando são positivas para a variante E6350T $(\mathrm{OR}=10,87)$ quanto quando são positivas para a variante $\mathrm{E} 6350 \mathrm{G}(\mathrm{OR}=4,40)$. Entretanto, o risco é quase três vezes maior em pacientes positivas para a variante E6350T. Em Belém, a substituição E6350T foi mais freqüentemente encontrada nas variantes do ramo E, sendo que no caso da variante B-12 esta substituição foi encontrada em $50 \%$ dos isolados. Contudo não 
foi possível estimar o risco atribuído a variante européia B-12, uma vez que nenhuma paciente positiva para esta variante portava o alelo $\mathrm{DR} * 1501$.

Em uma amostra de mulheres japonesas foi observado um aumento significativo nas freqüências dos alelos DRB1*1501 e DQB1*0602 entre pacientes positivas para a variante E6350T (Matsumoto et al., 2003). Contudo, em um estudo realizado com mulheres britânicas não foi encontrada uma correlação entre o polimorfismo E6350T $\rightarrow \mathrm{G}$ e os genótipos de HLA ou desenvolvimento de CCU (Brady et al., 1999). A análise do polimorfismo de HLA de classe I em mulheres suecas mostrou que mulheres portadoras dos alelos HLA-B*44, HLAB*51 ou HLA-B*57 positivas para E6350G, apresentavam um risco 5 vezes maior de desenvolver CCU (Zehbe et al., 2003).

Já o alelo de origem indígena DRB $1 * 1602$ foi associado significativamente somente no grupo de mulheres positivas para as variantes E6350G $(\mathrm{OR}=4,73)$. Interessante que esta substituição é encontrada em $95 \%$ dos isolados do ramo AA, nos quais DRB $1 * 1602$ também foi associado ao CCU.

Alguns estudos anteriores tentaram verificar uma possível correlação entre etnia e a distribuição de variantes. Em 2001, Hildesheim e col. utilizando STR (kit Profiler Plus) aplicaram um teste de distância genética entre grupos de mulheres positivas para variantes E e mulheres com variantes não-E. Os resultados não evidenciaram diferenças genéticas significativas entre os dois grupos de mulheres (Hildesheim et al., 2001). Posteriormente, Xi e col. (2002) sugeriu que o risco de aquisição de variantes não-protótipo é maior em homens e mulheres não-brancos, residindo nos Estados Unidos.

Na população de Belém, nenhuma variante de HPV-16 foi mais associada a um determinado grupo étnico caracterizado por mtDNA. Todas as variantes foram encontradas em proporção similar nos três grupos étnicos que compõem a população estudada (europeu, ameríndio e africano). Entretanto, a distribuição das variantes moleculares parece seguir o 
mesmo padrão da contribuição étnica observada em Belém, pois foram encontradas variantes moleculares de HPV-16 representativas dos três principais grupos étnicos humanos (variantes do ramos AA, E e Af). Resultados similares são observados em estudos realizados em populações miscigenadas tais como México (Berumen et al., 2001), Costa Rica (Hildesheim et al., 2001). Já os estudos realizados na Europa encontram na sua maioria variantes européias, assim como na Ásia as variantes mais freqüentes são do ramo As (Kozuka et al., 2000; Chan et al., 2002) e na África as variantes Af prevalecem (Yamada et al., 1997). Vale ressaltar que as variantes européias são encontradas em considerável frequiência em diversas partes do mundo, com exceção da Àfrica. As evidências de que em cada grupo étnico ocorre o aumento da freqüência de determinadas variantes em uma dada população, aliadas ao fato de que o HPV consegue evadir a detecção do sistema imune através das moléculas HLA, são consistentes com o modelo de seleção dirigida por patógeno. Isto supostamente ocasionaria um aumento na freqüência do mesmo na população. Da mesma forma, o processo de seleção poderia favorecer o indivíduo onde seria observado um aumento na freqüência do alelo resistente naquela população (revisado por Meyer \&Thomson, 2001).

Por conseguinte, os dados de HLA mostram que os maiores riscos de CCU observados para o alelo de origem européia $\mathrm{DRB} 1^{*} 1501$ foram atribuídos às variantes do ramo E. Assim como os maiores riscos envolvendo o alelo de origem ameríndia DRB $1 * 1602$ foram restritos às variantes do ramo AA. Além disso, um estudo realizado no Japão mostrou um elevado risco de CCU atribuído ao alelo de origem asiática DRB1*1502. em mulheres portadoras da variante asiática D25E (Matsumoto et al., 2003). Estes resultados indicam a existência de uma relação entre a variabilidade genética do HPV e os diferentes grupos étnicos humanos, corroborando a teoria de que o HPV vem co-evoluindo com o seu hospedeiro por longos períodos de tempo, como o sugerido pelos estudos filogenéticos do HPV-16 e 18 (Ho et al., 1993; Ong et al., 1993). 
O nosso estudo fornece evidências epidemiológicas de que variantes específicas de HPV-16 associadas a certos alelos de HLA classe II estão envolvidos na determinação de risco de CCU. Variações em epítopos de proteínas virais podem tanto alterar a ligação às moléculas HLA, quanto, no caso desta ligação ser preservada, apresentar uma superfície modificada ao receptor da célula T (TCR) (Ellis et al., 1995). Assim, o desempenho das moléculas HLA no risco de CCU está relacionado a uma melhor ou pior resposta imune na eliminação do vírus. No caso do alelo DQB1*0201 a interação resultante com as variantes protótipo (ramo E), levaria a uma resposta imune mais eficaz na eliminação do vírus, uma vez que foi observada uma tendência a um efeito protetor contra o CCU. O oposto seria esperado para as portadoras dos alelos DRB1*1501, DRB1*1602 e DQB1*0602, uma interação ineficiente com o peptídeo antigênico não eliminaria o vírus permitindo a persistência do genoma viral, um fator central no desenvolvimento de CCU (Villa et al., 2000).

Por outro lado, uma alteração ou ligação ineficiente do peptídeo ao TCR poderia afetar a natureza Th1 x Th2 da resposta imune contra o peptídeo viral. Os peptídeos alterados denominados ligantes peptídicos alterados (APL), modificam a proliferação de células T $\mathrm{CD} 4^{+}$ e o padrão de citocinas liberados por estes linfócitos (Murray, 1998). Assim como a proliferação de linfócitos T citotóxicos (CTL) pode ser regulada negativamente (Bertoletti et al., 1994), e desta forma, permitir a persistência do genoma viral. Este seria mais um provável mecanismo de evasão das variantes de HPV, onde algumas delas agiriam como APL ocasionando respostas celulares pouco eficientes. A identificação de epítopos de antígenos tumorais ou peptídeos virais que conferem um efeito protetor ou susceptibilidade poderia se tornar importantes ferramentas no tratamento ou no desenho de vacinas contra o CCU.

Com o objetivo de diminuir a incidência e mortalidade mundial induzida por CCU causado por HPV, dois tipos de vacinas estão atualmente sendo desenvolvidas: vacinas profiláticas para a prevenção da infecção por HPV e vacinas terapêuticas para eliminar a 
infecção e induzir a regressão das lesões causadas por HPV. As vacinas terapêuticas são necessárias para o tratamento das lesões já estabelecidas. Estas são baseadas na indução de uma resposta imune celular contra as proteínas do HPV expressas nas células tumorais. Assim, os produtos dos genes E6 e E7 são potenciais alvos antigênicos para estas vacinas de DNA (revisado por Villa, 2003). A vacina profilática é baseada na indução de anticorpos neutralizantes dirigidos contra epítopos das proteínas do capsídeo viral. A proteção contra a infecção depende da quantidade de anticorpos produzidos pelo hospedeiro, da viabilidade do sítio de infecção e da persistência de anticorpos neutralizantes por um longo período de tempo. Recentemente, foi publicado o resultado de uma vacina quadrivalente que inclui os tipos de HPV de alto risco 16 e 18, e os tipos de baixo risco 6 e 11 . Juntos estes vírus são responsáveis por $70 \%$ dos CCU e das NIC, e $90 \%$ das verrugas anogenitais, respectivamente. Cerca de 277 mulheres foram vacinas e os resultados demonstram que a vacina foi altamente imunogênica. Todas as mulheres desenvolveram altos títulos de anticorpos. Por conseguinte, a incidência de infecção persistente foi $90 \%$ menor em mulheres vacinadas comparada com mulheres vacinadas com o placebo (Villa et al., 2005). A melhor caracterização das respostas imunes disparadas contra o HPV deverá servir de base para o desenvolvimento de melhores abordagens profiláticas e terapeuticas no manejo do CCU. 


\section{CONCLUSÃO}

- 1) Nas amostras de CCU a prevelência das variantes foi de $42 \%$ de variantes do ramo E, $43,2 \%$ de isolado do ramo AA e $4,9 \%$ de variantes do ramo Af. Nas amostras normais foi observado $81 \%$ de variantes do ramo $\mathrm{E}$ e $18 \%$ de variantes do ramo $\mathrm{AA}$.

- 2) Alta susceptibilidade ao desenvolvimento de $\mathrm{CCU}$ foi encontrada envolvendo os alelos DRB1*1501, DRB1*1602, DRB1*0401 e DQB1*0602. Um efeito protetor contra CCU foi observado para o grupo $\mathrm{DRB} 1 * 01$.

- 2.1) Os haplótipos DRB1*1501-DQB1*0602, DRB1*1602-DQB1*0301, DRB1*04DQB1*0301 foram positivamente associados ao CCU. O haplótipo DRB1*01DQB 1*05 foi associado negativamente ao CCU.

- 2.2) Os alelos DRB1*1501, DRB1*0401 e DQB1*0602 foram associados ao risco de CCU em mulheres com idade menor que 40 anos. Um efeito protetor dos grupos $\mathrm{DQB} 1 * 05, \mathrm{DRB} 1 * 01$ e DRB $1 * 13$ foi encontrado em mulheres com idade maior que 40 anos.

- 2.3) Os alelos DRB $1 * 0804, \mathrm{DQB} 1 * 0402$ apresentaram efeito protetor contra positividade para $\mathrm{HPV}$. O alelo $\mathrm{DQB} 1{ }^{*} 0502$ e o grupo $\mathrm{DRB} 1 * 15$ e seus respectivos haplótipos, apresentaram altos riscos de susceptibilidade a infecção por HPV-16.

- 3) A composição étnica entre casos e controles não diferiu significativamente tanto pela análise do mtDNA quanto pela análise do DNA nuclear.

- 3.1) Não foi encontrada uma associação entre distribuição de variantes de HPV-16 e a origem étnica das pacientes, uma vez que a presença das variantes de HPV-16 foi similar dentro de cada grupo étnico. 
- 3.2) Um risco de desenvolvimento de CCU foi observado entre as portadoras do alelo de origem ameríndia DRB $1 * 1602$ positivas para as variantes do ramo asiáticoamericano. O alelo de origem européia $\mathrm{DRB} 1 * 1501$ foi mais fortemente associado ao CCU em portadoras da variante européia protótipo.

- 3.3) Os elevados risco de CCU atribuídos aos alelos DRB*1501 e DRB1*1602 foram principalmente devido à presença da variante asiático-americana $\mathrm{B}-2$ e a variante européia protótipo.

- 3.4) A substituição nucleotídica E6350T foi associada positivamente com o CCU em portadoras do alelo DRB1*1501. Enquanto que as variantes E6350G foram associadas ao $\mathrm{CCU}$ tanto em portadoras do alelo DRB ${ }^{*} 1501$ quanto em portadoras do alelo $\mathrm{DRB} 1^{*} 1602$. 


\section{REFERÊNCIAS BIBLIOGRÁFICAS}

ANDERSON S.; BANKIER, A.T; BARRELL, B.G.; DE BRUIJN, M.H.; COULSON, A.R.; DROUIN, J.; EPERON, I.C.; NIERLICH, D.P.; ROE, B.A.; SANGER, F.; SCHREIER, P.H.; SMITH, A.J.; STADEN, R.; YOUNG, I.G. Sequence and organization of the human mitochondrial genome. Nature, 290 (5806):457-465, 1981.

APPLE, R.J.; BECKER, T.M.; WHEELER, C.M.; ERLICH, H.A. Comparison of human leukocyte antigen DR-DQ disease associations found with cervical dysplasia and invasive cervical carcinoma. J. Natl. Cancer Inst., 87 (6): 427-36, 1995.

APPLE, R.J.; ERLICH, H.A.; KLITZ, W.; MANOS, M.M.; BECKER, T.M.; WHEELER, C.H. HLA DR-DQ associations with cervical carcinoma show papillomavirus-type specificity. Nature Genet., 6: 157-62, 1994.

ARMOUR, J.A.L.; ANTTINEN, T.; MAY C.A. et al. Minisatellites diversity support a recent African origin for modern humans. Natur. Genet., 13:154-160, 1996.

BARBOSA, M.S. \& SCHLEGEL, R. The E6 and E7 genes of HPV-18 are sufficient for inducing two-stage in vitro transformation of human keratinocytes. Oncogene, 4: 1529-32, 1989.

BATISTA-DOS-SANTOS, E.B.; RODRIGUES, J.D.; RIBEIRO-DOS-SANTOS, A.K.; ZAGO, M.A. Differential contribution of indigenous men and women to the formation of an urban population in the Amazon region as revealed by mtDNA and Y-DNA. Am. J. Phys. Antropol., 109 (2): 175-80, 1999.

BATISTA-DOS-SANTOS, S.E.; RODRIGUES, J.D.; RIBEIRO-DOS-SANTOS, A.K.; ZAGO, M.A. Differential contribution of indigenous men and women to the formation of an urban population in the Amazon region as revealed by mtDNA and Y-DNA. Am J Phys Anthropol., 109(2): 175-180, 1999.

BAUER, H.M.; TING, Y.; GREER, C.E.; CHAMBERS, J.C.; TASHIRO, C.J.; CHIMERA, J.; REINGOLD, A.; MANOS, M.M. Genital human papillomavirus infection in students as determined by a PCR-based method. JAMA, 265: 472-77, 1991.

BERNARD, H.; CHAN, S.; MANOS, M.M.; ONG, C.; VILLA, L.L.; DELIUS, H.; PEYTON, C.L.; BAUER, H.M.; WHEELER, C.H. Identification and assesment of known and novel human papillomavirus by polimerase chain reaction amplification, restriction fragment polymorphisms, nucleotide sequence, and phylogeny algorithms. J. Infec. Dis., 170: 1077-85, 1994.

BERNARD, H.U. Gene expression of genital human papillomaviruses and considerations on potential antiviral approaches. Antiviral therapy, 7: 219-37, 2002.

BERNARD, H.U. The clinical importance of the nomenclature, evolution and taxonomy of human papillomaviruses. J. Clin. Virol., 32S: S1-S6, 2005.

BERTOLETTI A, SETTE A, CHISARI FV, PENNA A, LEVRERO M, DE CARLI M, FIACCADORI F, FERRARI C Natural variants of cytotoxic epitopes are T-cell receptor antagonists for antiviral cytotoxic T cells. Nature.369(6479):407-410, 1994. 
BERTORELLE, G.; EXCOFFIER, L. Inferring Admixture proportion from molecular data. Mol. Biol. Evol. 15 (10): 1298-1311, 1998.

BERTORELLE, G.; EXCOFFIER, L. Inferring admixture proportions from molecular data. Mol. Biol. Evol. 15 (10): 1298-1311, 1998.

BERUMEN J; ORDONEZ RM; LAZCANO E; SALMERON J; GALVAN SC; ESTRADA RA; YUNES E; GARCIA-CARRANCA A; GONZALEZ-LIRA G; MADRIGAL-DE LA CAMPA A. Asian-American variants of human papillomavirus 16 and risk for cervical cancer: a case-control study. J Natl Cancer Inst., 93(17):1325-30, 2001.

BESKOW AH, JOSEFSSON AM, GYLLENSTEN UB. HLA class II alleles associated with infection by HPV16 in cervical cancer in situ. Int. J. Cancer. 93(6):817-822, 2001.

BIGNON, J. D. ; FERNANDEZ-VIÑA, M. $12^{\text {th }}$ IHWC HLA class II reference protocol. In: Twelfth International Histocompatibility Workshop and conference - Technical Handbook, 1994.

BJORKMAN, P.J.; SAPER, M.A.; SAMRAOUI, B.; BENNETT, W.S.; STROMINGER, J.L.; WILEY, D.C.; Structure of the human class I histocompatibility antigen, HLA-A2. Nature, 320: 506-12, 1987.

BOSCH, F.X.; MANOS, M.M.; MUÑOZ, N., SHERMAN, M.; JANSEN, A.M.; PETO, J.; SCHIFFMAN, M.H.; MORENO, V.; KURMAN, R.; SHAH, S.K. AND THE IBSCC STUDY GROUP. Prevalence of human papillomavirus in cervical cancer: a worldwide perspective. J. Natl. Cancer Inst., 87: 796-802, 1995.

BOSCH, F.X.; MUÑOZ, N.; DE SANJOSÉ, S.; GUERRERO, E.; GAFFARI, A.M.; KALDOR, J.; CASTELLSAGUÉ, X.; SHAH, K.V. Importance of human papillomavirus endemicity in incidence of cervical cancer: an extension of hypothesis on sexual behavior. Cancer Epidemiol. Biomarkers Prev., 3: 375-79, 1994.

BRADY CS, DUGGAN-KEEN MF, DAVIDSON JA, VARLEY JM, STERN PL. Human papillomavirus type $16 \mathrm{E} 6$ variants in cervical carcinoma: relationship to host genetic factors and clinical parameters. J. Gen. Virol., 80(12):3233-40, 1999.

BROWN, J.H.; JARDETZKY, T.S.; GORGA, J.C.; STERN, L.J.; URBAN, R.G.; STROMINGER, J.L.; WILEY, D.C. Three-dimentional structure of the human class II histocompatibility antigen HLA-DR1. Nature, 364: 33-9, 1993.

CALLEJA-MACIAS IE; KALANTARI M; HUH J; ORTIZ-LOPEZ R; ROJAS-MARTINEZ A; GONZALEZ-GUERRERO JF; WILLIAMSON AL; HAGMAR B; WILEY DJ; VILLARREAL L; BERNARD HU; BARRERA-SALDANA HA. Genomic diversity of human papillomavirus-16,18,31, and 35 isolates in a Mexican population and relationship to European, African, and Native American variants. Virology, 319(2):315-23, 2004.

CASTELLSAGUÉ, X.; GHAFFARI, A.; DANIEL, R.W.; BOSCH, F.X.; MUÑOZ, N.; SHAH, K.V. Prevalence of penile human papillomavirus DNA in husbands of women with and without cervical neoplasia: A study in Spain and Colombia. J. Infect. Dis., 176: 353-61. 1997.

CAVALLI-SFORZA, L.L.; MENOZZI, P.; PIAZZA, A. The history and geography of humans genes. Princeton, Princeton University, 1994. 518p. 
CERDAS-FLORES, R.M.; BUDOWLE, B.; JIN, L.; BARTON, S.A.; DEKA, R.; CHAKRABORTY, R. Maximum likelihood estimates of admixture in Northeastern Mexico using 13 Short Tandem Repeat loci. Am. J. Hum. Biol. 14: 429-439, 2002.

CHAKRABORTY R. Gene identity in racial hybrids and estimation of admixture rates rares. In: Neel JV, Ahuja Y, editors. Genetic microdifferenciation in man and other animals. New Delhi: Indian Anthropological Association. p. 171-180, 1985.

CHAKRABORTY, R.; DEKA, R.; JIN, L.; FERRELL, R.E. Allele sharing at six VNTR loci and genetic distances among three ethnically defined human populations. Am. J. Hum. Biol., 4: 387-397, 1992.

CHAKRABORTY, R.; KAMBOH, M.I.; FERRELL, R.E. Unique alleles in admixed populations: a strategy for determining hereditary population differences of disease frequencies. Ethnic Disease, 1: 245-56, 1991.

CHAN PK, LAM CW, CHELNG TH, LI WW, LO KW, CHAN MY, CHEUNG JL, XU LY, CHENG AF. Human papillomavirus type 16 intratypic variant infection and risk for cervical neoplasia in southern China. J. Infect Dis., 186(5):696-700, 2002.

CHAN, S.Y.; BERNARD, H.U.; ONG, C.K.; CHAN, S.P.; HOFMANN, B.; DELIUS, H. Phylogenetic analysis of 48 papillomavirus types and 28 subtypes and variants: a showcase for the molecular evolution of DNA viruses. J. Virol., 66: 5714-25, 1992b.

CHAN, S.Y.; HO, L.; ONG, C.K.; CHOW, V.; DRESCHER, B.; DUERST, M.; TER MEULEN, J.; VILLA, L.; LUANDE, J.; MGAYA, H.N.; BERNARD, H.U. Molecular variants of human papillomavirus -16 from four continents suggest ancient pandemic spread of the virus and its coevolution with humankind. J. Virol., 66: 2057-66, 1992a.

CRUZ MR, CERQUEIRA DM, CRUZ WB, CAMARA GN, BRIGIDO MM, SILVA EO, CARVALHO LG, MARTINS CR. Prevalence of human papillomavirus type 16 variants in the Federal District, Central Brazil. Mem Inst Oswaldo Cruz. 99(3):281-2, 2004.

CUZICK, J.; TERRY, G.; HO, L.; MONAGHAN, J.; LOPES, A.; CLARKSON, P.; DUNCAN, I. Association between high-risk HPV types, HLA DRB1* and DQB ${ }^{*}$ alleles and cervical cancer in British women. Br. J. Cancer., 82 (7):1348-52, 2000.

DAVID, A.L.M.; TAYLOR, G.M.; GOKHALE, D.; APLIN, J.D.; SEIF, M.W.; TINDALL, V.R. HLA-DQB 1*03 and cervical intraepithelial neoplasia type III. Lancet, 340: 52, 1992.

DE ARAUJO SOUZA, P.S.; VILLA, L.L. Genetic susceptibility to infection with human papillomavirus and development of cervical cancer in women in Brazil. Mut. Res. 544: $375-$ $83,2003$.

DE VILLIERS, E.M.; FAUQUET, C.; BROKER, T.R.; BERNARD, H.U.; ZUR HAUSEN. H. Classification of papillomaviruses. Virology, 324: 17-27, 2004

DEAN, M.; STEPHENS, J.C.; WINKLER, C.; LOMB, D.A.; RAMSBURG, M.; BOAZE, R.; STEWART, C. et al. Polymorphic admixture typing in human ethnic populations. Am. J. Hum. Genet., 55: 788-808, 1994.

DEKA, R.; DECROO, S.; YU, L.M.; FERRELL, R.E.; Variable number oftandem repeat (VNTR) polymorphism at locus D17S5 (YNZ22) in four ethnically defined human populations. Hum. Genetics, 90: 86-90, 1992. 
DEKA, R; CHAKRABORTY, R.; DECROO, S.; ROTHHAMMER, F.; FERRELL, R.E. Characteristics of polymorphism at a VNTR locus 3' to the apolipoprotein B gene in five human populations. Am. J. Hum. Genet., 51: 1325-33, 1992.

DEMBIC, Z.; HAAS, W.; WEISS, S.; McCUBREY, J.; KIEFER, H.; von BOEHMER, H.; STEINMETZ, M. Transfer of specificity by murine $\alpha$ and $\beta$ T-cell receptor genes 232-38, 1986.

DOORBAR, J. Large stages of the papillomavirus life cycle. Papillomavirus Report, 9 (5): 119-26, 1998.

DUPANLOUP, I; BERTORELLE, G. Inferring admixture proportions from molecular data: extension to any number of parental populations. Mol. Biol. Evol. 18(4): 672-675, (2001).

DYSON, N.; HOWLEY, P.M.; MÜNGER, K.; HARLOW, E. The human papillomavirus 16 E7 oncoprotein is able to bind to the retinoblastoma gene product. Science, 243: 934-37, 1989.

ELLIS, J.R.M.; KEATING, P.J.; BAIRD, J.; HOUNSELL, E.F.; RENOUF, D.V.; ROWE, M.; HOPKINS, D.; DUGGAN-KEEN, M.F.; BARTHOLOMEW, J.S.; YOUNG, L.S.; STERN, P.L. The association of an HPV16 oncogene variant with HLA-B7 has implications for vaccine design in cervical cancer. Nature Med., v.1 p.464-70, 1995.

ESCHLE, D.; DÜRST, M.; TER MEULEN, J.; LUANDE, J.; EBERHARDT, H.C.; PAWLITA, M.; GISSMAN, L. Geographical dependence of sequence variation in the E7 gene of human papillomavirus type 16. J. Gen. Virol., 73: 1829-32, 1992.

FAVRE, M.; BREITBURD, F.; CROISSANT, O.; ORTH, G. Structural polypeptides of rabbit, bovine papilloma viruses. J. Virol., 15: 1239-47, 1975.

FERLAY, J.; BRAY, F.; PISANI, P. GLOBOCAN 2002: cancer incidence, mortality and prevalence worldwide. IARC CancerBase No. 5. Version 2.0 Lyon: IARC Press, 2004.

FERNANDEZ-VIÑA, M.; TIERCY, J.M.; TONAL, R.; KATOVICH-HURLEY, C.; TSAI, J.; STASTNY, P. DNA typing of DRB1 and DRB3 DR53-related specificities. In: TSUJI, K.; AIZAWA, M.; SASAZUKI, T. HLA 1991 - Proceeding of the eleventh International Histocompatibility Workshop and Conference. Nova York: Oxford Scientific Publications, v, 1, 471-77, 1992.

FIGUEIREDO, A. M. Belém dos imigrandes: história e memória, 1616 -2004 Belém : Museu de Arte de Belém, 2004.

FRANCESCHI S. The IARC commitment to cancer prevention: the example of papillomavirus and cervical cancer. Recent Results Cancer Res.,166: 277-297, 2005.

FRANCO, E.; VILLA, L.; ROHAN, T.; FERENCZY, A.; PETZL-ERLER, M.; MATLASHEWSKI, G. Design and methods of the Ludwig-McGill longitudinal study of the natural history of human papillomavirus infcetion and cervical neoplasia in Brazil. LudwigMcGill Study Group. Rev. Panam. Salud Publica, 6(4): 223-33, 1999.

FRANCO, E.L.; VILLA, L.L.; RICHARDSON, H.; ROHAN, T.; FERENCZY, A. Epidemiology of cervical human papillomavirus infection. In: Franco, E. L. and Monsonego, J. Ed. New Developments in Cervical Cancer and Prevetion. WHO/EUROGIN monograph, Blackwell Science p.14-22, 1997. 
FRALIMENI JR.; DEVESA, S.S.; HOOVER, R.N.; KINLEN, L.J. Epidemiolgy of cancer. In: De Vita jr. V.T.; Hellman, S.; Rosenberg, S.A. Cancer: principles and pratice of oncology. $4^{0}$. Ed. Philadelphia: J.B. Lippincott Co., p. 150-81, 1993.

GILES RE, BLANC H, CANN HM, WALLACE DC. Maternal inheritance of human mitochondrial DNA. Proc Natl Acad Sci., 77(11): 6715-9, 1980.

GONZALEZ-LOSA MDEL R, RODRIGUEZ-ANGULO E, MANZANO-CABRERA L, MEJIA-CAMARA J, PUERTO-SOLIS M. Detection of unusual strains of RV in patients with acute diarrhoea in Mexico. J. Clin Virol., 32(4): 325-328, 2005.

GREGOIRE, 1.; LAWRENCE, W.D.; KUKURUGA, D.; EISENBREY, A.B.; LANCASTER, W.D. Association between HLA-DQB1 alleles and risk for cervical cancer in africanamerican women. Int. J. Cancer, 57: 504-07, 1994.

HARDING, R. VNTRs in review. Evol. Anthropol., 1: 62-71, 1992.

HELLAND A, BORRESEN AL, KRISTENSEN G, RONNINGEN KS. DQA1 and DQB 1 genes in patients with squamous cell carcinoma of the cervix: relationship to human papillomavirus infection and prognosis Cancer Epidemiol. Biomarkers Prev., 3(6): 479-486, 1994.

HERTZBERG, M.; MICKLESON, K.N.P.; SERJEANNTSON, S.W.; PRIOR, J.F.; TRENT, R.J. An asian-specific 9 pb deletion of mitochondrial DNA is frequently found in polinesians. Am. J. Hum. Genet., 44: 504-10, 1989.

HILDESHEIM, A.; SCHIFFMAN, M.; SCOTT, BROMLEY, C.; WACHOLDER, S.; HERRERO, R.; RODRIGUEZ, A.C.; BRATTI, M.C.; SHERMAN, M.E, LIN, U.S.Q-Q.; TERAI, M.; BROMLEY, R.L.; BUETOW, K.; APPLE, R.J.; BURK, R.D. Human papillomavirus type 16 variants and risk of cervical cancer. J. Nat. Cancer Institute, 93 (4): 315-318, 2001.

HILDESHEIM, A.; SCHIFFMAN, M.; SCOTT, D.R.; MARTI, D.; KISSNER, T.; SHERMAN, M.E.; GLASS, A.G.; MANOS, M.M.; LORINCZ, A.T.; KURMAN, R.J.; BUCKLAND, J.; RUSH, B.B.; CARRINGTON, M. Human leukocyte antigen class I/II alleles and development of human papillomavirus-related cervical neoplasia: results from a case-control study conducted in the United States. Cancer Epidemiol. Biomarkers Prev., 7 (11):1035$41,1998$.

HO, L., CHAN S.Y.; BURK, R.D.; DAS, B.C.; FUJINAGA, K.; ICENOGLE, J.P.; KAHN, T.; KIVIAT, N.; LANCASTER, W.; MAVROMARA-NAZOS, P.; LABROPOULOU, V.; MITRANI-ROSENBAUM, S.; NORRILD, B.; PILLAI, M.R.; STOERKER, J.; SYRJAENEN, K.; TAY, S.K.; VILLA, L.L.; WHEELER, C.M.; WILLIAMSON, A.L.; BERNARD, H.U. The genetic drift of human papillomavirus type 16 is a means of reconstructing prehistoric viral spread and the movement of ancient human populations. J. Virol., 67: 6413-23, 1993.

HO, L.; CHAN, S.Y.; CHOW, V.; CHONG, T.; TAY, S.K.; VILLA, L.L.; BERNARD, H.U. Sequence variants of human papillomavirus type 16 in clinical samples permit verification and extension of epidemiological studies and construction of a philogenetic tree. J. Clin. Microbiol., 29: 1765-72, 1991.

HORAI, S.; HAYASAKA, K. Intraspecific nucleotide sequence differences in the major noncoding region of human mitochondrial DNA. Am. J. hum. Genet., 48: 828-42,1990. 
HORAI, S.; KONDO, R.; HATTORI, Y.N.; HAYASHI, S.; SONODA, S.; TAJIMA, K. Peopling of the Americas, founded by four major lineages of mitochondrial DNA. Mol. Biol. Evol., 10: 23-47, 1993.

HUTZ, M.H.; MATTEVI, V.S.; CALLEGARI-JACQUES, S.M.; SALZANO, F.M.; COIMBRA JR., C.E.A.; SANTOS, R.V.; CARNESE, R.F.; GOICOECHEAS, A.S.; DEJEAN, C.B. D1S80 locus variability in South American Indians. Ann. Hum. Bio., 24: 249-255, 1997.

IARC Working Group. IARC Monogr. Eval. Carcinog. Risk Chem. Man. v. 64, 1995.

ICENOGLE, J.P.; SATHY, P.; MILLER, D.L.; TUCKER, R.A.; RAWLS, W.E. Nucleotide and amino acid sequence variation in the $\mathrm{L} 1$ and $\mathrm{E} 7$ open reading frames of human papillomavirus type 6 and type 16. Virology, 184: 101-7, 1991.

INCA - INSTITUTO NACIONAL DO CÂNCER. Estimativas da incidência e mortalidade por câncer no Brasil; Rio de Janeiro, 1999.

INGMAN $M$, KAESSMANN $H$, PAABO $S$, GYLLENSTEN U. Mitochondrial genome variation and the origin of modern humans. Nature, 410(6828): 61 1, 2001.

JEON, S.; LAMBERT, P.F. Integration of human papillomavirus type 16 DNA into human genome leads to increased stability of E6 and E7 mRNAs: implications for cervical carcinogenesis. Proc. Natl. Acad. Sci. USA, 92: 1654-58, 1995.

JUNES, K.S. Variabilidade intratípica de HPV 16 e 18 em carcinomas do colo do útero de uma área de alto risco para o câncer cervical. Belém, 2000. 98 p. Dissertação de Mestrado Centro de Ciências Biológicas da Universidade Federal do Pará.

KATSUYAMA, Y.; INOKO, H.; IMANISHI, T.; MIZUKI, N.; GOJOBORI, T.; OTA, M.; Genetic relationships among japanese, northern Han, Hui, Uygur, Kazakh, Greek, Saudi Arabian, and Italian populations based on allelic frequencies at four VNTR (D1S80, D4S43, COL2A1, D17S5) and one STR (ACTBP2) loci. Hum. Hered., 48 (3): 126-37, 1998

KIMURA, M.; OHTA, T. Stepwise mutation model and distribution of allelic frequencies in a finite. population. Proc Natl Acad Sci., 75(6): 2868-2872, 1978.

KOZUKA, T.; AOKI, Y.; NAKAGAWA, K.; OHTOMO, K.; YOSHIKAWA, H.; MATSUMOTO, K.; YOSHIIKE, K.; KANDA, Y. Enhancer-promoter activity of human papillomavirus type 16 long control region isolated from cell lines $\mathrm{SiHa}$ and CasKi and cervical cancer biopsies. Jpn. J. Cancer 91: 271-279, 2000.

LIZANO, M. \& GARCIA-CARRANCÁ, A. Variantes moleculares de papiloma virus humanos 16, 18 y 45 en tumores del cuello uterino, en México. Gac. Med. Mex., 133 (1): 43-48, 1997 a.

LONDESBOROUGH, P.; HO, L.; TERRY, G.; CUZICK, J.; WHEELER, C.; SINGER, A. Human papillomavirus genotype as a predictor of persistence and development of highgrade lesions in women with minor cervical abnormalities. Int. J. Cancer., 69: 364-68, 1996.

LÖRINCZ, A.T.; REID, R.; JENSON, A.B.; GREENBERG, M.D.; LANCASTER, W.; KURMAN, R.J. Human papillomavirus infection of the cervix: relative risk associations of 15 common anogenital types. Obstet. Gynecol., 79: 328-37, 1992. 
MACIAG, P.C. \& VILLA, L.L. Genetic susceptibility to HPV infection and cervical cancer. Braz. J. Med. Biol. Res., 32: 915-22, 1999.

MACIAG, P.C.; SCHLECHT, N.; ARAUJO-SOUZA, P.S.; FRANCO, E.L.; PETZL-ERLER, M.L.; VILLA, L.L. Major histocompatibility complex class II polymorphism and risk for cervical cancer and human papillomavirus infection in Brazilian women. Cancer Epidemiol. Bio. Prev., 9: 1183-91, 2000.

MACIAG, P.C.; VILLA, L.L.; Genetic susceptibility to HPV infection and cervical cancer. Braz. J. Med. Biol. Res. 32: 915-22, 1999.

MATSUMOTO $\mathrm{K}$, YASUGI T, NAKAGAWA S, OKUBO M, HIRATA R, MAEDA $H$, YOSHIKAWA H, TAKETANI Y. Human papillomavirus type 16 E6 variants and HLA class II alleles among Japanese women with cervical cancer. Int. J. Cancer., 106(6):919-922, 2003.

MEYER D, THOMSON G. How selection shapes variation of the human major histocompatibility complex: a review. Ann. Hum. Genet., 65(1):1-26, 2001.

MORAES, M.E; FERNANDEZ-VIÑA, M.; SALATIEL, I.; TSAI, S.; MORAES, J.R.; STASTNY, P. HLA class II DNA typing in two Brazilian populations. Tissue Antigens, 41: $238-42,1993$

MOSS, D.J.; KHANNA, R. Major histocompatibility complex: from genes to function. Imunol., Today, 20 (4): 165-67, 1999.

MUNÕZ, N.; Human papillomavirus and cervical cancer: epidemiological evidence. . In: Franco, E.L. and Monsonego, J. Ed. New Developments in Cervical Cancer Screening and Prevention. WHO/EUROGIN monograph, Blackwell Science, p. 374-79, 1997.

MURRAY JS. How the MHC selects Th1/Th2 immunity. Immunol. Today, 19(4):157-63. 1998

NAWA, A., NISHIYAMA, Y., KOBAYASHI, T., WAKAHARA, Y., OKAMOTO, T., KIKKAWA, F., SUGANUMA N., GOTO, S., KUZUYA, K.; TOMODA, Y. Association of human leukocyte antigen-B $1 * 03$ with cervical cancer in Japanese women aged 35 years and younger. Cancer, 75: 518-21, 1995.

NINDL, I.; RINDFLEISCH, K.; LOTZ, B.; SCHNEIDER, A.; DÜRST, M. Uniform distribution of HPV 16 E6 and E7 variants in patients with normal histology, cervical intra-epithelial neoplasia and cervical cancer. Int. J. Cancer, 82: 203-7, 1999 b.

NORONHA, V.; MELLO, W.; VILLA, L.; BRITO, A.; MACÊDO, R.; BISI, F.; MOTA, R.; SASSAMOTO, K.; MONTEIRO, T.; LINHARES, A. Papilomavírus humano associado a lesões de cérvix uterina. Rev. Soc. Bras. Med. Trop., 32 (3): 235-40, 1999.

NOVELLI, G.; SPINELLA, A.; GENNARELLI, M.; MINGARELLI, R.; DALLAPICCOLA, B. Análisis of Apo-B, HLADQ alpha, and DIS80 polymorphisms in the Italian population using the polymerase chain reaction. Am. J. Hum. Biol., 4: 381-386, 1992.

O'CONNOR, M.; CHAN, S.Y.; BERNARD, H.U. Transcription factor binding sites in the LCR of genital HPVs. In: Myers, G. et al. Human Papillomaviruses. A compilation and analysis of nucleic acid and amino acid sequences. Los Alamos National Laboratory, p. III 21-41, 1995. 
ODUNSII, K.; TERRY, G.; HO, L.; BELL, J.; CUZICK, J.; GANESAN, T.S. Susceptibilidade to human papillomavirus-associated cervical intra-epithelial neoplasia is determined by specific HLA DR-DQ alleles. Int. J. Cancer, 67: 595-02, 1996.

ONG, C.K.; CHAN, S.Y.; CAMPO, M.S.; FUGINAGA, K.; MAVROMARA-NAZOS, P.; LABROPOULOU, V.; PFISTER, H.; TAY, S.K.; TER MEULEN, J.; VILLA, L.L.; BERNARD, H.U. Evolution of human papillomavirus type 18: an ancient phylogenetic root in Africa and intratype diversity reflect co evolution with human ethnic groups. J. Virol., 67: 6424-31, 1993.

Parsons TJ.; Holland, M.M.; mitochondrial mutation rate revised: hot spots and polymorphism Nat. Gen., 18: 110, 1998

PICCONI, A.; ALONIO, L.V.; SICHERO, L.; GOZÁLEZ, J.V.; GRONDA, J.; MIRANDA, S.; VILLA, L.L.; TEYSSIÉ, A.R. Virus papilloma humano (HPV) en mujeres Quechuas: tipos virales y variantes de HPV-16. In: Congreso Argentino de Virologia, Buenos Aires, Argentina. Resumos, agosto 1999.

REMMINK, A.J.; WALBOOMERS, J.M.M.; HELMERHORST, T.J. M.; VOORHORST, F.J.; ROZENDAAL, L.; RISSE, E.K.J.; MEIJER, C.J.L.M.; KENEMANS, P. The presence of persistent high-risk HPV genotypes in dysplastic cervical lesions is associated with progressive disease: natural history up to 36 months. Int. J. Cancer, 61: 306-11, 1995.

RIBEIRO-DOS-SANTOS, A.K.; PEREIRA, J.M.; LOBATO, M.R.; CARVALHO, B.M.; GUERREIRO, J.F.; BATISTA-DOS-SANTOS, S.E. Dissimilarities in the process of formation of Curiau, a semi-isolated Afro-Brazilian population of the Amazon region. Am. J. Hum. Biol., 14(4):440-447, 2002.

RODRIGUES, J.A. Análise da estrutura genética da população de Belém utilizando polimorfismos de DNA nuclear, mitocondriais e do cromossomo Y. Belém, 1999. 177p. Dissertação de Mestrado - Centro de Ciências Biológicas da Universidade Federal do Pará.

SAMBROOK, J.; FRITSCH, E.F.; MANIATIS, T. Molecular cloning: a laboratory manual, $2^{0}$ Ed., New York: Cold Spring Harbor Laboratory Press, 1989.

SVEJGAARD, A.; RYDER, L.P. HLA and disease association: detecting the strongest association. Tissue Antigens, 43: 18-27, 1994.

SANJEEVI, C.B.; HJELMSTRÖM, P.; HALLMANS, G.; WIKLUND, F.; LENNER, P.; ANGSTRÖM, T.; DILLNER, J. LERNMARK, A. Different HLADR-DQ haplotypes are associated with cervical intraepithelial neoplasia among human papillomavirus type-16 seropositive and seronegative swedish women. Int. J. Cancer, 68: 409-14, 1996.

SASTRE-GARAU, X.; LOSTE, M.N.; VINCENT-SALOMON, A.; FAVRE, M.; MOURET, E.; ROCHEFORDIERE, A. DE LA.; DURAND, J.C.; TARTOUR, E.; LEPAGE, V.; CHARRON, D. Decreased frequency of HLA-DRB ${ }^{*} 13$ alleles in French woman with HPVpositive carcinoma of the cervix. Int. J. Cancer (Pred. Oncol.), 69: 159-64, 1996.

SCHEFFNER, M.; HUIBREGTSE, J.M.; VIERSTRA, R.D.; HOWLEY, P.M. The HPV-16 E6 and E6-AP complex functions as a ubiquitin-protein ligase in the ubiquitination of $\mathrm{p} 53$. Cell, 75: 495-505, 1993. 
SCHEFFNER, M.; WERNESS, B.A.; HUTBREGTSE, J.M.; LEVINE, A.J.; HOWLEY, P.M. The E6 oncoprotein encoded by human papillomavirus types 16 and 18 promotes the degradation of p53. Cell, 63: 1129-36, 1990.

SCHIFFMAN, M.H.; BAUER, H.M.; HOOVER, R.N.; GLASS, A.G.; CADELL, D.M.; RUSH, B.B.; SCOTT, D.R.; SHERMAN, M.E.; KURMAN, R.J.; WACHOLDER, S.; STANTON, C.K.; MANOS, M.M. Epidemiological evidence showing papillomavirus infection causes most cervical intraepithelial neoplasia. J. Natl. Cancer Inst., 85: 958-64, 1993.

SCHNEIDER, S.,ROESSLI, D., AND EXCOFFIER, L. Arlequin: A software for population genetics data analysis. Ver 2.000. Genetics and Biometry Lab, Dept. of Anthropology, University of Geneva, 2000.

SEDMAN SA, BARBOSA MS, VASS WC, HUBBERT NL, HAAS JA, LOWY DR, SCHILLER JT. The full-length E6 protein of human papillomavirus type 16 has transforming and trans-activating activities and cooperates with E7 to immortalize keratinocytes in culture. J. Virol., 65(9):4860-6, 1991.

SHERLAW-JOHNSON, C.; GALLIVAN, S.; JENKINS, D. Evaluating cervical cancer screening programmes for developing countries. Int. J. Cancer, 72: 210-16, 1997.

SHERMAN, L.; JACKMAN, A.; LTZHAKI, H.; STÖPPLER, M.C.; KOVAL, D.; SCHLEGELT, R. Inhibition of Serum and Calcium-Induced Differentiation of Human Keratinocytes by HPV16 E6 Oncoprotein: Role of p53 Inactivation. Virol., 237: 296-306, 1997.

SHRIVER, M.D.; JIN, L.; BOERWINKLE, E.; DEKA, R.; FERREL, R.E.; CHAKRABORTY, R. A novel measure of genetic distance for highly polymorphic tandem repeat loci. Mol. Biol. Evol., 12 (5): 914-920, 1995.

SHRIVER, M.D.; SMITH, M.W.; JIN, L.; MARCINI, A.; AKEY, J.M.; DEKA, R.; FERRELL, R.E. Ethnic-affiliation estimation by use of population-specific DNA markers. Am. J. Hum. Genet., 60: 957-964, 1997.

SICHERO, L.; FRANCO, E.L.; VILLA, L.L. Different P105 Activities among natural variants of human papillomavirus type 18. J. Infect. Dis. 191: 739-42, 2005.

SILVA, W.A.JR.; BORTOLINI, M.C.B.; MEYER, D.; SALZANO, F.M.; SCHNEIDER, M.C.P.; ELION, J.; KRISHNAMOORTHY, R.; DE GUERRA, D.C.; LAYRISSE, Z.; CASTELLANO, H.M.; WEIMER, T.A.; ZAGO, M.A. Diversity of six hipervariable loci studied in two African and 16 South American populations. Am. J. Phys. Anthropol., 109(4):425-37, 1999 .

SLATKIN, M. A Measure of population subdivision based on microsatellite allele frequencies. Genetics, 139: 457-462.

STONEKING, M. DNA and recent human evolution. Evolutionary Anthropology, 92: 60-73, 1993.

STÖPPLER, M.C.; CHING, K.; STÖPPLER, H.; CLANCY, K.; SCHLEGEL, R.; ICENOGLE, J. Natural variants of human papillomavirus type $16 \mathrm{E} 6$ protein differ in their abilities to alter keratinocyte differentiation and to induce p53 degradation. J. Virol., 70: 6987-93, 1996.

STOREY, A. \& BANKS, L. Human papillomavirus type 16 E6 oncogene cooperates with EJ-ras to immortalize primary mouse cells. Oncogene, 8: 919-24, 1993. 
TORRONI, A.; CHEN. Y.S.; SEMINO, O.; SANTACHIARA-BENECERETTI, A.S.; SCOTT, C.R.; LOTT, M.T.; WINTER, M.; WALLACE, D.C. mtDINA and Y chromosome polymorphisms in four native American populations from Southern Mexico. Am. J. hum. Genet., 54: 303-18, 1994.

TORRONI, A.; SCHURR, T.; CABELL, M.; BROWN, M.; NEEL, J.; LARSEN, M.; SMITH. D.; VULLO, C.; WALLACE, D. Asian affinities and continental radiation of the four founding native american mtDNAs. Am. J. Hum. Genet., 53: 563-590, 1993.

VALLINOTO, A.C.R.; CAYRES-VALLINOTO, I.M.V.; ZAGO, M. A.; SANTOS, S.E.B.; GUERREIRO, J.F. D1S80 Polymorphism in Amerindians from the Amazon Region of Brazil. Hum. Biol., 70(3): 507-516, 1998.

VANDENVELDE, C., de FOOR, M.; van BEERS, D. HLA-DQB1*03 and cervical intraepithelial neoplasia grades I. Lancet 341: 442, 1993.

VERESS, G.; SZARKA, K.; DONG, X-P.; GERGELY, L.; PFISTER, P. Functional significance of sequence variation in the E2 gene and the long control region of human papillomavirus type 16. J. Gen. Virol., 80: 1035-43, 1999.

VERNON, S.D.; UINGER, E.R.; MILLER, D.R.; LEE, D.R.; REEVES, W.C. Association of human papillomavirus type 16 integration in the $E 2$ gene with poor disease-free survival from cervical cancer. Int. J. Cancer, 74: 50-56, 1997.

VILLA, L.L.; RAHAL, P.; FRANCO, E.L. Molecular variant analysis as a tool in natural history studies of human papillomavirus infection and cervical neoplasia. In: Franco, E. L. Ed. New Developments in Cervical Cancer Screening and Prevention. WHO/EUROGIN monograph, Blackwell Science p. 374-79, 1997.

VILLA, LL. Vaccines against papillomavirus infections and disease. Salud Pública de México, 45 (3): 443-448, 2003.

WALLACE, D.C.; GARRISON, K.; KNOWLER, W.C. Dramatic founder effects in Amerindian mitochondrial DNAs. Am. J. Physical .Anthropol, 68: 149-55, 1985.

WANK, R. \& THOMSSEN, C. High risk of squamous cell carcinoma of the cervix for women with HLADQw3. Nature, 352: 723-25, 1991.

WANK, R., MEULEN, J., LUANDE, J., EBERHARDT, H., PAWLITA, M. Cervical intraepithelial neoplasia, cervical carcinoma, and risk for patients with HLA-DQB1*0602. *0301, *0303 alleles. Lancet 341: 1215, 1993.

WERNESS, B.A.; LEVINE, A.J.; HOWLEY, P.M. Association of human papillomavirus types 16 and 18 E6 proteins with p53. Science, 248: 76-79, 1990.

WHEELER, C.M.; YAMADA, T.; HILDESHEIM, A.; JENISON, S.A. Human papillomavirus type 16 sequences variants: identification by E6 and L1 lineage-specific hybridization. J. Clin. Microbiol. 35: 11-19, 1997.

WOOLF, B.; On estimating the relation between blood group and disease. Ann. Hum. Genet., 19: $251-53,1955$.

XI LF; CARTER JJ; GALLOWAY DA; KUYPERS J; HUGHES JP; LEE SK; ADAM DE; KIVIAT NB; KOUTSKY LA. Acquisition and natural history of human papillomavirus type 
16 variant infection among a cohort of female university students. Cancer Epidemiol Biomarkers Prev.; 11(4):343-51. 2002.

XI, L.F.; CARTER, J.J.; GALLOWAY, D.A.; KUYPERS, J.; HUGHES, J.P.; LEE, S.K; ADAM, D.E.; KIVIAT, N.B.; KOUTSKY, L.A. Acquisition and natural history of human papillomavirus type 16 variant infection among a cohort of female university students. Cancer Epidemiol. Biomarkers \& Prevention, 11: 343-351, 2002.

XI, L.F.; DEMERS, W.; KOUTSKY, L.A.; KIVIAT, N.B.; KUYPERS, J.; WATTS, D.H.; HOLMES, K.K.; GALLOWAY, D.A. Analysis of human papillomavirus type 16 variants indicates establishment of persistent infection. J. Infect. Dis., 172: 747-55, 1995.

YAMADA, T.; MANOS, M.; PETO, J.; GREER, C.E.; MUÑOZ, N.; BOSCH, X.; WHEELER, C.M. Human papillomavirus type 16 sequence variation in cervical cancers: a worldwide perspective. J. Virol., 71: 2463-72, 1997.

ZAGO, M.A.; SILVA. W.A. Jr.; TAVELLA, M.H.; SANTOS, S.E.B.; GUERREIRO, J.F.; FIGUEIREDO, M.S. Interpopulational and intrapopulational genetic diversity of Amerindians as revealed by six variable number of tandem repeats. Hum. Hered., 46: 274289, 1996.

ZEHBE I, MYTILINEOS J, WIKSTROM I, HENRIKSEN R, EDLER L, TOMMASINO M. Association between human papillomavirus $16 \mathrm{E} 6$ variants and human leukocyte antigen class I polymorphism in cervical cancer of Swedish women. Hum. Immunol., 64(5): 538-542, 2003.

ZEHBE I, VOGLINO G, DELIUS H, WILANDER E, TOMMASINO M. Risk of cervical cancer and geographical variations of human papillomavirus 16 E6 polymorphisms. Lancet. 352(9138): 1441-2, 1998b.

ZEHBE, I.; WILANDER, E.; DELIUS, H.; TOMMASINO, M. Human papillomavirus 16 E6 variants are more prevalent in invasive cervical carcinoma than the prototype. Cancer Res., 58: 829-33, 1998a.

ZUR HAUSEN H. Papillomaviruses and cancer: from basic studies to clinical application. Nat. Rev. Cancer., 2(5):342-50, 2002.

ZUR HAUSEN, H. Papillomavirus infections: a major cause of human cancer. Biochim. Biophys. Acta, 1288: F55-F78, 1996. 